University of South Florida

DIGITAL COMMONS

Digital Commons @ University of

@ UNIVERSITY OF SOUTH FLORIDA

South Florida

Research Reports

National Institute for Congestion Reduction

(NICR) 2019-

4-2021

\title{
Comparing Pricing Mechanisms for Managed Lanes
}

Mark Burris

Kartikeya Jha

Sayantan Biswas

Laura Holloway

Follow this and additional works at: https://digitalcommons.usf.edu/cutr_nicr

\section{Scholar Commons Citation}

Burris, Mark; Jha, Kartikeya; Biswas, Sayantan; and Holloway, Laura, "Comparing Pricing Mechanisms for Managed Lanes" (2021). Research Reports. 1.

https://digitalcommons.usf.edu/cutr_nicr/1

This Technical Report is brought to you for free and open access by the National Institute for Congestion Reduction (NICR) 2019- at Digital Commons @ University of South Florida. It has been accepted for inclusion in Research Reports by an authorized administrator of Digital Commons @ University of South Florida. For more information, please contact digitalcommons@usf.edu. 


\section{Comparing Pricing Mechanisms for Managed Lanes}

Mark Burris

Kartikeya Jha

Sayantan Biswas

Laura Holloway

Follow this and additional works at: https://digitalcommons.usf.edu/cutr_nicr

\section{Scholar Commons Citation}

Burris, Mark; Jha, Kartikeya; Biswas, Sayantan; and Holloway, Laura, "Comparing Pricing Mechanisms for Managed Lanes" (2021). Research Reports. 1.

https://digitalcommons.usf.edu/cutr_nicr/1

This Technical Report is brought to you for free and open access by the National Institute for Congestion Reduction (NICR) 2019- at Digital Commons @ University of South Florida. It has been accepted for inclusion in Research Reports by an authorized administrator of Digital Commons @ University of South Florida. For more information, please contact scholarcommons@usf.edu. 


\title{
NATIONAL INSTITUTE FOR CONGESTION REDUCTION
}

\author{
FINAL REPORT
}

APRIL 2021

\section{Comparing Pricing Mechanisms for Managed Lanes}

\author{
Mark Burris \\ Kartikeya Jha \\ Sayantan Biswas \\ Laura Holloway
}

For:

National Institute for Congestion Reduction

University of South Florida

Center for Urban Transportation Research | University of South Florida

4202 E. Fowler Avenue, ENG030, Tampa, FL 33620-5375

nicr@usf.edu 


\section{Disclaimer}

The contents of this report reflect the views of the authors, who are responsible for the facts and the accuracy of the information presented herein. This document is disseminated in the interest of information exchange. The report is funded, partially or entirely, by a grant from the U.S. Department of Transportation's University Transportation Centers Program. However, the U.S. Government assumes no liability for the contents or use thereof.

\section{Acknowledgements}

This project was sponsored by the National Institute for Congestion Reduction (NICR) and financially supported with match funds designated by the State of Texas to the Texas A\&M Transportation Institute (TTI) for the purpose of matching national centers. The authors are grateful for that support. We are also grateful for the collaborative efforts with the team from the University of Puerto Rico at Mayaguez (UPRM). The UPRM team (Dr. Alberto Figueroa, Dr. Benjamín Colucci, Dr. Daniel Rodríguez, Dr. Carlos del Valle, Luis Nieves, Isaac Cortez and Gilmarie O'Neill) were an integral part of this research and the teaming of the two universities greatly improved the final product.

We are also very appreciative of the efforts of the Minnesota and Colorado Departments of Transportation and the Central Texas Regional Mobility Authority. These agencies shared their data and provided important insight on that data and aspects of their lanes. In addition, Dr. Bruce Wang and Dr. William Eisele of Texas A\&M University provided valuable guidance on this research. 
4202 E. Fowler Avenue, ENG 030

Tampa, FL 33620-5375 


\section{Technical Report Documentation Page}

\begin{tabular}{|c|c|c|c|}
\hline 1. Report No. & 2. Government Accession No. & \multicolumn{2}{|c|}{ 3. Recipient's Catalog No. } \\
\hline \multicolumn{2}{|l|}{ 4. Title and Subtitle } & \multicolumn{2}{|l|}{ 5. Report Date } \\
\hline \multirow{2}{*}{\multicolumn{2}{|c|}{ Comparing Pricing Mechanisms for Managed Lanes }} & \multicolumn{2}{|l|}{ April 2021} \\
\hline & & \multicolumn{2}{|c|}{ 6. Performing Organization Code } \\
\hline \multicolumn{2}{|c|}{ 7. Author(s) Mark Burris, Kartikeya Jha, Sayantan Biswas, Laura Holloway } & \multicolumn{2}{|c|}{ 8. Performing Organization Report No. } \\
\hline \multicolumn{2}{|c|}{ 9. Performing Organization Name and Address } & \multicolumn{2}{|c|}{ 10. Work Unit No. (TRAIS) } \\
\hline \multicolumn{2}{|c|}{ Texas A\&M Transportation Institute } & & \\
\hline \multirow{2}{*}{\multicolumn{2}{|c|}{$\begin{array}{l}3136 \text { TAMU } \\
\text { College Station, TX } 77843\end{array}$}} & \multicolumn{2}{|c|}{ 11. Contract or Grant No. } \\
\hline & & \multicolumn{2}{|c|}{ 69A3551947136 } \\
\hline \multicolumn{2}{|c|}{ 12. Sponsoring Organization Name and Address } & \multicolumn{2}{|c|}{ 13. Type of Report and Period Covered } \\
\hline \multicolumn{2}{|c|}{ U.S. Department of Transportation } & & \\
\hline \multicolumn{2}{|c|}{ University Transportation Centers } & & \\
\hline \multicolumn{2}{|l|}{1200 New Jersey Avenue, SE } & & \\
\hline \multicolumn{2}{|l|}{ Washington, DC 20590} & & \\
\hline \multicolumn{2}{|l|}{ United States } & & \\
\hline & & \multicolumn{2}{|c|}{ 14. Sponsoring Agency Code } \\
\hline \multicolumn{4}{|l|}{ 15. Supplementary Notes } \\
\hline \multicolumn{4}{|l|}{ 16. Abstract } \\
\hline \multicolumn{4}{|c|}{$\begin{array}{l}\text { Two common means of pricing managed lanes (MLs) are to vary tolls based on time of day or to vary them dynamically based } \\
\text { on real-time congestion. It is not clear which of the two tolling options is more effective in regulating ML usage. In this study, } \\
\text { large datasets on toll prices, vehicle travel speeds, and traffic volumes were used to assess the effects of the two different } \\
\text { congestion pricing strategies on traffic conditions on six MLs around the United States. The MLs included two that were } \\
\text { variably priced: SR-91 and I-25; and four that were dynamically priced: I-35W, I-394, I-35E, and MoPac. The study used seven } \\
\text { different performance measures to examine the ability of the toll to regulate traffic on the MLs. Overall, both pricing } \\
\text { measures were found to keep traffic flowing on MLs, and neither pricing method was clearly superior. Dynamic pricing was } \\
\text { found to perform slightly better in most metrics. }\end{array}$} \\
\hline \multicolumn{2}{|l|}{ 17. Key Words } & \multicolumn{2}{|c|}{ 18. Distribution Statement } \\
\hline \multicolumn{4}{|c|}{ Managed lanes, express lanes, variable pricing, dynamic pricing, evaluation } \\
\hline $\begin{array}{l}\text { 19. Security Classification (of this } \\
\text { report) }\end{array}$ & $\begin{array}{l}\text { 20. Security Classification (of this } \\
\text { page) }\end{array}$ & 21. No. of Pages & 22. Price \\
\hline Unclassified. & Unclassified. & 83 & \\
\hline
\end{tabular}




\section{Table of Contents}

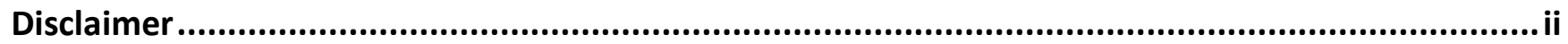

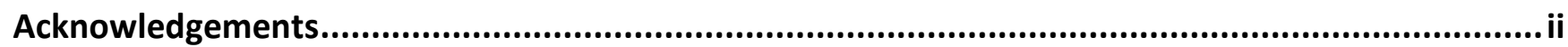

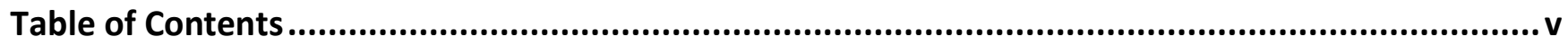

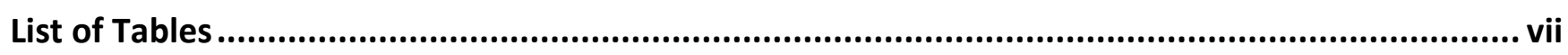

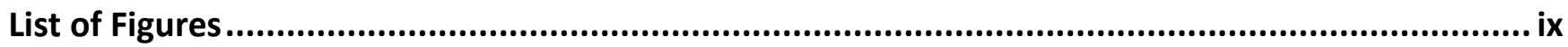

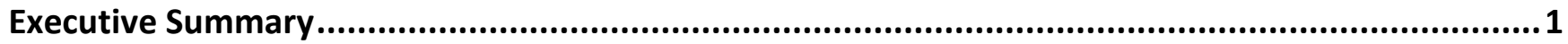

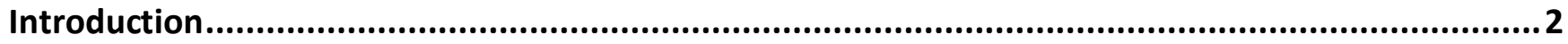

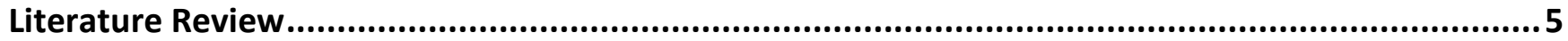

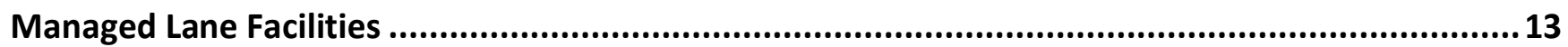

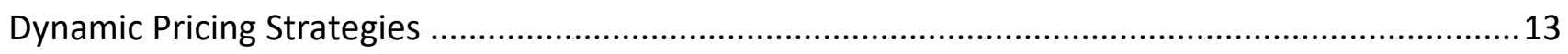

Dynamic Pricing Algorithms that Consider ML Metrics Only............................................................14

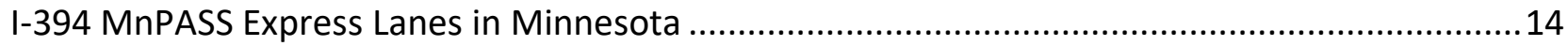

I-15 Express Lanes (South) in San Diego, CA ...............................................................................

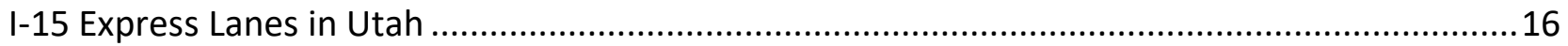

Dynamic Pricing Algorithms that Consider Both ML and GPL Metrics ............................................17

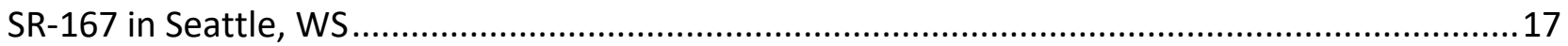

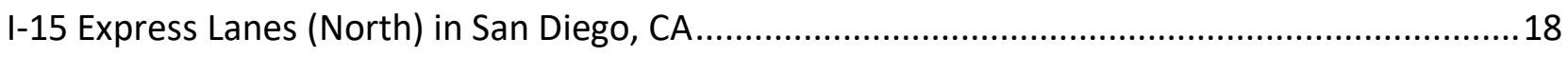

Existing Variable Pricing Algorithms ………………..............................................................19

SR-91 Express Lanes in Orange County, CA …….....................................................................

Performance Measures/Metrics for Managed Lanes ..........................................................................23

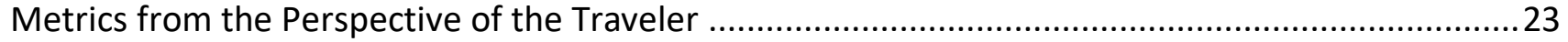

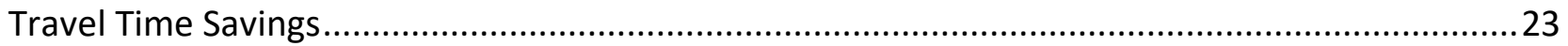

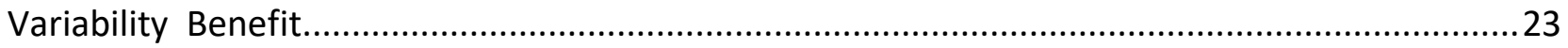

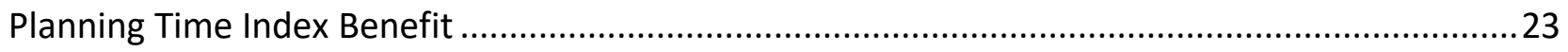

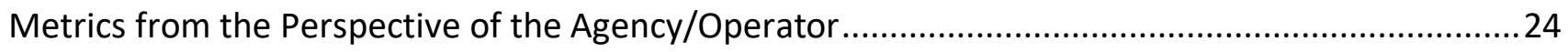

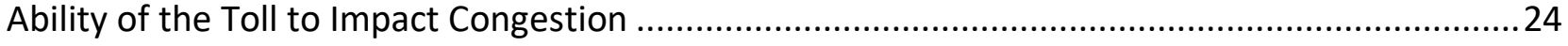

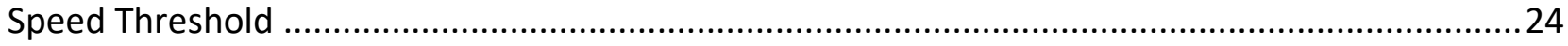

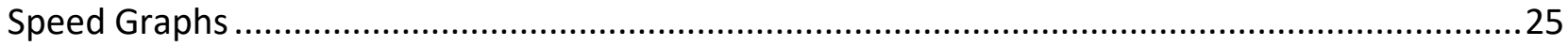

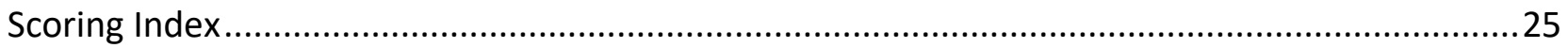




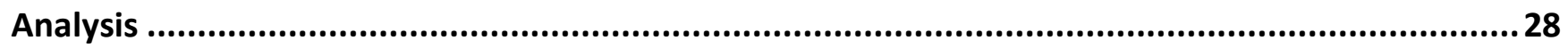

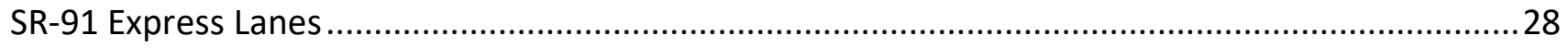

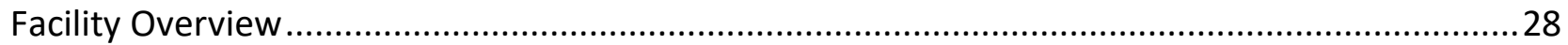

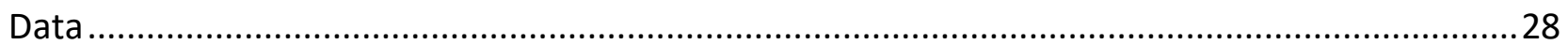

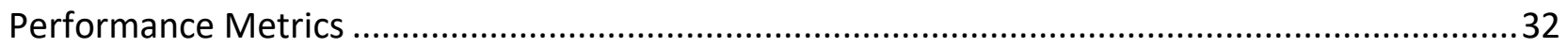

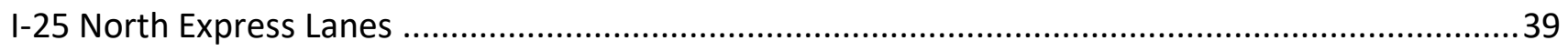

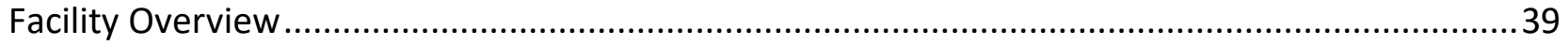

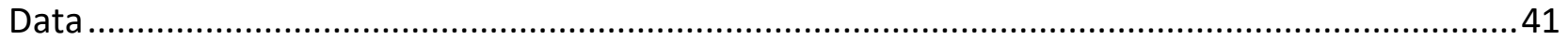

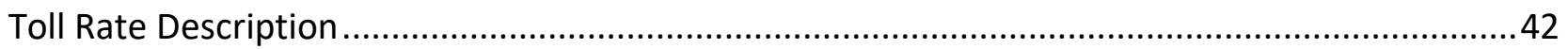

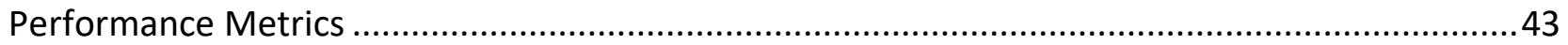

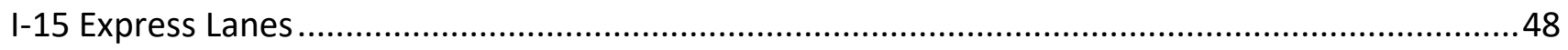

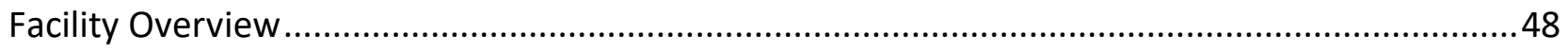

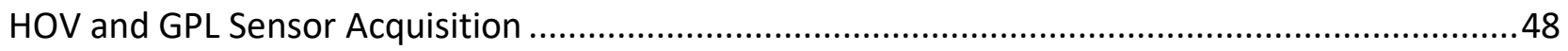

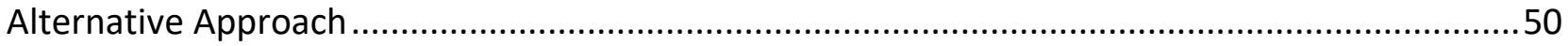

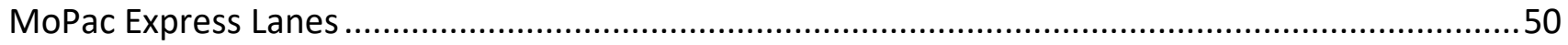

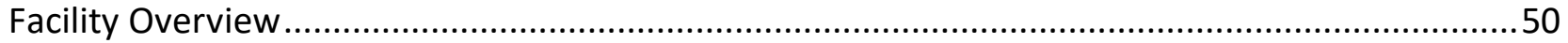

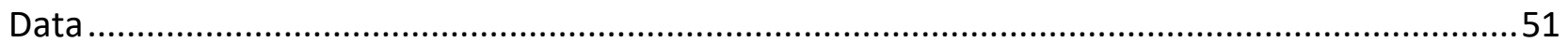



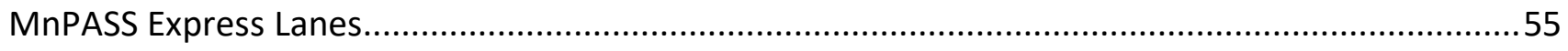

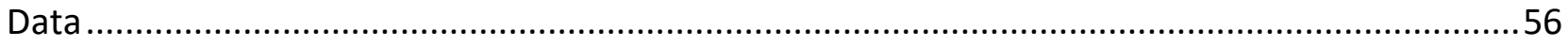

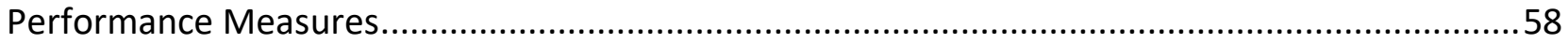

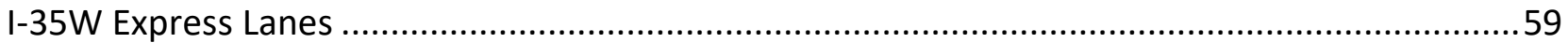

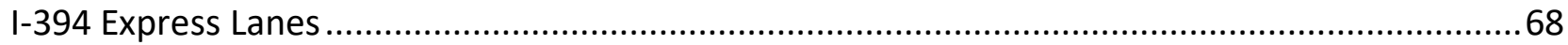

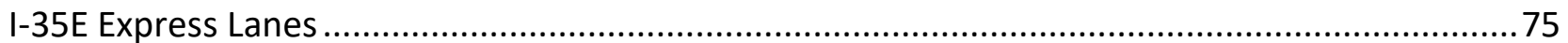

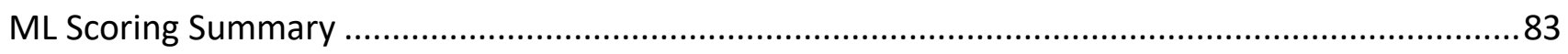

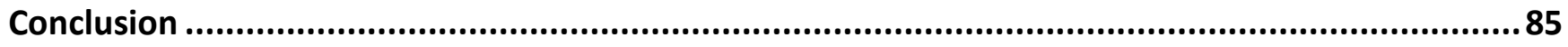

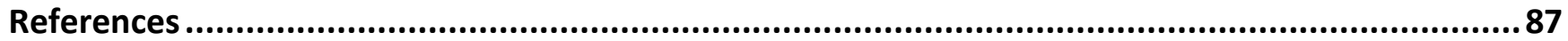




\section{List of Tables}

Table 1: Performance Measures on Operational MLs ............................................................ 6

Table 2: MnPASS LOS and Density Relationship (Source: Hourdos, 2015) .........................................14

Table 3: MnPASS Toll Increment per Change in Density (Source: Hourdos, 2015) ...............................14

Table 4: MnPASS Toll Rates for Each LOS (Source: Hourdos, 2015) ..................................................15

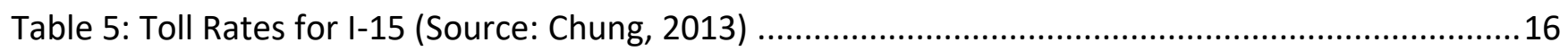

Table 6: Flow Rates by Score for East of Gypsum in Eastbound in SR-91 ........................................27

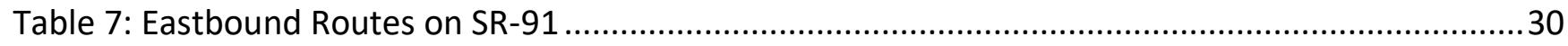

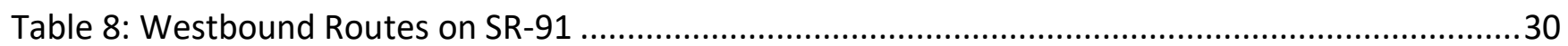

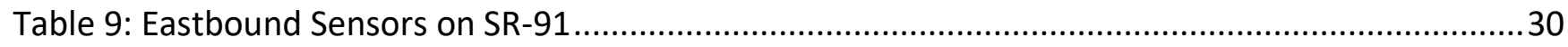

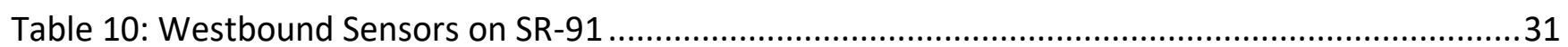

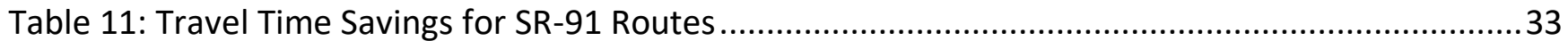

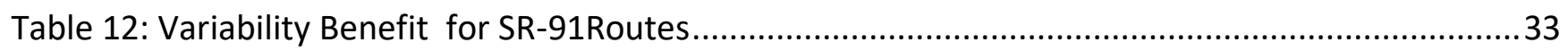

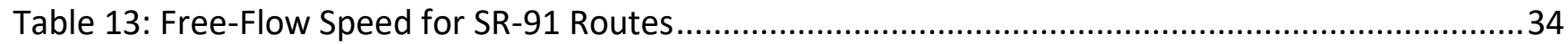

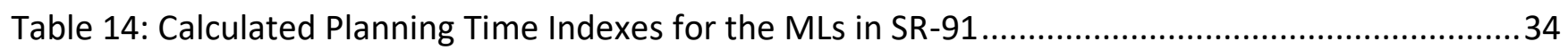

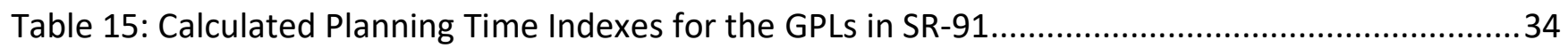

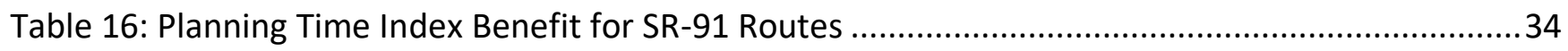

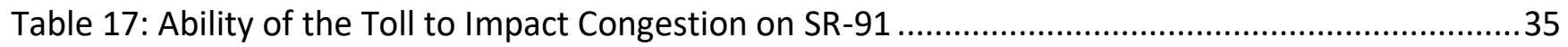

Table 18: Percent of Time Speeds Exceeded the Speed Threshold for SR-91 ....................................36

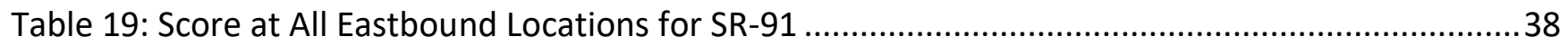

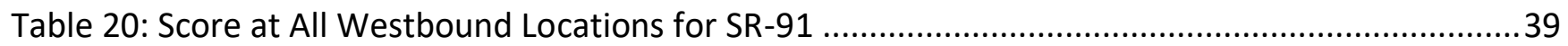

Table 21: Express Lane Toll Rates -Weighted Average for I-25...................................................43

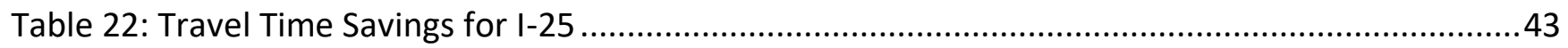

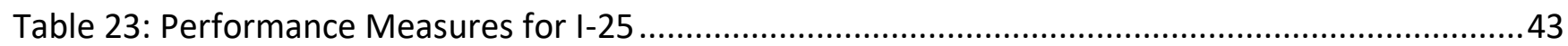

Table 24: Results from Performance Measure-Ability of Toll to Impact Congestion

(Northbound) ..........................................................................................................45

Table 25: Results from Performance Measure-Ability of Toll to Impact Congestion

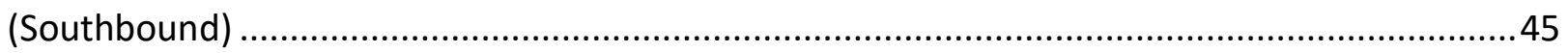

Table 26: Results for EL Operating Speeds Meeting Threshold Speeds ..........................................46

Table 27: Summary of Index Results for I-25 Northbound ..........................................................47

Table 28: Summary of Index Results for I-25 Southbound ............................................................47

Table 29: Percentage of Time MLs Were Faster Based on Travel-Time Data for I-15..........................50

Table 30: Alternative Approach-Percentage of Time MLs Were Faster Based on Travel-Time

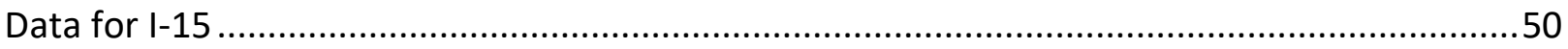

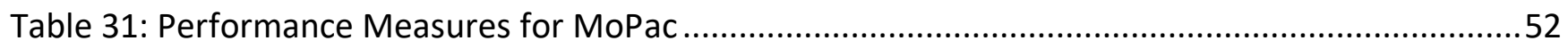


Table 32: Results from Performance Measure-Ability of Toll to Impact Congestion

(Northbound)

Table 33: Results from Performance Measure-Ability of Toll to Impact Congestion

(Southbound) .53

Table 34: Results for EL Operating Speeds Meeting Threshold Speeds for MoPac ...........................53

Table 35: Summary of Index Results for MoPac Northbound .......................................................55

Table 36: Summary of Index Results for MoPac Southbound .........................................................55

Table 37: Sample Toll Transaction Data for I-35W ..........................................................................58

Table 38: MnPASS Transactions for Each Facility .....................................................................58

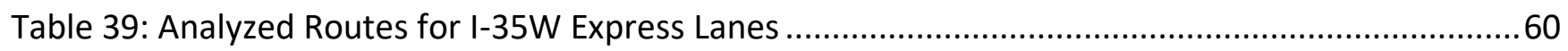

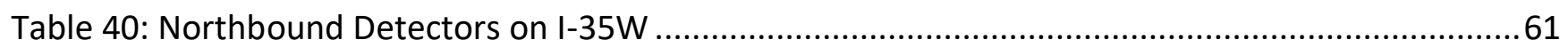

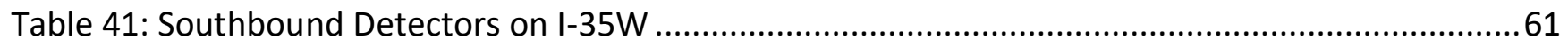

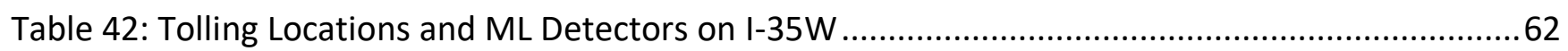

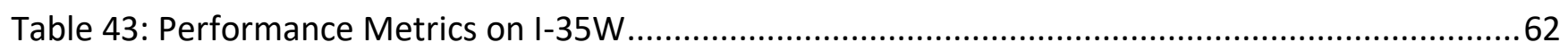

Table 44: Ability of the Toll to Impact Congestion for Entire I-35W Facility .......................................63

Table 45: Ability of the Toll Metric for Trips Originating at Burnsville in I-35W ................................63

Table 46: Percent of Time Speeds Exceeded the Speed Threshold for I-35W .................................63

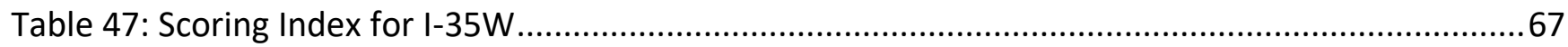

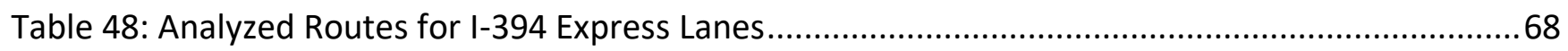

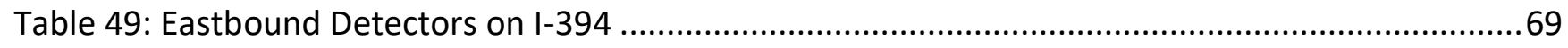

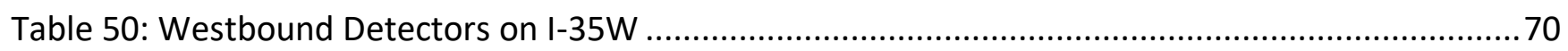

Table 51: Tolling Locations and ML Detectors on I-394 ….......................................................... 70

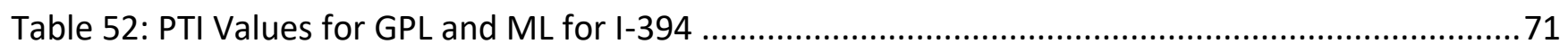

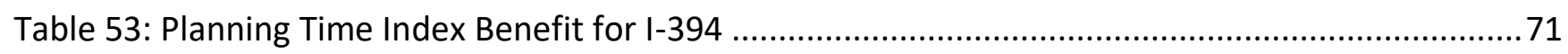

Table 54: Ability of the Toll to Impact Congestion on I-394 ............................................................71

Table 55: Percent of Time Speeds Exceeded the Speed Threshold for I-394 ....................................71

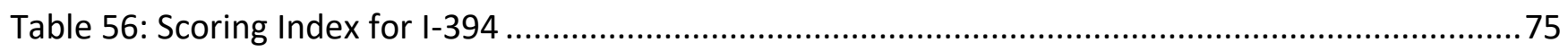

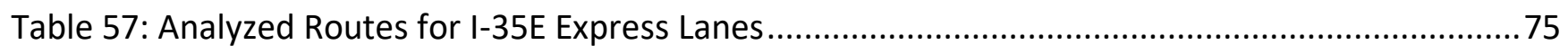



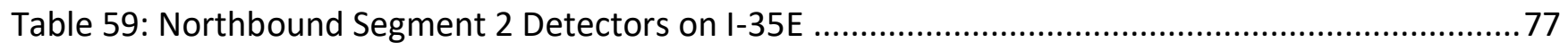

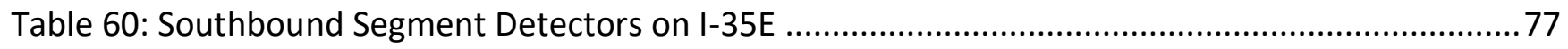

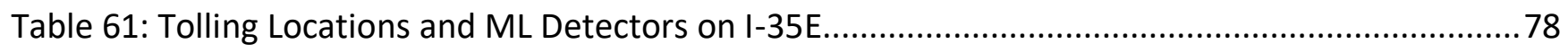

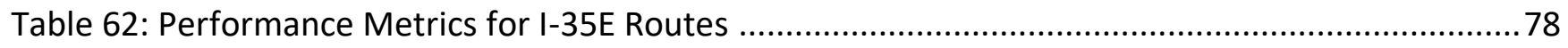

Table 63: Ability of the Toll to Impact Congestion for Entire I-35E Facility.........................................79

Table 64: Percent of Time that Speeds Exceeded the Speed Threshold for I-35E .............................79

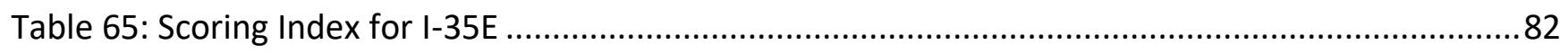

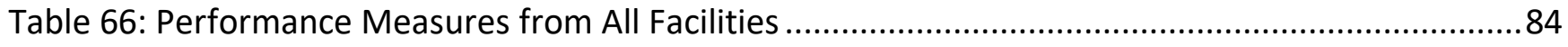

Viii 


\section{List of Figures}

Figure 1: Toll Rate Calculation for ELs in Utah (Source:

https://www.udot.utah.gov/connect/docs/express-lanes-toll-rate-algorithm/)

Figure 2: The Current Variable Toll Prices on SR-91 (Source: https://www.octa.net/91-Express-

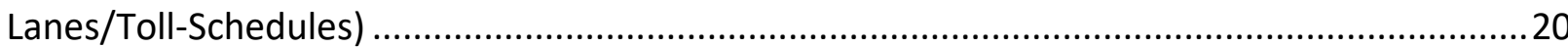

Figure 3: Graphical Display of Performance for Route 22775 in SR-91 ..........................................25

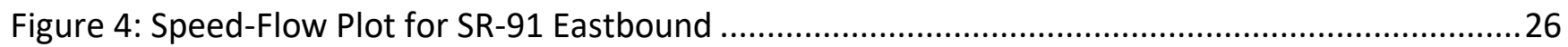

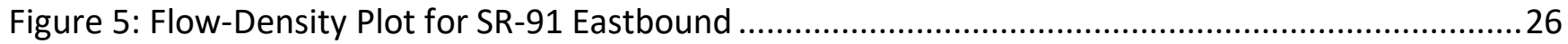

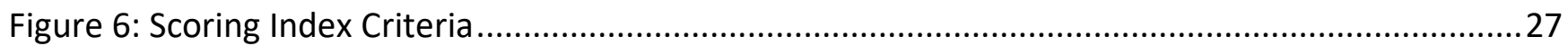

Figure 7: Map of SR-91 Express Lanes (Source: https://blog.octa.net/now-open\%2C-91-project-

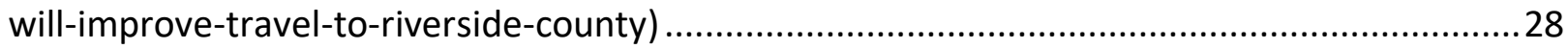

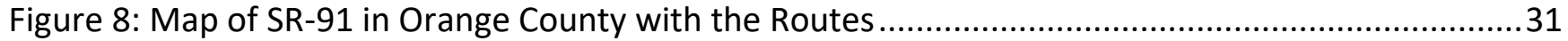

Figure 9: PeMS Data Showing Traffic Flows at 5-Minute Granularity in the Mainline (GPLS)................32

Figure 10: PeMS Data Showing Travel Times in the Mainline (GPLS) and the HOV/HOT Lanes

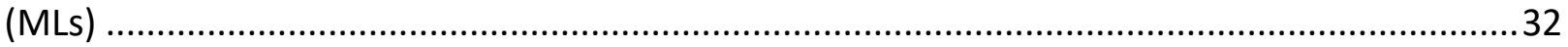

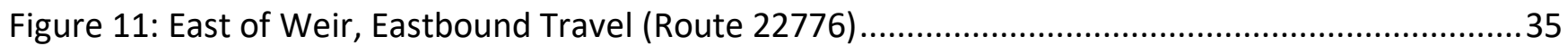

Figure 12: Graphical Display of Performance for Route 22776 in SR-91 ..........................................36

Figure 13: Graphical Display of Performance for Route 22778 in SR-91 ........................................37

Figure 14: Graphical Display of Performance for Route 22779 in SR-91 .......................................37

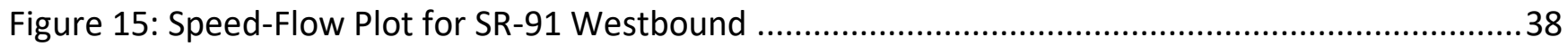

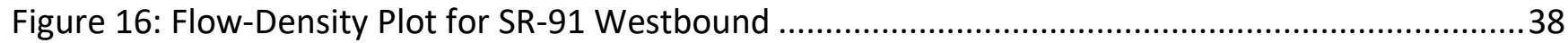

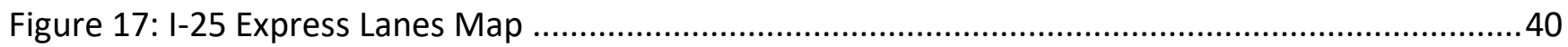

Figure 18: I-25 Lane Schematic (Source: https://www.kristalsellsdenver.com/denvermap/) .............41

Figure 19: I-25 Express Lane Toll Rates (Source:

https://www.codot.gov/programs/expresslanes/copy_of_toll-rates/toll-rates-effective-

july-20-2018-for-i-25-north-us-36-to-120th-seg-2.pdf) .

Figure 20: Graphical Display of Performance for I-25 Northbound ...................................................46

Figure 21: Graphical Display of Performance for I-25 Southbound ...............................................47

Figure 22: Sections of I-15 Expressway (Source: https://511sd.com/fastrak511sd/how-to-use-

the-I-15-Express-Lanes).

Figure 23: Express Lanes in Austin, TX (Source:

https://www.txtag.org/en/about/tollroad_austin_area.shtml) .............................................51

Figure 24: Graphical Display of Performance for MoPac Northbound..............................................54

Figure 25: Graphical Display of Performance for MoPac Southbound...............................................54

Figure 26: MnPASS Express Lanes in Minnesota (Source: www.Mnpass.org) ......................................56

Figure 27: Sample Loop Detector Data Extracted at ML Detector 5455 Located on I-394 _..................57

Figure 28: Map of MnPASS I-35W Express Lanes (Source: www.mnpass.org) ...................................60

Figure 29: Graphical Display of Performance for Northbound Segment 1 in I-35W ...........................64

Figure 30: Graphical Display of Performance for Northbound Segment 2 in I-35W..........................64 
Figure 31: Graphical Display of Performance for Southbound Segment 1 in I-35W

Figure 32: Graphical Display of Performance for Southbound Segment 2 in I-35W .

Figure 33: Flow-Density Plot for I-35W Northbound. .66

Figure 34: Flow-Speed Plot for I-35W Northbound. 66

Figure 35: Flow-Density Plot for I-35W Southbound... .67

Figure 36: Flow-Speed Plot for I-35W Southbound. .67

Figure 37: Map of MnPASS I-394 Express Lanes (Source:

https://www.dot.state.mn.us/mnpass/) .... .68

Figure 38: Graphical Display of Performance for Eastbound Segment in I-394 . .72

Figure 39: Graphical Display of Performance for Westbound Segment in I-394 ...............................72

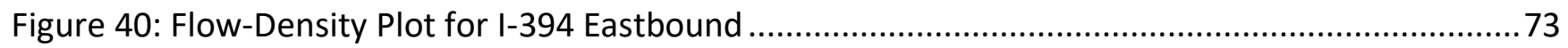

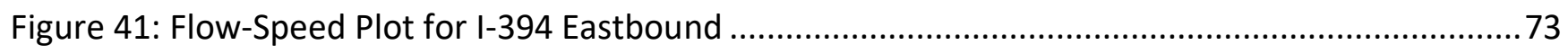

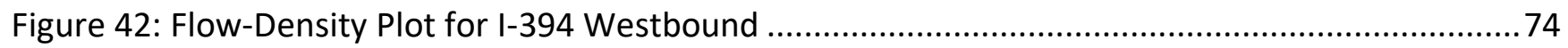



Figure 44: Map of MnPASS I-35E Express Lanes (Source: www.mnpass.org) ....................................76

Figure 45: Graphical Display of Performance for Northbound Segment 1 in I-35E ............................79

Figure 46: Graphical Display of Performance for Northbound Segment 2 in I-35E ...........................80

Figure 47: Graphical Display of Performance for Southbound Segment in I-35E ..............................80

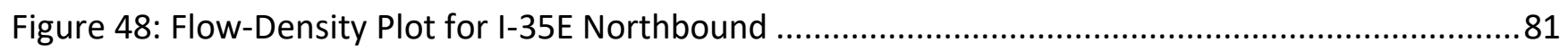

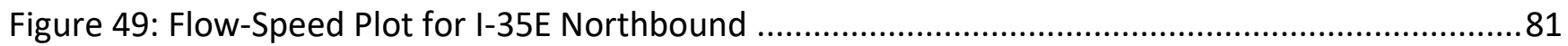



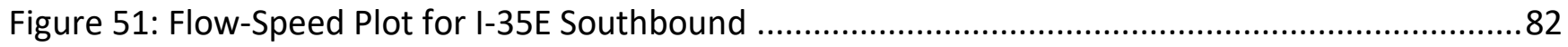




\section{Executive Summary}

Two common means of pricing managed lanes (MLS) are to vary tolls based on time of day or to vary them dynamically based on real-time congestion. It is not clear which of the two tolling options is more effective in regulating ML usage. In this study, large datasets on toll prices, vehicle travel speeds, and traffic volumes were used to assess the effects of the two different congestion pricing strategies on traffic conditions on six MLs around the United States. The MLS included two that were variably priced: SR-91 and I-25; and four that were dynamically priced: $\mathrm{I}-35 \mathrm{~W}, \mathrm{I}-394, \mathrm{I}-35 \mathrm{E}$, and MoPac.

The study used seven different performance measures to examine the ability of the toll to regulate traffic on the MLs. These included travel time savings, variability benefit, planning time index benefit, the ability of the toll to impact congestion, speed threshold achievement, speed graphs, and scoring index. These performance measures included several unique measures developed as part of this project and proved useful in measuring how well the ML toll was able to regulate traffic flow and keep the MLs operating smoothly.

Using these seven performance measures, researchers evaluated the impact of the two pricing approaches on traffic conditions. Overall, both pricing measures were found to keep traffic flowing on MLs, and neither pricing method was clearly superior. Dynamic pricing was found to perform slightly better in most metrics. However, both pricing mechanisms did work well to keep MLs flowing and thus are viable options for ML operators. One item for future research would be to apply these performance measures to additional ML datasets to see if one method does perform significantly better given a larger set of MLs to investigate. These performance measures are a key contribution of this research and provide excellent benchmarking for the effectiveness of tolling on regulating $M L$ traffic flow. 


\section{Introduction}

Priced managed lanes (MLs) are used on some of the busiest freeways throughout the United States. These lanes use pricing (tolls) to manage demand so that the lanes are generally uncongested. Therefore, the MLs generally offer a superior travel option to the general purpose lanes (GPLs), which are not tolled. The lanes also bring in revenue, helping fund the operation of the lanes.

To keep the lanes uncongested, the toll rate increases during periods of greater demand. This toll rate can be set in advance based on the time of day. For example, the toll might be $\$ 8$ at 7:30 a.m. and only $\$ 1$ at 3:30 a.m. This toll rate for a given time of day is set in advance and is known as variable pricing. The other option is to vary the toll price dynamically based on prevailing traffic conditions. As traffic increases, so does the toll rate. Similarly, as traffic decreases, the toll rate declines. This method of tolling is known as dynamic pricing. With dynamic pricing, the exact toll travelers may have to pay is unknown until they approach the lane and observe the price sign.

Both dynamic and variable pricing systems have worked well on multiple ML facilities across the United States. This report discusses several of these facilities and their pricing strategies. The research performed for this study examined if one form of pricing could be shown to be superior to the other. In theory, dynamic pricing has an advantage over variable pricing because dynamic pricing can react to current traffic conditions with higher granularity, accuracy, and adaptability. However, dynamic pricing generally faces additional political and public opposition because the exact toll rate at any given time is unknown. This concept is unfamiliar to many people and garners additional opposition. Also, dynamic pricing requires accurate information on traffic conditions at all times and the development of a pricing algorithm. Finally, there are some instances where a high price signal has the unintended effect of attracting people to use the lane. Travelers observe a high price on the MLs and assume the GPLSs have congested traffic conditions, thereby deciding to pay the toll for the MLs (Janson and Levinson, 2014). Putting together all of these issues with recent research showing many travelers are not influenced by price when making their lane choices (Burris and Brady, 2018). These issues call into question whether dynamic pricing is superior to variable pricing.

This research examined six ML facilities, two with variable pricing and four with dynamic pricing, to explore if one form of pricing is superior. The lanes have many differences in addition to their tolling technique. Some have geometric constraints, some have one lane per direction while others have two lanes per direction, and one location even has a maximum allowable price. Thus, it may be easier on some lanes and more difficult on others for the toll to maintain acceptable traffic conditions. However, this research focuses on if and how well the toll maintained acceptable traffic conditions, regardless of how easy or difficult it may have been.

The research begins by examining relevant literature on pricing mechanisms. Next, the metrics or performance measures used to determine which pricing method is superior are discussed. Then several ML facilities and their pricing mechanisms, along with the data available from each 
facility on tolling and traffic, are analyzed using those metrics. The major findings of the study are then discussed along with conclusions based on these results. 


\section{Literature Review}

There are two major reasons for measuring performance on MLs:

- To confirm whether the traffic speeds, service, and reliability in the MLs meet the facility's standards. If they are not met, adjustments in tolls and stipulations for vehicle occupancy rates are implemented as necessary.

- To validate the use of congestion pricing by documenting the performance of MLs to stakeholders such as the public (Perez et al., 2011).

Typical performance metrics used by tolling agencies include vehicle speeds; travel time savings (TTS) during the peak period; travel time reliability; person throughput; safety; the number of toll transactions; the ability for system expansion; the increase in the use of high-occupancy vehicles (HOVs) through means like carpooling, transit, etc.; and the number of transponder purchases during the pilot period (Ginn et al., 2018). These metrics are used to determine the overall performance of the MLs. Table 1 shows the performance metrics used in some MLs across the United States. Several of these metrics are useful to this research, which focuses on the ability of the toll to keep traffic flowing. 
Table 1: Performance Measures on Operational MLs

\begin{tabular}{|c|c|c|c|c|c|c|}
\hline $\begin{array}{l}\text { Facility } \\
\text { Name }\end{array}$ & Facility Owner & $\begin{array}{l}\text { Pricing } \\
\text { Strategy }\end{array}$ & Facility Goals & Primary Metrics & Secondary Metrics & Sources \\
\hline $\begin{array}{l}\text { l-405 } \\
\text { Express } \\
\text { Lanes }\end{array}$ & $\begin{array}{l}\text { Washington } \\
\text { State } \\
\text { Department of } \\
\text { Transportation }\end{array}$ & Dynamic & $\begin{array}{l}\text { - Provide a choice for } \\
\text { drivers } \\
\text { - Provide a faster and } \\
\text { more reliable trip } \\
\text { - Generate revenue to } \\
\text { invest in the corridor }\end{array}$ & $\begin{array}{l}\text { - Maintain } 45-\text { mph speed } \\
\text { at least } 90 \text { percent of the } \\
\text { time during the peak } \\
\text { period } \\
\text { - Generate revenue to pay } \\
\text { for all toll operating costs } \\
\text { - Average traffic speed in } \\
\text { the GPL }\end{array}$ & - & $\begin{array}{l}\text { - Fleckenstein et } \\
\text { al. (2018) } \\
\text { - Washington } \\
\text { State Legislature } \\
\text { (n.d.) }\end{array}$ \\
\hline $\begin{array}{l}\text { I-680 Sunol } \\
\text { Express } \\
\text { Lanes }\end{array}$ & $\begin{array}{l}\text { Alameda } \\
\text { County } \\
\text { Transportation } \\
\text { Commission }\end{array}$ & Dynamic & $\begin{array}{l}\text { - Maintain level of service } \\
\text { (LOS) C or better in the } \\
\text { express lanes (ELs) } \\
\text { - Use net revenue to } \\
\text { improve highway and } \\
\text { transit in the corridor } \\
\text { - Optimize lane usage to } \\
\text { improve traffic } \\
\text { throughput }\end{array}$ & $\begin{array}{l}\text { - Travel times and speed } \\
\text { by segment and corridor } \\
\text { - Vehicle and person } \\
\text { throughput } \\
\text { - Vehicle hours of delay } \\
\text { - LOS in GPL and EL }\end{array}$ & $\begin{array}{l}\text { - Vehicle occupancy in } \\
\text { the GPL and EL } \\
\text { - Bottlenecks and } \\
\text { queues } \\
\text { - Vehicle miles traveled } \\
\text { (VMT) and transit } \\
\text { ridership } \\
\text { - Safety measured by } \\
\text { collision rates } \\
\text { - EL defaulters and } \\
\text { enforcement } \\
\end{array}$ & $\begin{array}{l}\text { Kittelson and } \\
\text { Associates, Inc. } \\
\text { (2013) }\end{array}$ \\
\hline $\begin{array}{l}95 \text { Express } \\
\text { Lanes }\end{array}$ & $\begin{array}{l}\text { Florida } \\
\text { Department of } \\
\text { Transportation }\end{array}$ & Dynamic & $\begin{array}{l}\text { - } \text { Reduce overall } \\
\text { congestion } \\
\text { - Improve travel time } \\
\text { reliability } \\
\text { - Free-flow speed (FFS) at } \\
\text { least } 45 \mathrm{mph} \\
\text { - Increase person } \\
\text { throughput }\end{array}$ & $\begin{array}{l}\text { - Traffic speed over } \\
45 \text { mph greater than or } \\
\text { equal to } 90 \text { percent of } \\
\text { the time }\end{array}$ & $\begin{array}{l}\text { - Intelligent } \\
\text { transportation system } \\
\text { equipment } \\
\text { performance } \\
\text { - Volume and person } \\
\text { throughput } \\
\text { - Tolls and revenue } \\
\text { composition of exempt } \\
\text { traffic } \\
\text { - Availability of the ELs } \\
\text { (during maintenance } \\
\text { and incidents) } \\
\text { - Transit use and } \\
\text { incident management }\end{array}$ & $\begin{array}{l}\text { - } \text { Cambridge } \\
\text { Systematics, Inc. } \\
\text { (2014) } \\
\text { - HNTB (2017) }\end{array}$ \\
\hline
\end{tabular}




\begin{tabular}{|c|c|c|c|c|c|c|}
\hline $\begin{array}{l}\text { Facility } \\
\text { Name }\end{array}$ & Facility Owner & $\begin{array}{c}\text { Pricing } \\
\text { Strategy }\end{array}$ & Facility Goals & Primary Metrics & Secondary Metrics & Sources \\
\hline $\begin{array}{l}91 \text { Express } \\
\text { Lanes }\end{array}$ & $\begin{array}{l}\text { Orange County } \\
\text { Transportation } \\
\text { Authority, } \\
\text { Riverside } \\
\text { County } \\
\text { Transportation } \\
\text { Commission }\end{array}$ & $\begin{array}{l}\text { Variable } \\
\text { (time of } \\
\text { day) }\end{array}$ & $\begin{array}{l}\text { - Manage traffic volumes } \\
\text { to maintain travel } \\
\text { speeds of } \\
60-65 \mathrm{mph} \text { at all times } \\
\text { - Optimize vehicle } \\
\text { throughput at FFS } \\
\text { - Increase average vehicle } \\
\text { occupancy } \\
\text { - Revenue generation }\end{array}$ & - Traffic volumes & $\begin{array}{l}\text { - } \text { Speed } \\
\text { - } \text { Frequency of use and } \\
\text { origin-destination } \\
\text { (O-D) } \\
\text { - Revenue } \\
\text { - Operation and } \\
\text { maintenance (O\&M) } \\
\text { costs } \\
\text { - Incident response time }\end{array}$ & $\begin{array}{l}\text { - } \text { Cambridge } \\
\text { Systematics, Inc. } \\
\text { (2014) } \\
\text { - } 91 \text { Express } \\
\text { Lanes (2019) }\end{array}$ \\
\hline $\begin{array}{l}\text { I-15 Express } \\
\text { Lanes }\end{array}$ & $\begin{array}{l}\text { San Diego } \\
\text { Association of } \\
\text { Governments }\end{array}$ & Dynamic & $\begin{array}{l}\text { - Provide all travelers } \\
\text { with a smoother, } \\
\text { quicker, and more } \\
\text { reliable trip } \\
\text { - Maintain at least LOS C }\end{array}$ & - LOS & $\begin{array}{l}\text { - Speed volume } \\
\text { - VMT and mode share } \\
\text { - Time of departure and } \\
\text { trip length } \\
\text { - Revenue and O\&M } \\
\text { costs }\end{array}$ & $\begin{array}{l}\text { - California } \\
\text { Department of } \\
\text { Transportation } \\
\text { (n.d.) } \\
\text { - Cambridge } \\
\text { Systematics, Inc. } \\
\text { (2014) }\end{array}$ \\
\hline $\begin{array}{l}\text { I-394, I-35E, } \\
\text { and I-35W } \\
\text { MnPASS } \\
\text { Express } \\
\text { Lanes }\end{array}$ & $\begin{array}{l}\text { Minnesota } \\
\text { Department of } \\
\text { Transportation }\end{array}$ & Dynamic & $\begin{array}{l}\text { - Increase person } \\
\text { throughput during peak } \\
\text { hours } \\
\text { - Provide faster and } \\
\text { reliable travel choice for } \\
\text { commuters } \\
\text { - Improve public transit } \\
\text { and increase ridership } \\
\text { - Increase car/vanpools }\end{array}$ & $\begin{array}{l}\text { - Speeds above } 45 \mathrm{mph} \text { at } \\
\text { least } 90 \text { percent of the } \\
\text { time during peak hours } \\
\text { - Speed differential }\end{array}$ & $\begin{array}{l}\text { - LOS } \\
\text { - Travel time and TTS } \\
\text { - Traffic volumes (daily } \\
\text { and hourly) } \\
\text { - Mode share and } \\
\text { vehicle occupancy } \\
\text { - Vehicle classification } \\
\text { and trip length } \\
\text { - O-D and departure } \\
\text { times } \\
\text { - Average toll, revenue, } \\
\text { and total transactions } \\
\text { - Incident response time } \\
\text { - O\&M costs }\end{array}$ & $\begin{array}{l}\text { - Cambridge } \\
\text { Systematics, Inc. } \\
\text { (2014) } \\
\text { - Minnesota } \\
\text { Department of } \\
\text { Transportation } \\
\text { (n.d.) }\end{array}$ \\
\hline
\end{tabular}




\begin{tabular}{|c|c|c|c|c|c|c|}
\hline $\begin{array}{l}\text { Facility } \\
\text { Name }\end{array}$ & Facility Owner & $\begin{array}{c}\text { Pricing } \\
\text { Strategy }\end{array}$ & Facility Goals & Primary Metrics & Secondary Metrics & Sources \\
\hline $\begin{array}{l}\text { SR-167 High } \\
\text { Occupancy } \\
\text { Toll (HOT) } \\
\text { Lanes }\end{array}$ & $\begin{array}{l}\text { Washington } \\
\text { State } \\
\text { Department of } \\
\text { Transportation }\end{array}$ & Dynamic & $\begin{array}{l}\text { - Speeds above } 45 \mathrm{mph} \text { at } \\
\text { least } 90 \text { percent of the } \\
\text { time during peak hours } \\
\text { - Speed differential }\end{array}$ & $\begin{array}{l}\text { - Speed } \\
\text { - Travel time }\end{array}$ & $\begin{array}{l}\text { - TTS and volume } \\
\text { - Vehicle make } \\
\text { - O-D and revenue } \\
\text { - Traffic stops and } \\
\text { collisions } \\
\text { - Incident response time }\end{array}$ & $\begin{array}{l}\text { - Washington } \\
\text { State Legislature } \\
\text { (n.d.) } \\
\text { - Cambridge } \\
\text { Systematics, Inc. } \\
\text { (2014) } \\
\end{array}$ \\
\hline $\begin{array}{l}\text { I-15 Express } \\
\text { Lanes }\end{array}$ & $\begin{array}{l}\text { Utah } \\
\text { Department of } \\
\text { Transportation }\end{array}$ & Dynamic & $\begin{array}{l}\text { - Maintain average } \\
\text { speeds of } 55 \mathrm{mph} \text { in the } \\
\text { ELs } \\
\text { - Generate sufficient } \\
\text { revenue for O\&M }\end{array}$ & - & - & $\begin{array}{l}\text { - Schultz et al. } \\
\text { (2015) }\end{array}$ \\
\hline $\begin{array}{l}\text { I-25 Central } \\
\text { Express } \\
\text { Lanes }\end{array}$ & $\begin{array}{l}\text { Colorado } \\
\text { Department of } \\
\text { Transportation }\end{array}$ & $\begin{array}{l}\text { Variable } \\
\text { (time of } \\
\text { day) }\end{array}$ & $\begin{array}{l}\text { - Maintain average } \\
\text { speeds of } 45 \mathrm{mph} \text { for all } \\
\text { vehicles }\end{array}$ & - Travel times & $\begin{array}{l}\text { - TTS and volume } \\
\text { - Mode share and } \\
\text { frequency of use } \\
\text { - O-D and trip purpose } \\
\text { - Revenue and O\&M } \\
\text { costs } \\
\text { - Traffic stops } \\
\text { (enforcement) and } \\
\text { accidents/collisions } \\
\text { - Transit travel times }\end{array}$ & $\begin{array}{l}\text { - Cambridge } \\
\text { Systematics, Inc. } \\
\text { (2014) }\end{array}$ \\
\hline
\end{tabular}




\begin{tabular}{|c|c|c|c|c|c|c|}
\hline $\begin{array}{l}\text { Facility } \\
\text { Name }\end{array}$ & Facility Owner & $\begin{array}{l}\text { Pricing } \\
\text { Strategy }\end{array}$ & Facility Goals & Primary Metrics & Secondary Metrics & Sources \\
\hline $\begin{array}{l}\text { I-30 } \\
\text { TEXpress } \\
\text { Lanes }\end{array}$ & $\begin{array}{l}\text { Texas } \\
\text { Department of } \\
\text { Transportation }\end{array}$ & Dynamic & $\begin{array}{l}\text { - Average travel speeds } \\
\text { should be } 50 \text { mph or } \\
\text { more } \\
\text { - Time and speed } \\
\text { reliability in the ELs } \\
\text { should be more than in } \\
\text { the GPLs } \\
\text { - Provide choice for } \\
\text { travelers } \\
\text { - Maximize person } \\
\text { throughput } \\
\text { - Provide safe and secure } \\
\text { trips in both the ELs and } \\
\text { GPLs }\end{array}$ & $\begin{array}{l}\text { - Travel speeds (at least } \\
50 \text { mph) } \\
\text { - Travel time } \\
\text { (95th percentile should } \\
\text { not exceed } 13 \text { minutes in } \\
\text { westbound and } \\
8 \text { minutes in eastbound) } \\
\text { - Travel time index and } \\
\text { planning time index } \\
\text { should not exceed } 1.05 \\
\text { - Buffer index limited to } \\
5 \text { percent } \\
\text { - Days per month below } \\
\text { threshold speed } \\
\text { (maximum } 1 \text { day for } \\
15 \text { minutes) }\end{array}$ & $\begin{array}{l}\text { - Public perception of } \\
\text { user choice and HOV } \\
\text { count in the ELs } \\
\text { - Occupancy ratio and } \\
\text { person throughput } \\
\text { - Number of crashes and } \\
\text { crash rate }\end{array}$ & $\begin{array}{l}\text { - Goodin et al. } \\
\text { (2013) }\end{array}$ \\
\hline $\begin{array}{l}\text { I-77 Express } \\
\text { Lanes }\end{array}$ & $\begin{array}{l}\text { North Carolina } \\
\text { Department of } \\
\text { Transportation }\end{array}$ & Dynamic & $\begin{array}{l}\text { - Maintain average } \\
\text { speeds of } 45 \mathrm{mph} \text { on } \\
\text { ELs or } 80 \text { percent of the } \\
\text { posted speed limit for } \\
\text { GPLs, whichever is } \\
\text { higher } \\
\text { - Ease congestion } \\
\text { - Establish operating } \\
\text { speeds on the ELs } \\
\text { during peak }\end{array}$ & $\begin{array}{l}\text { - Maintain speeds at } \\
48 \text { mph or more in the } \\
\text { ELs } \\
\text { - TTS and reliability during } \\
\text { peak hours } \\
\text { - Reduce fuel consumption } \\
\text { - Revenue generation }\end{array}$ & - & $\begin{array}{l}\text { - North Carolina } \\
\text { Department of } \\
\text { Transportation } \\
\text { (2018) } \\
\text { - } 177 \text { Express } \\
\text { Lanes (n.d.) }\end{array}$ \\
\hline $\begin{array}{l}\text { MoPac } \\
\text { Express } \\
\text { Lanes }\end{array}$ & $\begin{array}{l}\text { Central Texas } \\
\text { Regional } \\
\text { Mobility } \\
\text { Authority }\end{array}$ & Dynamic & $\begin{array}{l}\text { - Maintain speeds above } \\
45 \mathrm{mph} \text { at all times }\end{array}$ & $\begin{array}{l}\text { - Average speeds (greater } \\
\text { than } 50 \mathrm{mph} \text { ) } \\
\text { - Maintain lane capacity } \\
\text { up to } 1600 \mathrm{vph}\end{array}$ & $\begin{array}{l}\text { Increase Express bus } \\
\text { ridership } \\
\text { Real-time traffic and } \\
\text { incident management }\end{array}$ & $\begin{array}{l}\text { - MoPac Express } \\
\text { Lane Fact Sheet } \\
\text { (2019) }\end{array}$ \\
\hline
\end{tabular}


A congestion pricing feasibility study was done in Chicago with the primary goal of improving mobility in the metropolitan region. When asked about variable and dynamic pricing, 60 percent of the public agency representatives and 89 percent of the elected officials preferred variable pricing, and felt that dynamic pricing was complex and hampers the ability of travelers to decide their travel mode in advance (Wilbur Smith Associates, 2010). In the absence of a toll cap, the dynamically priced lanes have witnessed some public frustration and political opposition. The tolls on the 66 Express Lanes in Virginia have exceeded \$40 multiple times after the lanes opened. Previous research has shown that as toll rates rise, some travelers become more attracted to the MLs because it gives them a false indication that the GPLs are congested (Janson and Levinson, 2014). However, this instead results in the MLs experiencing high congestion. There are facilities where operators have used "Hybrid Variable" pricing, which is a mix of dynamic and variable pricing (Perez et al., 2012). For I-30 in Dallas, time-of-day pricing was used during the first 6 months after opening, and then dynamic pricing was adopted (Poe and MacGregor, 2008). The toll operators can use empirical data from the first phase of implementation (time-of-day pricing) to help them determine the dynamic tolling rates.

Yin et al. (2012) used simulation to compare the pricing algorithm implemented on the 95 Express Lanes in south Florida with static and time-of-day tolls. The results showed that dynamic tolling effectively regulates traffic demand and maintains superior performance on the MLs. However, when the travel demand pattern is predictable, time-of-day or even static tolling could perform as well as dynamic tolling, provided that the toll profiles are optimized against the demand pattern (Yin et al., 2012). It was recognized that dynamic pricing is more flexible because it can adjust to demand fluctuations. The authors concluded that by opting for dynamic pricing, the TTS are higher; however, it is more expensive to implement than variable pricing.

Laval et al. (2012) investigated the performance of MLs by modeling different dynamic pricing strategies. The authors used simulation and concluded that the variable bottleneck capacity linear toll pricing strategy was the most efficient pricing mechanism to minimize the total system delay, while the fixed-toll pricing strategy generated the maximum revenue.

Ye (2017) examined the current and emerging tolling practices by developing a dynamically priced tolling algorithm for a connected and autonomous vehicle (CAV) environment, the current non-CAV environment, and a mixed environment. Both variable and dynamic tolling components were used to develop a tolling framework for the non-CAV environment for I-66 inside the Beltway. Considering full CAV penetration, a reservation-based dynamic pricing scheme was developed. Yin and Lou (2009) used simulation and developed a feedback control and a reactive self-learning approach to determine the optimal pricing strategies. Feedback control requires one detector station located downstream of the toll tag reader. Control logic is developed to determine the toll at time $t+1$ based on the detector occupancy and previous toll $t$. In the self-learning approach, a logit model is developed by mining the detector data to learn a traveler's willingness to pay. The self-learning approach outperforms the feedback controller approach but is costly and difficult to implement (Yin and Lou, 2009). This further highlights the 
increasing complexity and cost of implementation when more sophisticated models are used to control traffic conditions by varying toll at a more granular spatiotemporal level.

The majority of prior research has used simulation to determine the best algorithm for dynamic pricing. The underlying assumption in these studies is that travelers make economically rational decisions on toll facilities. However, real-world data show that this is often not the case (Burris and Brady, 2018). To better answer the question regarding which type of pricing is better, it is imperative to analyze empirical data from different $M L$ facilities. This research is novel because it examines the real-world tolling performance of dynamically and variably priced MLs.

Table 1 includes performance metrics found for ML facilities in existence around the country. These were useful in determining what current operators of MLs deem key performance measures. The primary performance measures include measuring traffic speeds, travel times, delay, and revenue generation. These are paramount for the operation of ML facilities but are not exactly what this research is focused on (the ability of the toll to maintain the high performance of the MLs). Therefore, the metrics used in this research deviate somewhat from those seen in Table 1. 


\section{Managed Lane Facilities}

\section{Dynamic Pricing Strategies}

As noted previously, dynamic pricing varies the toll frequently based on some measure of congestion in the lanes. However, exactly how the toll is calculated can vary considerably. One aspect of the toll calculation is the location of the traveler. The following four methods are most common:

- Origin based: The toll paid by a traveler is calculated based on the origin or the entry point of the tolling location and is independent of the distance traveled on the MLs. One example is the SR-167 HOT lanes in Washington.

- Distance based: The toll is calculated based on the distance the user travels. The toll paid is the toll per mile.

- Trip based: The toll charged depends on the specific point of entry and exit, or O-D.

- Segment based: The facility is divided into several segments or zones. The toll paid depends on the number of zones a user traverses. Each segment can have multiple ingress and egress points. Examples include the I-35W MnPASS Express Lanes in Minnesota, Katy Freeway in Houston, TX, I-15 Express Lanes in Salt Lake City, UT, and I15 Express Lanes in San Diego, CA.

Another aspect of setting the dynamic toll rate is how to measure the level of congestion upon which the toll is determined. In most of the dynamic pricing algorithms, the tolls are calculated based on the most congested segment of the facility. This strategy is employed in the MnPASS Express Lanes (I-394 and I-35W) in Minnesota, SR-167 and I-405 in Washington, and I-85 Express Lanes in Georgia.

The next aspect of setting the toll rate is the dynamic pricing algorithm used to set the toll. These can be generally classified into two categories:

- Discrete toll algorithms: The toll rates are based on a table, and changes are based on pre-defined incremental changes in traffic speeds or volumes. For example, in the MnPASS lanes in Minnesota, the tolls can vary between $\$ 0.25$ and $\$ 8$, in multiples of $\$ 0.25$.

- Continuous toll algorithms: Similar to the discrete toll algorithm, the toll rates are based on real-time traffic conditions. However, the tolls are not pre-defined and can take any value based on the algorithm used. The MoPac Express Lanes in Texas are an example of this.

The final aspect of existing dynamic toll algorithms is whether or not the toll rate incorporates GPL traffic conditions:

- ML metrics only: The toll considers only the traffic parameters in the MLs for deciding the toll rates, such as for the MnPASS lanes in Minnesota. 
- ML and GPL metrics: The toll is based on both ML and GPL metrics, such as for SR-167 in Washington.

The next subsection provides additional details/examples of some of these different tolling algorithms.

\section{Dynamic Pricing Algorithms that Consider ML Metrics Only}

\section{I-394 MnPASS Express Lanes in Minnesota}

I-394 in Minnesota includes 11 miles of HOT lanes between Wayzata and downtown

Minneapolis. The facility has five toll zones and two toll sections. The total toll is the sum of the tolls for the two sections. The minimum toll is $\$ 0.25$, and the maximum toll is $\$ 8$. The tolls can be updated every 3 minutes and are adjusted to keep the traffic flowing in the MLs between 50 and $55 \mathrm{mph}$. The following steps were involved in determining the toll from the initial opening until 2015:

1. The traffic volume is converted to the corresponding density at every 30-second interval. The density calculations are then averaged over 6-minute time periods. Table 2 shows the relationship between traffic density and LOS.

Table 2: MnPASS LOS and Density Relationship (Source: Hourdos, 2015)

\begin{tabular}{|l|l|}
\hline \multicolumn{1}{|c|}{ LOS } & \multicolumn{1}{|c|}{ Traffic Density (D) (Vehicles/Lane/Mile) } \\
\hline A & $0-11$ \\
\hline B & $>11-18$ \\
\hline C & $>18-29$ \\
\hline D & $>29-35$ \\
\hline E & $>35-45$ \\
\hline F & $>45$ \\
\hline
\end{tabular}

2. The next step is to determine the change in density between consecutive tolling periods. For each zone, density in period $t, D_{t}$, is the maximum 6-minute density downstream. Change in density at $\mathrm{t}$ is given by Equation 1.

$$
\Delta \mathrm{D}=\mathrm{D}_{\mathrm{t}}-\mathrm{D}_{\mathrm{t}-1}
$$

Table 3 shows the toll increment lookup for LOS C.

Table 3: MnPASS Toll Increment per Change in Density (Source: Hourdos, 2015)

\begin{tabular}{|l|c|c|c|c|c|c|}
\hline$D_{t}$ & $\mathbf{1}$ & $\mathbf{2}$ & $\mathbf{3}$ & $\mathbf{4}$ & $\mathbf{5}$ & $\begin{array}{c}\mathbf{6} \text { or } \\
\text { Greater }\end{array}$ \\
\hline $19-29$ & $\$ 0.00$ & $\$ 0.25$ & $\$ 0.50$ & $\$ 0.75$ & $\$ 1.00$ & $\$ 1.25$ \\
\hline
\end{tabular}


$\Delta$ Toll $=(\Delta \mathrm{D}-1) * 0.25$ if $\Delta \mathrm{D}$ is positive; Maximum $\Delta$ Toll $=1.25$

$\Delta$ Toll $=(\Delta \mathrm{D}+1) * 0.25$ if $\Delta \mathrm{D}$ is negative; Maximum $\Delta$ Toll $=-1.25$

3. Toll in period t equals toll in period t-1 plus the change from the lookup table (see Equation 2).

$\operatorname{Toll}_{t}=\operatorname{Toll}_{t-1}+\Delta$ Toll

For each LOS, there is a minimum, maximum, and default toll rate. The default rate is used only at system startup when there are no previous data to calculate an initial $\Delta D$. Table 4 provides the boundaries and default rates.

Table 4: MnPASS Toll Rates for Each LOS (Source: Hourdos, 2015)

\begin{tabular}{|l|c|c|c|c|c|}
\hline LOS & $\begin{array}{c}\text { Minimum } \\
\text { Density }\end{array}$ & $\begin{array}{c}\text { Maximum } \\
\text { Density }\end{array}$ & Minimum Rate & Maximum Rate & Default Rate \\
\hline A & 0 & 11 & $\$ 0.25$ & $\$ 0.50$ & $\$ 0.25$ \\
\hline B & 12 & 18 & $\$ 0.50$ & $\$ 1.50$ & $\$ 0.25$ \\
\hline C & 19 & 29 & $\$ 1.50$ & $\$ 2.50$ & $\$ 1.50$ \\
\hline D & 30 & 35 & $\$ 2.50$ & $\$ 3.50$ & $\$ 3.00$ \\
\hline E & 36 & 45 & $\$ 3.50$ & $\$ 6.00$ & $\$ 5.00$ \\
\hline F & 46 & 50 & $\$ 6.00$ & $\$ 8.00$ & $\$ 8.00$ \\
\hline
\end{tabular}

The pricing algorithm discussed above was used till 2015. In 2015, the tolling algorithm was completely revised to a simpler algorithm. The tolling algorithm is called the "Continuous Function" algorithm (Hourdos,2015). A toll zone is defined as the segment of the roadway between two stations. All the ML detectors between the first and the last station can be used to calculate the toll. The tolls are calculated every 3 minutes using the data from the most recent 6 minutes. Each station has an associated toll within a zone, based on the highest density (k) recorded among the $\mathrm{ML}$ detectors downstream of that station. The algorithm is shown in Equation 3.

Toll $=a * k^{b}$

Where:

$\mathrm{k}$ is the maximum density of a downstream station

$a$ is the toll density alpha system attribute, default 0.045

$\mathrm{b}$ is the toll density beta system attribute, default 1.10 
The toll is then rounded to the nearest $\$ 0.25$. Thus, the algorithm does not need to be overly complex...although explaining this to the general public and elected officials may prove more difficult than the lookup table.

\section{I-15 Express Lanes (South) in San Diego, CA}

The I-15 Express Lanes started operating in 1998, and the facility was 8 miles long. The tolling algorithm was based on a volume lookup table to achieve a desired LOS. The toll rates were adjusted as often as every 6 minutes and determined by the latest 12-minute volume of the two HOT lanes (see Table 5) (Ye, 2017). There are 23 distinct tolls ranging from a minimum of $\$ 0.50$ at LOS A to a maximum of $\$ 8.00$ at LOS D. The goal of the dynamic tolling algorithm was to maintain at least LOS C on the HOT lanes.

Table 5: Toll Rates for I-15 (Source: Chung, 2013)

\begin{tabular}{|c|c|c|c|}
\hline $\begin{array}{c}\text { 12-Minute Volume } \\
\text { Lower Threshold } \\
\text { (Vehicles) }\end{array}$ & $\begin{array}{c}\text { Equivalent Hourly } \\
\text { Volume (Vehicles } \\
\text { per Hour) }\end{array}$ & LOS & Toll (\$) \\
\hline$<240$ & $<1,200$ & $A$ & $\$ 0.50$ \\
\hline 240 & 1,200 & A & $\$ 0.75$ \\
\hline 290 & 1,450 & $B$ & $\$ 1.00$ \\
\hline 320 & 1,600 & $B$ & $\$ 1.25$ \\
\hline 350 & 1,750 & B & $\$ 1.50$ \\
\hline 380 & 1,900 & $B$ & $\$ 1.75$ \\
\hline 410 & 2,050 & B & $\$ 2.00$ \\
\hline 424 & 2,120 & C & $\$ 2.25$ \\
\hline 440 & 2,200 & C & $\$ 2.50$ \\
\hline 450 & 2,250 & C & $\$ 2.75$ \\
\hline 460 & 2,300 & C & $\$ 3.00$ \\
\hline 470 & 2,350 & $C$ & $\$ 3.25$ \\
\hline 480 & 2,400 & C & $\$ 3.50$ \\
\hline 490 & 2,450 & C & $\$ 3.75$ \\
\hline 500 & 2,500 & $C$ & $\$ 4.00$ \\
\hline 610 & 3,050 & $D$ & $\$ 4.50$ \\
\hline 620 & 3,100 & $D$ & $\$ 5.00$ \\
\hline 630 & 3,150 & $\mathrm{D}$ & $\$ 5.50$ \\
\hline 640 & 3,200 & $\mathrm{D}$ & $\$ 6.00$ \\
\hline 650 & 3,250 & $D$ & $\$ 6.50$ \\
\hline 660 & 3,300 & $\mathrm{D}$ & $\$ 7.00$ \\
\hline 670 & 3,350 & $D$ & $\$ 7.50$ \\
\hline 680 & 3,400 & $D$ & $\$ 8.00$ \\
\hline
\end{tabular}

\section{I-15 Express Lanes in Utah}

The I-15 Express Lanes are dynamically priced, and the tolls are adjusted based on the available capacity in the ELS. As the density increases in the ELs, the tolls are increased to reflect the available space in the lanes (see Equation 4).

$$
\text { Toll Rate }=\frac{\text { Zone Value }}{\text { Vol }_{\text {threshold }}-\text { Vol }_{\max }}
$$


where:

- Zone Value = theoretical value of using the ELs relative to the GPLs. Zone value increases as speeds in the ELs and the GPLs fall below the typical threshold speed of $50 \mathrm{mph}$ to 55 $\mathrm{mph}$, as defined by the performance goal set by the Utah Department of Transportation.

- Volthreshold $=$ volume threshold in the ELs taken as 1,675 vehicles per hour (vph).

- $\mathrm{Vol}_{\max }=$ maximum volume measured at any EL plaza in each zone.

The tolls in each zone can change every 5 minutes and range from $\$ 0.25$ to $\$ 2$. The toll can increase by only $\$ 0.25$ at a time unless the volume in the ELs exceeds the threshold volume (Vol threshold). Figure 1 shows the relationship between the toll rate and the EL volume.

Toll rate determined by volume in the Express Lanes

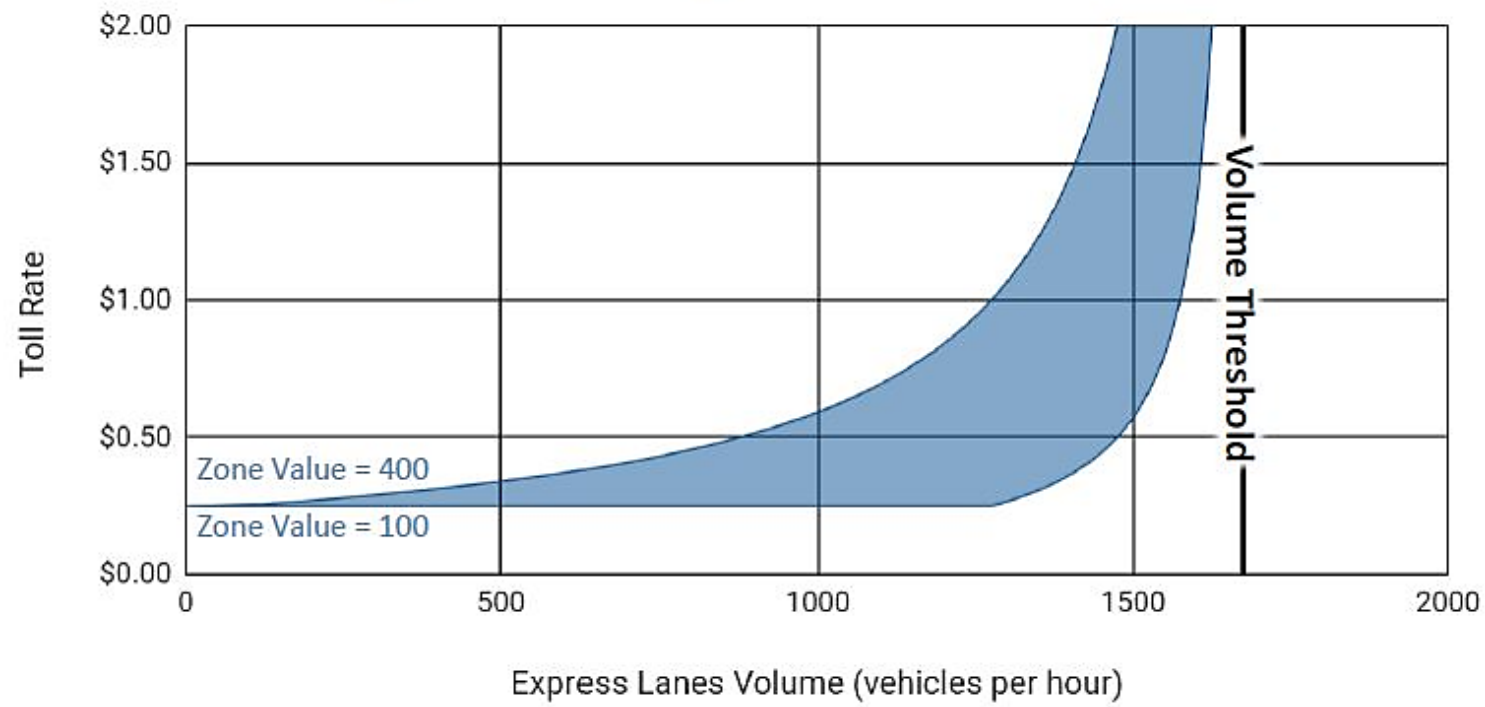

Figure 1: Toll Rate Calculation for ELs in Utah (Source:

https://www.udot.utah.gov/connect/docs/express-lanes-toll-rate-algorithm/)

\section{Dynamic Pricing Algorithms that Consider Both ML and GPL Metrics}

SR-167 in Seattle, WS

The tolling algorithm for SR-167 considers the volume and speed on both the MLs and the GPLs. The toll can change every 5 minutes based on Equation 5 (Chung, 2013).

$$
\text { Toll }_{t}=\text { Toll }_{t-1}+\text { Toll }_{\text {inc }} *(\text { Increment Level })
$$

Where:

- Toll $_{t}=$ toll at period $\mathrm{t}$.

- $\operatorname{Toll}_{\text {inc }}=$ default value of $\$ 0.25$. 
The toll increment places a heavier weight on the traffic conditions in the MLs than in the GPLs and depends on the respective toll increment measures (Equation 6).

$$
\text { Increment Level }=\text { Round }\left(\left(W_{\mathrm{ML}} * T I M_{\mathrm{ML}}+W_{G P \mathrm{~L}} * T I M_{G P \mathrm{~L}}\right) \mathrm{T}_{\mathrm{scale}}\right)
$$

Where:

- $\quad T_{I M} M_{\mathrm{ML}}$ and TIM $_{G P \mathrm{~L}}=$ toll increment measure.

- $T_{\text {scale }}=$ toll increment scaling factor (1 by default).

- $W_{\mathrm{ML}}$ and $W_{G P L}=$ weight for ML and GPL (0.9 and 0.1, respectively, by default).

The toll increment measure at any time depends on the volume and speed change in the ML and the GPLs. Also, the toll increment measure considers the proportion of heavy vehicles in the lanes (Equation 7 through Equation 10).

$$
\begin{aligned}
& T I M_{\mathrm{GPL}}=W_{v \mathrm{cf}} *\left(\frac{V^{\prime} G P L}{v_{\text {scale }-G P L}}\right) \cdot V W F_{\mathrm{GPL}}+W_{s c f}\left(-S_{\mathrm{GPL}}^{\prime}\right) * \mathrm{SWF}_{\mathrm{GPL}} \\
& T I M_{\mathrm{GPL}}=W_{v c f} *\left(\frac{V^{\prime} G P L}{v_{\text {scale }-G P L}}\right) \cdot V W F_{\mathrm{GPL}}+W_{s c f} *\left(-S_{\mathrm{GPL}}^{\prime}\right) * \mathrm{SWF}_{\mathrm{GPL}} \\
& W_{M L}+W_{G P L}=1 \\
& W_{v c f}+W_{s c f}=1
\end{aligned}
$$

Where:

- $\quad V^{\prime}\left(\mathrm{S}^{\prime}\right)=$ volume (speed) change at the period with respect to the ML and GPLs.

- $W_{\text {vcf }}$ and $W_{\text {scf }}=$ weight of volume/speed change ( 0.5 by default).

- $v_{\text {scale_ML }}=$ conversion factor of volume to speed.

- $\operatorname{VWF}(\mathrm{SWF})=$ volume (speed) weight factor for heavy traffic.

Thus, this algorithm takes into account conditions on both lanes at all times to adjust the toll in a logical manner.

\section{I-15 Express Lanes (North) in San Diego, CA}

I-15 North of SR-56 employs a segment-based dynamic tolling algorithm. The facility has multiple entries and exits along the corridor. The toll rates are calculated using inputs of TTS and the value of time (VOT) on the MLs. The pricing algorithm takes into account both time and downstream length.

The default parameters for the algorithm are as follows (Chung, 2013):

- The minimum or the base VOT and maximum VOT are $\$ 24 / \mathrm{hr}$ and $\$ 48 / \mathrm{hr}$, respectively.

- The VOT increment or decrement is $\$ 4.80 / \mathrm{hr}$. 
- The minimum toll during the peak period is $\$ 0.10 /$ mile and for the off-peak period is $\$ 0.05 /$ mile.

- The maximum toll is $\$ 1 /$ mile.

- The minimum acceptable ML average speed is $60 \mathrm{mph}$.

The following steps are involved in determining applicable toll rates (Chung, 2013):

1. Determine the VOT at time $t$ for segment $i$ : If the average speed on each downstream segment ( $\mathrm{i}=1$ to $\mathrm{n}$ ) is greater than $60 \mathrm{mph}$ for two consecutive periods $\mathrm{t}-1$ and $\mathrm{t}-2$, the VOT for each downstream segment at period t decreases by $\$ 4.80 / \mathrm{hr}$. However, if the average speed on any downstream segment is lower than $60 \mathrm{mph}$ for these two periods, the VOT for each downstream segment at period t increases by $\$ 4.80 / \mathrm{hr}$. Otherwise, the VOT remains the same.

2. Determine the toll rate at time $\mathbf{t}$ for segment $\mathrm{i}$ : The toll is found my multiplying the VOT by the cumulative downstream TTS. This is converted to a toll rate by dividing the toll by the total distance downstream. The downstream distance is the sum of all lengths from segment $i$ to the last downstream segment $n$.

3. To protect the tolls from extreme fluctuation, set the limits for the minimum and maximum VOT and tolls.

To illustrate the process of determining the toll at time $t$, consider that there are eight segments. The cumulative time savings at period t- 1 for, say, segment 4 is given in Equation 11 .

$$
C T S_{t-1}=\sum_{i=4}^{i=8} \frac{L_{i}}{V_{G P L i, t-1}}-\frac{L_{i}}{V_{M L i, t-1}}
$$

The toll (\$/mile) at period t for segment 4 can be calculated as in Equation 12 .

$$
\text { Toll }_{i}=\frac{C T S_{t-1} * V O T_{t}}{\sum_{i=4}^{i=8} L_{i}}
$$

Where:

- $\mathrm{Toll}_{\mathrm{i}}=$ toll rate at period $\mathrm{t}$ for segment $\mathrm{i}$.

- $C T S_{t-1}=$ cumulative time savings considering all downstream zones.

- $\mathrm{L}_{\mathrm{i}}=$ downstream length from segment $\mathrm{i}$ to segment $\mathrm{n}$.

- $\mathrm{V} O T_{\mathrm{t}}=\mathrm{VOT}$ at period $\mathrm{t}$ as discussed in step 1 .

\section{Existing Variable Pricing Algorithms}

\section{SR-91 Express Lanes in Orange County, CA}

The current toll schedule for the SR-91 Express Lanes in Orange County (effective January 1 , 2020) has a maximum toll of $\$ 8.65$. The toll is reviewed and potentially adjusted every 3 months depending on traffic volumes during those 3 months. The toll rates can change every hour (see Figure 2). 
Tolls Effective January 1.2020

\begin{tabular}{|c|c|c|c|c|c|c|c|}
\hline \multicolumn{2}{|c|}{ Qi Express } & \multicolumn{3}{|c|}{$\begin{array}{l}\text { Toll Schedule } \\
\text { EHective January } 1,2020^{*}\end{array}$} & \multicolumn{3}{|c|}{$\begin{array}{l}\text { Westbound } \\
\text { Riverside } \mathrm{Co} \text {. Line to SR-55 }\end{array}$} \\
\hline & Sun & Mon & Tue & Wed & Thur & $F r i$ & Sat \\
\hline Midnight & $\$ 1.70$ & $\$ 1.70$ & $\$ 1.70$ & $\$ 1.70$ & $\$ 1.70$ & $\$ 1.70$ & $\$ 1.70$ \\
\hline $1: 00 \mathrm{AM}$ & $\$ 1.70$ & $\$ 1.70$ & $\$ 1.70$ & $\$ 1.70$ & $\$ 1.70$ & $\$ 1.70$ & $\$ 1.70$ \\
\hline $2: 00 \mathrm{AM}$ & $\$ 1.70$ & $\$ 1.70$ & $\$ 1.70$ & $\$ 1.70$ & $\$ 1.70$ & $\$ 1.70$ & $\$ 1.70$ \\
\hline $3: 00$ AM & $\$ 1.70$ & $\$ 1.70$ & $\$ 1.70$ & $\$ 1.70$ & $\$ 1.70$ & $\$ 1.70$ & $\$ 1.70$ \\
\hline $4.00 \mathrm{AM}$ & $\$ 1.70$ & $\$ 3.05$ & $\$ 3.05$ & $\$ 3.05$ & $\$ 3.05$ & $\$ 3.05$ & $\$ 1.70$ \\
\hline $5.00 \mathrm{AM}$ & $\$ 1.70$ & $\$ 4.95$ & $\$ 4.95$ & $\$ 4.95$ & $\$ 4.95$ & $\$ 4.70$ & $\$ 1.70$ \\
\hline $6: 00 \mathrm{AM}$ & $\$ 1.70$ & $\$ 5.15$ & $\$ 5.15$ & $\$ 5.15$ & $\$ 5.15$ & $\$ 4.95$ & $\$ 1.70$ \\
\hline 7:00 AM & $\$ 1.70$ & $\$ 5.65$ & $\$ 5.65$ & $\$ 5.65$ & $\$ 5.65$ & $\$ 5.50$ & $\$ 2.15$ \\
\hline $8: 00$ AM & $\$ 2.15$ & $\$ 5.15$ & $\$ 5.15$ & $\$ 5.15$ & $\$ 5.15$ & $\$ 4.95$ & $\$ 2.50$ \\
\hline $9: 00 \mathrm{AM}$ & $\$ 2.15$ & $\$ 4.10$ & $\$ 4.10$ & $\$ 4.10$ & $\$ 4.10$ & $\$ 4.10$ & $\$ 3.20$ \\
\hline $10: 00 \mathrm{AM}$ & $\$ 3.20$ & $\$ 2.50$ & $\$ 2.50$ & $\$ 2.50$ & $\$ 2.50$ & $\$ 2.50$ & $\$ 3.20$ \\
\hline $11: 00 \mathrm{AM}$ & $\$ 3.20$ & $\$ 2.50$ & $\$ 2.50$ & $\$ 2.50$ & $\$ 2.50$ & $\$ 2.50$ & $\$ 3.60$ \\
\hline NOON & $\$ 3.20$ & $\$ 2.50$ & $\$ 2.50$ & $\$ 2.50$ & $\$ 2.50$ & $\$ 2.50$ & $\$ 3.60$ \\
\hline $1: 00 \mathrm{PM}$ & $\$ 3.60$ & $\$ 2.50$ & $\$ 2.50$ & $\$ 2.50$ & $\$ 2.50$ & $\$ 2.50$ & $\$ 3.60$ \\
\hline $2: 00 \mathrm{PM}$ & $\$ 3.60$ & $\$ 2.50$ & $\$ 2.50$ & $\$ 2.50$ & $\$ 2.50$ & $\$ 2.50$ & $\$ 3.60$ \\
\hline 3:00 PM & $\$ 3.60$ & $\$ 2.50$ & $\$ 2.50$ & $\$ 2.50$ & $\$ 2.50$ & $\$ 3.20$ & $\$ 3.60$ \\
\hline 4:00 PM & $\$ 3.75$ & $\$ 2.50$ & $\$ 2.50$ & $\$ 2.50$ & $\$ 2.50$ & $\$ 3.20$ & $\$ 3.75$ \\
\hline 5:00 PM & $\$ 3.75$ & $\$ 2.50$ & $\$ 2.50$ & $\$ 2.50$ & $\$ 2.50$ & $\$ 3.20$ & $\$ 3.75$ \\
\hline 6.00 PM & $\$ 3.75$ & $\$ 2.50$ & $\$ 2.50$ & $\$ 2.50$ & $\$ 2.50$ & $\$ 3.70$ & $\$ 3.20$ \\
\hline 7:00 PM & $\$ 3.20$ & $\$ 1.70$ & $\$ 1.70$ & $\$ 1.70$ & $\$ 1.70$ & $\$ 2.50$ & $\$ 2.50$ \\
\hline $8: 00 P M$ & $\$ 3.20$ & $\$ 1.70$ & $\$ 1.70$ & $\$ 1.70$ & $\$ 1.70$ & $\$ 1.70$ & $\$ 1.70$ \\
\hline 9:00 PM & $\$ 3.20$ & $\$ 1.70$ & $\$ 1.70$ & $\$ 1.70$ & $\$ 1.70$ & $\$ 1.70$ & $\$ 1.70$ \\
\hline $10: 00 \mathrm{PM}$ & $\$ 1.70$ & $\$ 1.70$ & $\$ 1.70$ & $\$ 1.70$ & $\$ 1.70$ & $\$ 1.70$ & $\$ 1.70$ \\
\hline $11: 00 P M$ & $\$ 1.70$ & $\$ 1.70$ & $\$ 1.70$ & $\$ 1.70$ & $\$ 1.70$ & $\$ 1.70$ & $\$ 1.70$ \\
\hline
\end{tabular}

\begin{tabular}{|c|c|c|c|c|c|c|c|}
\hline \multicolumn{2}{|c|}{ Miteness } & \multicolumn{3}{|c|}{$\begin{array}{l}\text { Toll Schedule } \\
\text { Ellective January } 1,2020^{*}\end{array}$} & \multicolumn{3}{|c|}{$\begin{array}{l}\text { Eastbound } \\
\text { SR-55 to Riverside } \mathrm{Co} \text {. Line }\end{array}$} \\
\hline & Sun & Mon & Tue & Wed & Thur & $F r i$ & Sat \\
\hline Midnight & $\$ 1.70$ & $\$ 1.70$ & $\$ 1.70$ & $\$ 1.70$ & $\$ 1.70$ & $\$ 1.70$ & $\$ 1.70$ \\
\hline 1:00 AM & $\$ 1.70$ & $\$ 1.70$ & $\$ 1.70$ & $\$ 1.70$ & $\$ 1.70$ & $\$ 1.70$ & $\$ 1.70$ \\
\hline $2: 00 \mathrm{AM}$ & $\$ 1.70$ & $\$ 1.70$ & $\$ 1.70$ & $\$ 1.70$ & $\$ 1.70$ & $\$ 1.70$ & $\$ 1.70$ \\
\hline 3:00 AM & $\$ 1.70$ & $\$ 1.70$ & $\$ 1.70$ & $\$ 1.70$ & $\$ 1.70$ & $\$ 1.70$ & $\$ 1.70$ \\
\hline 4:00 AM & $\$ 1.70$ & $\$ 1.70$ & $\$ 1.70$ & $\$ 1.70$ & $\$ 1.70$ & $\$ 1.70$ & $\$ 1.70$ \\
\hline 5:00 AM & $\$ 1.70$ & $\$ 1.70$ & $\$ 1.70$ & $\$ 1.70$ & $\$ 1.70$ & $\$ 1.70$ & $\$ 1.70$ \\
\hline $6: 00 \mathrm{AM}$ & $\$ 1.70$ & $\$ 2.50$ & $\$ 2.50$ & $\$ 2.50$ & $\$ 2.50$ & $\$ 2.50$ & $\$ 1.70$ \\
\hline 7:00 AM & $\$ 1.70$ & $\$ 2.50$ & $\$ 2.50$ & $\$ 2.50$ & $\$ 2.50$ & $\$ 2.50$ & $\$ 1.70$ \\
\hline 8:00 AM & $\$ 2.05$ & $\$ 2.50$ & $\$ 2.50$ & $\$ 2.50$ & $\$ 2.50$ & $\$ 2.50$ & $\$ 2.50$ \\
\hline 9:00 AM & $\$ 2.05$ & $\$ 2.50$ & $\$ 2.50$ & $\$ 2.50$ & $\$ 2.50$ & $\$ 2.50$ & $\$ 2.50$ \\
\hline $10: 00 \mathrm{AM}$ & $\$ 3.20$ & $\$ 2.50$ & $\$ 2.50$ & $\$ 2.50$ & $\$ 2.50$ & $\$ 2.50$ & $\$ 3.20$ \\
\hline 11:00 AM & $\$ 3.20$ & $\$ 2.50$ & $\$ 2.50$ & $\$ 2.50$ & $\$ 2.50$ & $\$ 2.50$ & $\$ 3.20$ \\
\hline NOON & $\$ 3.70$ & $\$ 2.50$ & $\$ 2.50$ & $\$ 2.50$ & $\$ 2.50$ & $\$ 3.85$ & $\$ 3.70$ \\
\hline 1:00 PM & $\$ 3.70$ & $\$ 3.55$ & $\$ 3.55$ & $\$ 3.55$ & $\$ 3.85$ & $\$ 6.00$ & $\$ 3.70$ \\
\hline $2: 00 P M$ & $\$ 3.70$ & $\$ 5.15$ & $\$ 5.15$ & $\$ 5.15$ & $\$ 7.45$ & $\$ 7.85$ & $\$ 3.70$ \\
\hline 3:00 PM & $\$ 3.20$ & $\$ 5.50$ & $\$ 5.75$ & $\$ 7.75$ & $\$ 6.75$ & 58.65 & $\$ 3.70$ \\
\hline 4:00 PM & $\$ 3.20$ & $\$ 5.35$ & $\$ 5.50$ & $\$ 7.50$ & 57.80 & $\$ 8.45$ & $\$ 3.70$ \\
\hline 5:00 PM & $\$ 3.20$ & $\$ 5.30$ & $\$ 5.40$ & $\$ 6.40$ & $\$ 8.20$ & $\$ 7.05$ & $\$ 3.70$ \\
\hline 6:00 PM & $\$ 3.20$ & $\$ 5.50$ & $\$ 3.95$ & $\$ 3.95$ & $\$ 4.85$ & $\$ 6.55$ & $\$ 3.20$ \\
\hline 7:00 PM & $\$ 3.20$ & $\$ 3.85$ & $\$ 3.85$ & $\$ 3.85$ & $\$ 5.60$ & $\$ 6.05$ & $\$ 2.50$ \\
\hline $8: 00 P M$ & $\$ 3.20$ & $\$ 2.50$ & $\$ 2.50$ & $\$ 2.50$ & $\$ 3.55$ & $\$ 5.60$ & $\$ 2.50$ \\
\hline 9:00 PM & $\$ 2.50$ & $\$ 2.50$ & $\$ 2.50$ & $\$ 2.50$ & $\$ 2.50$ & $\$ 3.55$ & $\$ 2.50$ \\
\hline $10: 00 P M$ & $\$ 1.70$ & $\$ 1.70$ & $\$ 1.70$ & $\$ 1.70$ & $\$ 1.70$ & $\$ 2.50$ & $\$ 1.70$ \\
\hline 11:00 PM & $\$ 1.70$ & $\$ 1.70$ & $\$ 1.70$ & $\$ 1.70$ & $\$ 1.70$ & $\$ 1.70$ & $\$ 1.70$ \\
\hline
\end{tabular}

Figure 2: The Current Variable Toll Prices on SR-91 (Source: https://www.octa.net/91Express-Lanes/Toll-Schedules)

The toll rates are determined by the Orange County Transportation Authority (OCTA). The hourly traffic volumes in both directions are monitored for a rolling 12-consecutive-week period. The hourly, daily, and directional traffic volumes above the threshold of 3,128 vph (for two lanes) are marked for further review. The toll remains unchanged if the average marked vehicle volume is less than 3,200 vph. If the average marked volume lies between 3,200 and 3,299 , the hourly toll rate is increased by $\$ 0.75$. The hourly toll is increased by $\$ 1.00$ if the average marked vehicle volume exceeds 3,300 . The current minimum toll rate is $\$ 1.70$.

The maximum optimal capacity is 3,400 vph per direction. The trigger point to raise the toll is at least 92 percent of the maximum optimal capacity (3,128 vph or more per direction). Super peak hours are defined as those hourly periods where the traffic volume meets or exceeds the trigger point.

A review is conducted 6 months after each toll increase for the most recent 12 consecutive weeks (weeks during which any incidents that occurred on a holiday are excluded) for the hour, day, and direction for which the toll was increased. If the average traffic volume drops below $2,720 \mathrm{vph}$, the toll should be reduced by $\$ 0.50$ to encourage more drivers to use the lanes. Prior to any toll adjustment, the public is informed at least 10 days before the modified toll rate 
is effective. The tolls for non-super-peak hours are considered only for annual inflation adjustments. 


\section{Performance Measures/Metrics for Managed Lanes}

This research compares variable pricing and dynamic pricing to determine if one form of pricing is more effective than the other. This is regardless of other potential geometric or design constraints of those lanes. The focus was on the bottom line - could the toll maintain acceptable traffic conditions regardless of any other constraints or issues.

To begin, several existing performance criteria on the MLs were examined for their applicability to this research. These include many of the ones in Table 1, such as TTS, travel time reliability, operating speeds, VMT, and revenue generation. In addition, several new performance measures were developed and applied to the MLs and GPLs studied in this project.

The ML tolling performance measures were developed from the perspective of both the traveler and the toll agency. Three performance measures were developed to capture what a traveler experiences in terms of ML operations. Similarly, four measures were developed to capture the ML performance from the perspective of the operator. Further, the metrics can be calculated for both variably (time-of-day) and dynamically priced lanes separately and compared for effectiveness for peak/non-peak periods. The metrics are described as follows.

\section{Metrics from the Perspective of the Traveler}

\section{Travel Time Savings}

The TTS measures the travel time saved by a traveler by choosing to travel on the MLS compared to the GPLs (see Equation 13). This metric was calculated for the available granularity of traffic data. For example, if granularity is $x$ minutes, the TTS is calculated for all available $\mathrm{x}$-minute periods. The TTS must be weighted by the volume of traffic in the MLs for each such period.

$$
T T S=T T_{G P L}-T T_{M L}
$$

Variability Benefit

The variability benefit is defined as the ratio of the standard deviation (国) of travel times in the GPLs and MLs (see Equation 14). This metric captures a traveler's perspective of travel on the MLs and the GPLs. The standard deviation of travel times is calculated for the applicable granularity level. For example, for a 5-minute granularity, ? of travel times is calculated for all available $6: 00$ to $6: 05$ time periods. The variability is weighted by the volume of traffic in the MLs for each time period.

$$
\text { Variability benefit }=\frac{\sigma_{T T, G P L}}{\sigma_{T T, M L}}
$$

\section{Planning Time Index Benefit}

The planning time index (PTI) is the ratio of the 95th percentile travel time to the free-flow travel time (see Equation 15). The PTI should be calculated for the MLs and the GPLs separately. The free-flow travel time is calculated by taking the average of operating speeds in periods of 
low traffic flows, such as operating speeds between midnight and 4 a.m. The 95th percentile travel time is found by weighting the travel times in the MLs and the GPLs separately. For example, for 5-minute granularity, if the average travel time from 6:00 to 6:05 a.m. is 4 minutes in the MLs, and the volume is 100 vehicles, then the travel times should be duplicated 100 times to calculate the required percentiles. Consequently, the free-flow and 95th percentile travel times are calculated for all available time-periods on the GPLS and MLs.

$$
P T I=\frac{95 \text { th percentile travel time }}{\text { Free-flow travel time }}
$$

The planning time index benefit is defined as the difference in the PTI of the GPLs and the MLs (see Equation 16).

$$
\text { Planning time index benefit }=P T I_{G P L}-P T I_{M L}
$$

\section{Metrics from the Perspective of the Agency/Operator}

\section{Ability of the Toll to Impact Congestion}

This metric is defined as shown in Equation 17.

$$
\begin{aligned}
& \begin{array}{l}
\text { Ability of the toll to impact congestion } \\
\% \text { change in average vehicle throughput in the MLs }
\end{array} \\
& \% \text { increase in toll }
\end{aligned}
$$

This metric should be computed for specific toll brackets. For example, the impact of change in toll on vehicle throughput can be measured from toll brackets $\$ 4-5$ to $\$ 5-6$. The average vehicle throughput is the average volume in the MLs at each toll. For example, each time the toll is

$\$ 4-5$, the average volume in the MLs is observed as $800 \mathrm{vph}$, and it increases to $1,000 \mathrm{vph}$ when the toll is $\$ 5-6$. The percent change in average vehicle throughput can be calculated for each consecutive toll bracket. The toll for a given toll bracket is the weighted average of the tolls. For example, if the ML throughput is 5,000 when the toll is $\$ 4$ and 8,000 when the toll is $\$ 5$, the toll for the bracket is $\$ 4.61$.

\section{Speed Threshold}

This metric measures the percentage of times the lanes achieve the desired speed and can be defined in two ways:

- External threshold: The Federal Highway Administration (FHWA) defines this speed threshold. The lanes must maintain speeds of $45 \mathrm{mph}$ or more at least 90 percent of the time during peak periods of operation.

- Internal threshold: The tolling agency may define this standard of maintaining speeds. For example, Minnesota adjusts tolls to keep ML traffic flowing at 50-55 mph. 


\section{Speed Graphs}

In this metric, the ML and the GPL speeds are plotted together. This metric is a visual representation of the percentage of total time that the lanes achieved the FHWA objective of maintaining speeds of at least $45 \mathrm{mph}$. A four-quadrant graph with the center at $(45,45)$ is plotted, as shown in Figure 3. The percentage of times the speeds lie in each of the quadrants is also displayed on the graph. However, several observations may overlap each other; therefore, this visual representation can sometimes be misleading or may not capture the complete picture.

\section{Scoring Index}

This metric provides a score at each time granularity of available data. For example, for 5minute granularity, a scoring index is calculated each time from 6:00 to 6:05. The first step is to determine the lane capacity for a facility. The approximate ML capacity is obtained from the fundamental traffic speed-flow-density diagrams. The flow is taken as the average ML flow across all lanes of traffic (see Equation 18). The speed-flow and the flow-density diagrams are plotted, as shown in Figure 4 and Figure 5, respectively. For example, the lane capacity is approximately 1,700 vph in Figures 4 and 5.

$$
\text { Average ML flow }=\frac{\text { Total ML flow }}{\text { Number of MLs }}
$$

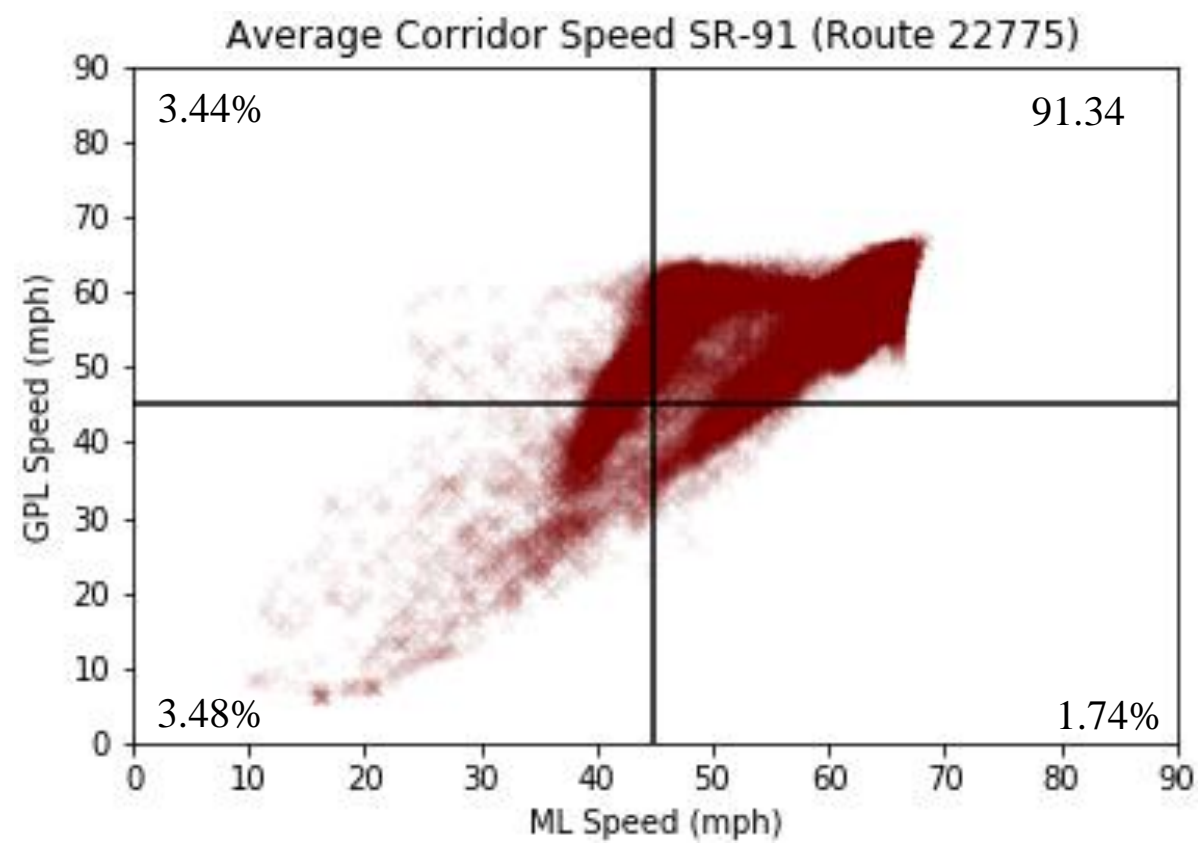

Figure 3: Graphical Display of Performance for Route 22775 in SR-91 


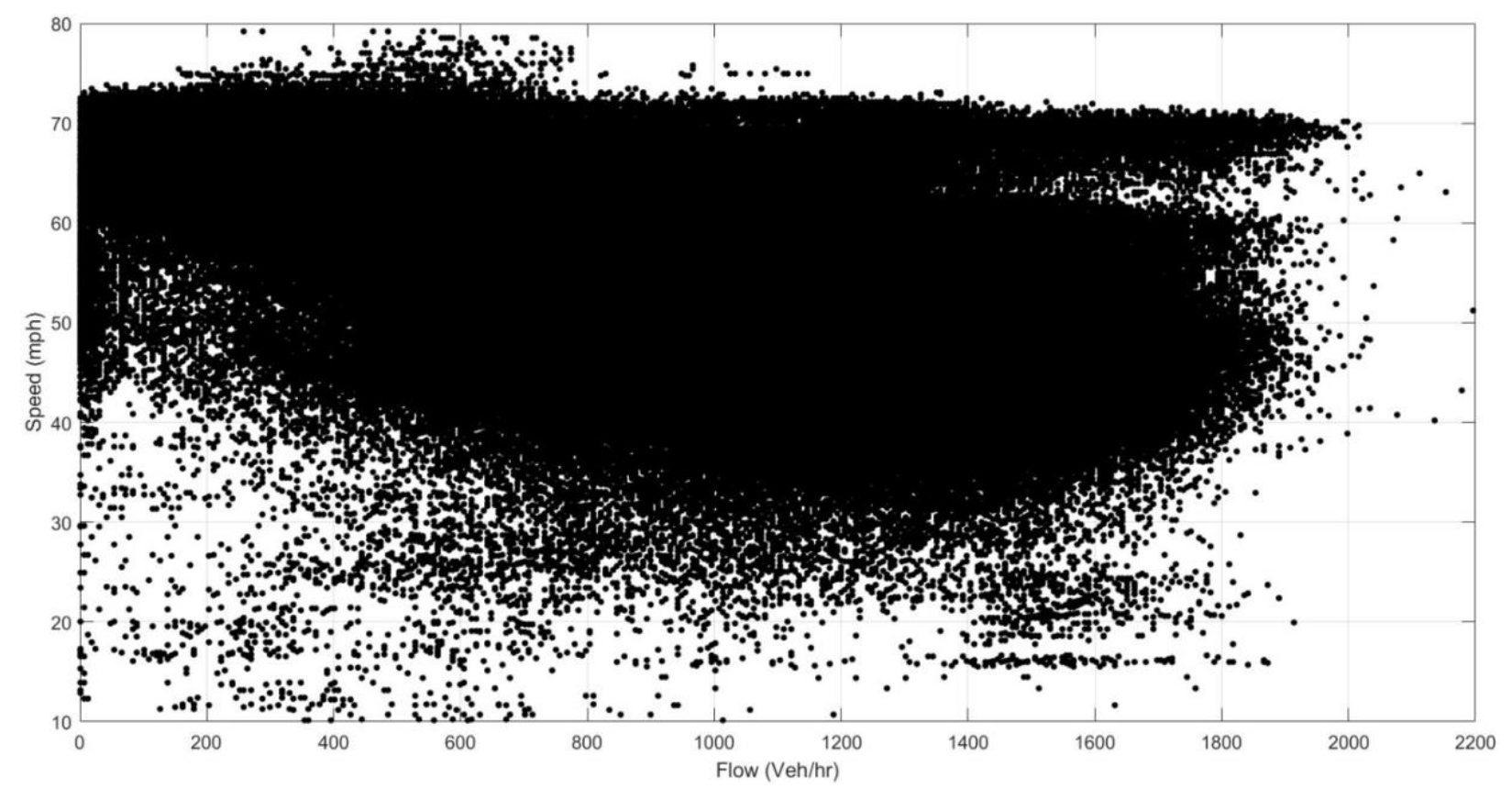

Figure 4: Speed-Flow Plot for SR-91 Eastbound

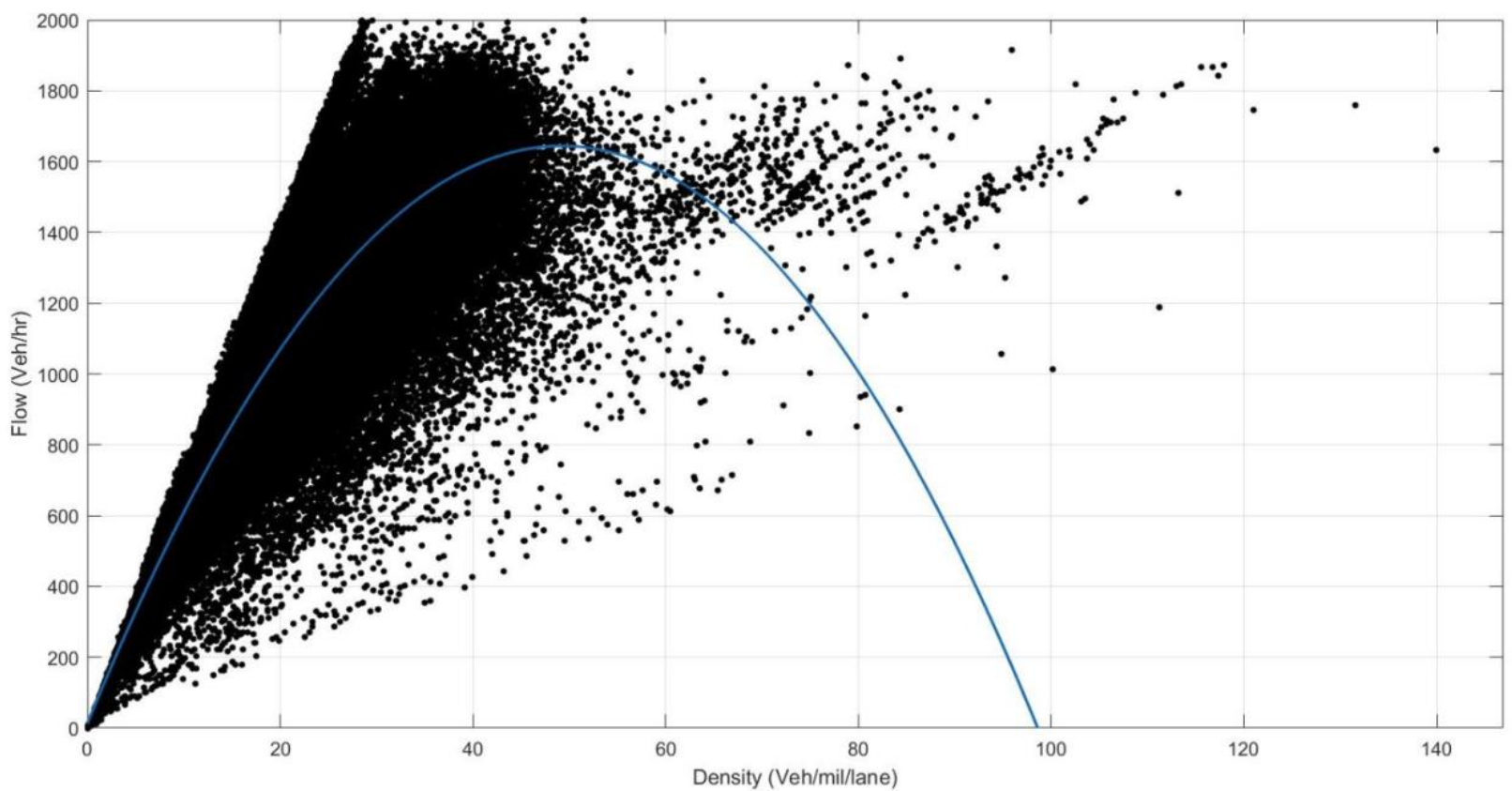

Figure 5: Flow-Density Plot for SR-91 Eastbound

After the lane capacity is determined, the next step is to assign a score to each period of observation based on chosen parameters. Figure 6 shows the criteria to assign a scoring index. The scoring index consists of integer values from -3 to +3 . The index takes the FHWA threshold of $45 \mathrm{mph}$ as the criterion for differentiating between a positive and a negative score. Since many toll operators aim to keep the ML speeds between 50 and $55 \mathrm{mph}$, the highest positive scores are allotted for speeds above $55 \mathrm{mph}$. The scoring index is developed such that it gives 
the highest score if the GPLs are worse than the MLs in terms of flows and speeds, and the lowest score if the GPLs perform better than the MLs.

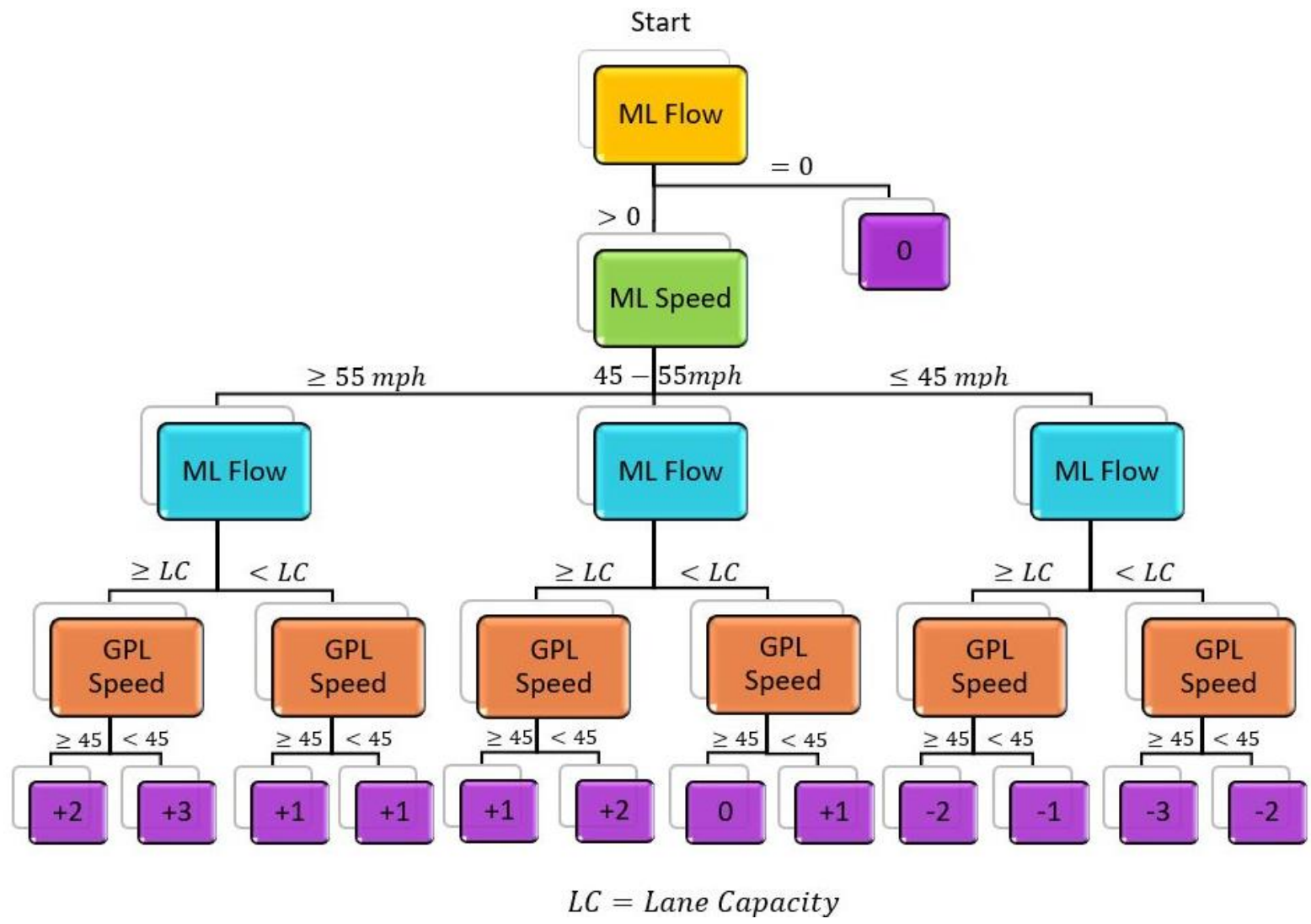

Figure 6: Scoring Index Criteria

Each raw score is weighted by the $\mathrm{ML}$ flow in that time period (see Table 6). The final score for the facility is obtained by weighting each score by the total traffic volume on the ML at that score, as shown in Equation 19.

$$
\text { Final Score }=\frac{\sum_{i=1}^{i=n} \text { Score }_{i} * \text { Total ML Flow Rate }}{i}=0.304
$$

Table 6: Flow Rates by Score for East of Gypsum in Eastbound in SR-91

\begin{tabular}{|c|c|c|c|c|c|c|}
\hline \multicolumn{7}{|c|}{ Number of Times (5-Minute) Raw Score Obtained } \\
\hline-3 & -2 & -1 & 0 & 1 & 2 & 3 \\
\hline 67 & 16,398 & 28 & 7,996 & 78,655 & 1,964 & 0 \\
\hline \multicolumn{7}{|c|}{ Total ML Flow at Each Raw Score } \\
\hline-3 & -2 & -1 & 0 & 1 & 2 & 3 \\
\hline 7,825 & $2,646,369$ & 8,950 & $1,134,517$ & $7,874,847$ & 587,481 & 0 \\
\hline \multicolumn{7}{|c|}{ Raw Score Times Total HOV Flow } \\
\hline-3 & -2 & -1 & 0 & 1 & 2 & 3 \\
\hline$-23,475$ & $-5,292,738$ & $-8,950$ & 0 & $7,874,847$ & $1,174,962$ & 0 \\
\hline
\end{tabular}




\section{Analysis}

\section{SR-91 Express Lanes}

\section{Facility Overview}

The SR-91 Express Lanes opened in 1995. The 91 Express Lanes are an 18-mile toll road built in the median of SR-91. The lanes start near the interchange of SR-55/SR-91 in Anaheim, CA, and end at the SR-91/I-15 interchange in Corona, CA (see Figure 7). There are two MLs and five to six GPLs (depending on location) in each direction. The ELs are separated from the GPLs with 3-foot-high, white plastic lane markers. The 91 Express Lanes route traverses Orange County and Riverside County. There is one exit near the midpoint, at the county line near Green River Road. The toll rate is variably priced and changes by the hour of the day (see Figure 2). For each direction, there are three different tolls charged depending on the length of the route traveled. The customers driving the entire route pay one rate. Similarly, customers using only the route in Orange County pay a separate toll compared to those using the route only in Riverside County. The 91 Express Lanes are owned and operated by OCTA and the Riverside County Transportation Commission.

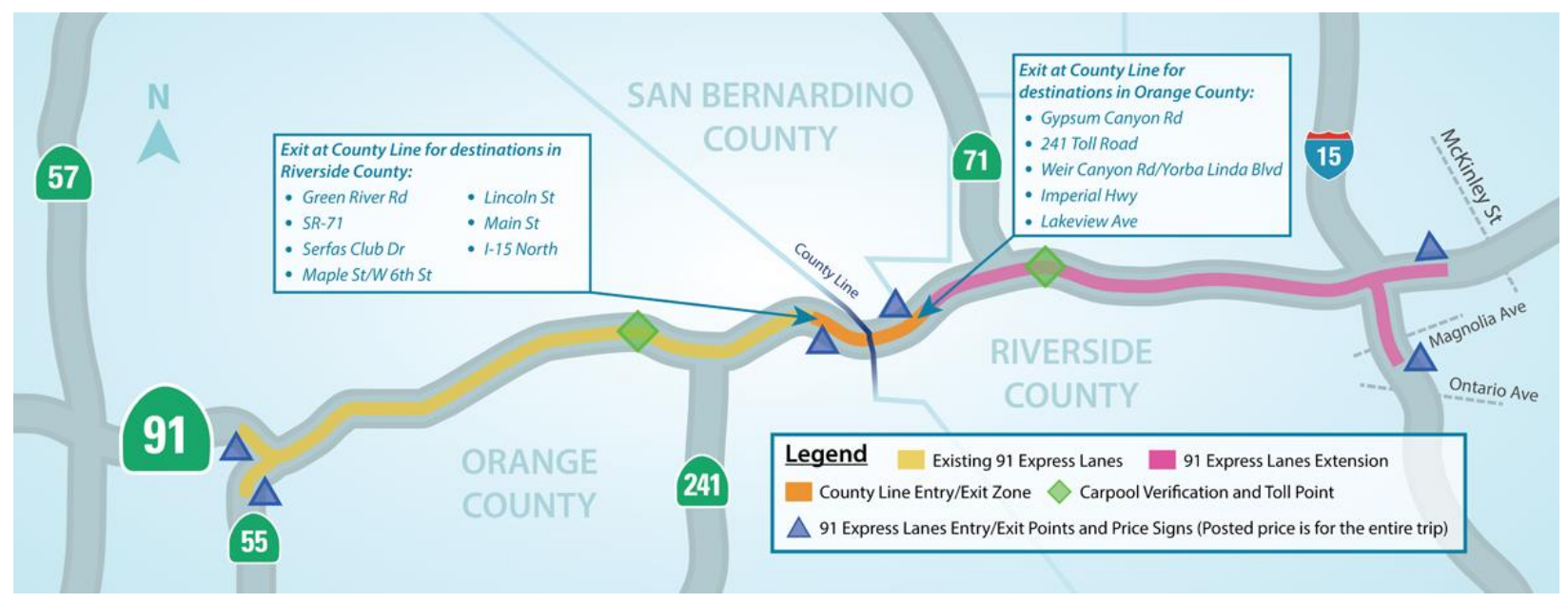

Figure 7: Map of SR-91 Express Lanes (Source: https://blog.octa.net/now-open\%2C-91-projectwill-improve-travel-to-riverside-county)

All vehicles using the ELs are required to have a FasTrak transponder, and the toll is deducted from a prepaid account. HOVs having three or more persons (HOV 3+) are eligible to travel without paying a toll except for eastbound travel, Monday to Friday, from 4 to 6 p.m. During this time on weekdays, the HOV $3+$ customers pay only 50 percent of the posted toll. Further, the HOV $3+$ vehicles must drive in the leftmost dedicated lane at the approach of toll gantries in each section of the ELs to receive the reduced rates.

\section{Data}

Several traffic parameters are extracted from the California Department of Transportation (Caltrans) Performance Measurement System (PeMS) website at http://pems.dot.ca.gov/ PeMS is a software tool designed for Caltrans that contains real-time traffic data of state highways in California. PeMS allows users to get the traffic data from any detector; compute performance 
measures such as delay, LOS, and VMT; and even calculate travel time and reliability measures such as travel time index and buffer time index, among many others. The data reported to PeMS from the detectors generally measure the occupancy of the vehicles. PeMS uses this occupancy to calculate other traffic performance measures, such as person delay and speed. For detectors that do not measure speed directly, the observed volume and occupancy are converted into speed using a conversion factor known as g-factor.

The loop detector data from nine vehicle detection stations (VDSs) in each direction for SR-91 in Orange County is used for analysis in this study. The VDS consists of a group of loop detector stations (LDSs). At each VDS, there are five or six LDSs for the GPLs and two LDSs for the ML. The speeds and flows are extracted for 5-minute granularity at each VDS for the MLs and the GPLs separately. Data are collected from January 1, 2019, to December 31, 2019. The aggregate speed at each VDS is volume weighted, and the flow is the total flow for all the individual LDSs. This aggregate speed and flow are determined for the MLs and the GPLs separately.

An initial analysis of the aggregate speed was conducted for each of the detectors in Orange County. The MLs were faster than the GPLs only 26 percent of the time in the eastbound direction. Similar observations were found for the westbound direction. Because speed is not directly measured but is derived from the occupancy, average length of the vehicle, and flow rates, it was concluded that the speeds in the PeMS database were unreasonable and therefore not used further.

PeMS has some routes defined in its system for which the travel time data are available. The travel time on a route is calculated by a method called walking the velocity field. Each route is composed of several small segments. For each segment in a route, the time it takes to traverse that segment is calculated, and then the speed for the next segment is taken at the time of arrival at that segment. These travel times are computed from the traffic parameters at the detector stations, and the traffic speeds are derived rather than measured. The speeds derived from the detectors are spot-mean speeds instead of space-mean speeds. The travel times were found to be reliable because the travel times on the MLs were shorter than those on the GPLs more than 90 percent of the time. The speeds were calculated from the travel times for the routes and were used for analysis.

The travel time data were available for four segments, which are located in Orange County. Travel time data for the Riverside County segment were not available. Table 7 and

Table 8 describe the eastbound and westbound routes, respectively.

Table 9 and 
Table 10 show the location of the sensors for each direction, and Figure 8 shows the map. Figure 9 and Figure 10 show PeMS data showing traffic flows in the GPLs and in the GPLs and MLs, respectively.

Table 7: Eastbound Routes on SR-91

\begin{tabular}{|l|l|l|l|c|}
\hline \multicolumn{1}{|c|}{ Direction } & \multicolumn{1}{|c|}{ Route Number } & \multicolumn{1}{|c|}{ Start Location } & \multicolumn{1}{c|}{ End Location } & $\begin{array}{c}\text { Length } \\
\text { (Miles) }\end{array}$ \\
\hline Eastbound & 22775 & Tustin Street & Weir Canyon Road & 5.255 \\
\cline { 2 - 6 } & 22776 & Weir Canyon Road & Coal Canyon Road & 4.712 \\
\hline
\end{tabular}

Table 8: Westbound Routes on SR-91

\begin{tabular}{|l|l|l|l|c|}
\hline \multicolumn{1}{c|}{ Direction } & \multicolumn{1}{|c|}{ Route Number } & \multicolumn{1}{|c|}{ Start Location } & \multicolumn{1}{c|}{ End Location } & $\begin{array}{c}\text { Length } \\
\text { (Miles) }\end{array}$ \\
\hline \multirow{2}{*}{ Westbound } & 22779 & Weir Canyon Road & Tustin Street & 5.255 \\
\cline { 2 - 5 } & 22778 & Coal Canyon Road & Weir Canyon Road & 4.672 \\
\hline
\end{tabular}

Table 9: Eastbound Sensors on SR-91

\begin{tabular}{|l|l|l|l|c|c|}
\hline \multicolumn{1}{|c|}{ S. No. } & \multicolumn{1}{|c|}{ Location } & ML VDS & \multicolumn{1}{c|}{ GPL VDS } & $\begin{array}{c}\text { Distance between } \\
\text { Locations (Miles) }\end{array}$ & $\begin{array}{c}\text { Route } \\
\text { Number }\end{array}$ \\
\hline 1 & SR-91 Entrance & - & - & - & 1.4 \\
\hline 2 & Lakeview 1 & 1218312 & 1203984 & 0.8 \\
\hline 3 & West of Imperial & 1208109 & 1208108 & 0.9 \\
\hline 4 & Imperial 2 & 1218302 & 1204064 & 0.5 \\
\hline 5 & East of Imperial & 1208133 & 1208121 & 0.6 \\
\hline 6 & Midpoint & 1218952 & 1208147 & 0.6 \\
\hline 7 & West of Scales & 1208175 & 1208161 & 0.5 \\
\hline 8 & Weir Canyon Road & - & - & 1.2 \\
\hline 9 & East of Weir & 1208194 & 1208180 & 0.7 \\
\hline 10 & West of Gypsum & 1208212 & 1208199 & 1.3 \\
\hline 11 & East of Gypsum & 1208232 & 1208226 & 22776 \\
\hline 12 & Coal Canyon Road & - & - & 1.5 \\
\hline 13 & County Line Exit & - & - & 0.2 \\
\hline
\end{tabular}


Table 10: Westbound Sensors on SR-91

\begin{tabular}{|l|l|l|l|c|c|}
\hline \multicolumn{1}{|c|}{ S. No. } & \multicolumn{1}{|c|}{ Location } & \multicolumn{1}{|c|}{ ML VDS } & \multicolumn{1}{c|}{ GPL VDS } & $\begin{array}{c}\text { Distance between } \\
\text { Locations (Miles) }\end{array}$ & $\begin{array}{c}\text { Route } \\
\text { Number }\end{array}$ \\
\hline 1 & County Line Entrance & - & - & - & 0.2 \\
\hline 2 & Coal Canyon Road & - & - & 0.6 \\
\hline 3 & West of Coal & 1213690 & 1213686 & 1 \\
\hline 4 & East of Gypsum & 1208234 & 1208230 & 1.2 \\
\hline 5 & West of Gypsum & 1208214 & 1208208 & 1.3 \\
\hline 6 & Weir Canyon 2 & 1218339 & 1204105 & 0.2 \\
\hline 7 & Weir Canyon 1 & 1218326 & 1204076 & 0.3 \\
\hline 8 & Weir Canyon Road & - & - & 0.6 \\
\hline 9 & West of Scales & 1208177 & 1208176 & 1.2 \\
\hline 10 & East of Imperial & 1208135 & 1208134 & 0.6 \\
\hline 11 & Imperial 2 & 1218526 & 1204052 & 22779 \\
\hline 12 & West of Imperial & 1208111 & 1208110 & 0.8 \\
\hline 13 & SR-91 Exit & - & - & 2.1 \\
\hline
\end{tabular}

Route 22779

$\longleftarrow$ Route $22778 \longrightarrow$

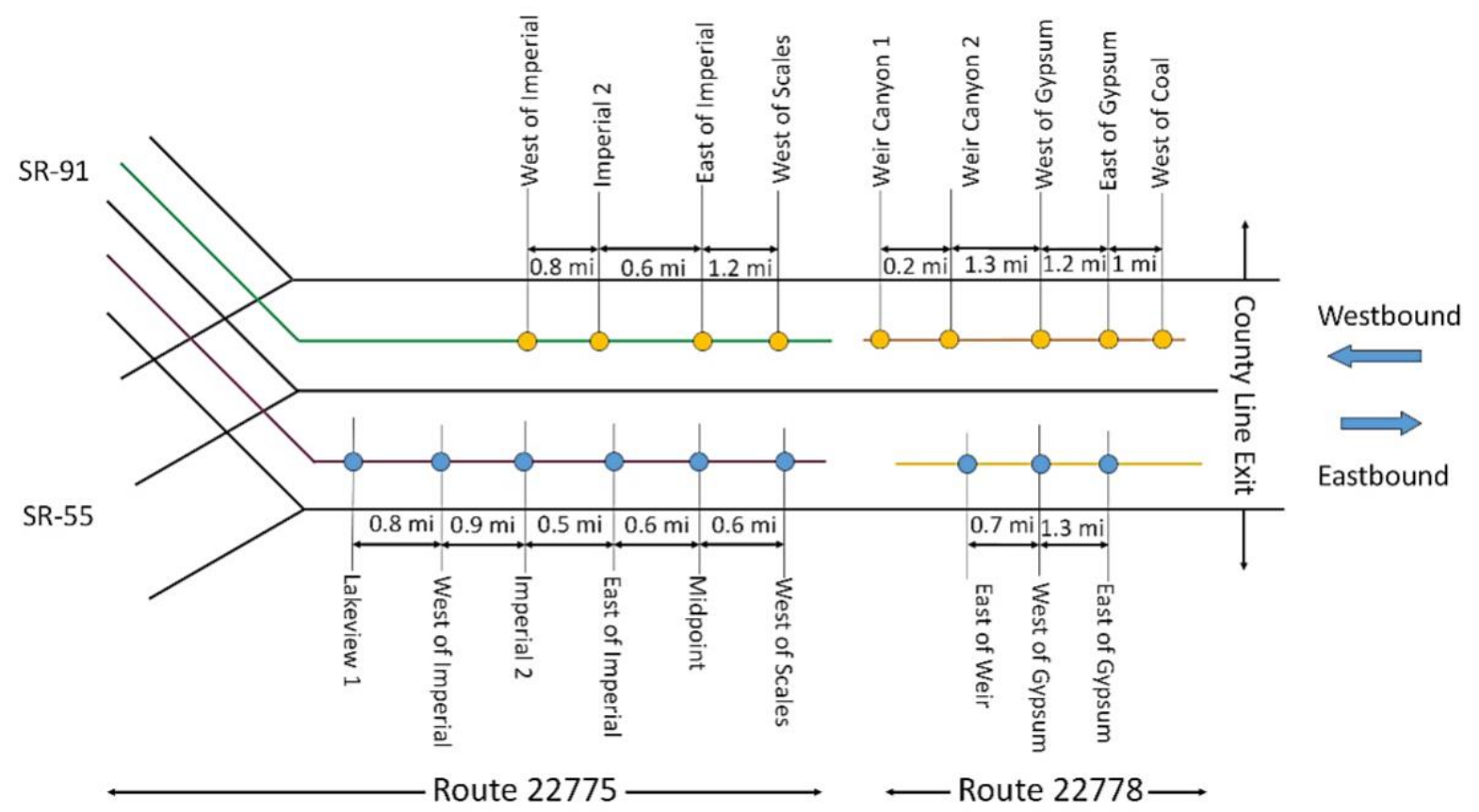

Figure 8: Map of SR-91 in Orange County with the Routes 


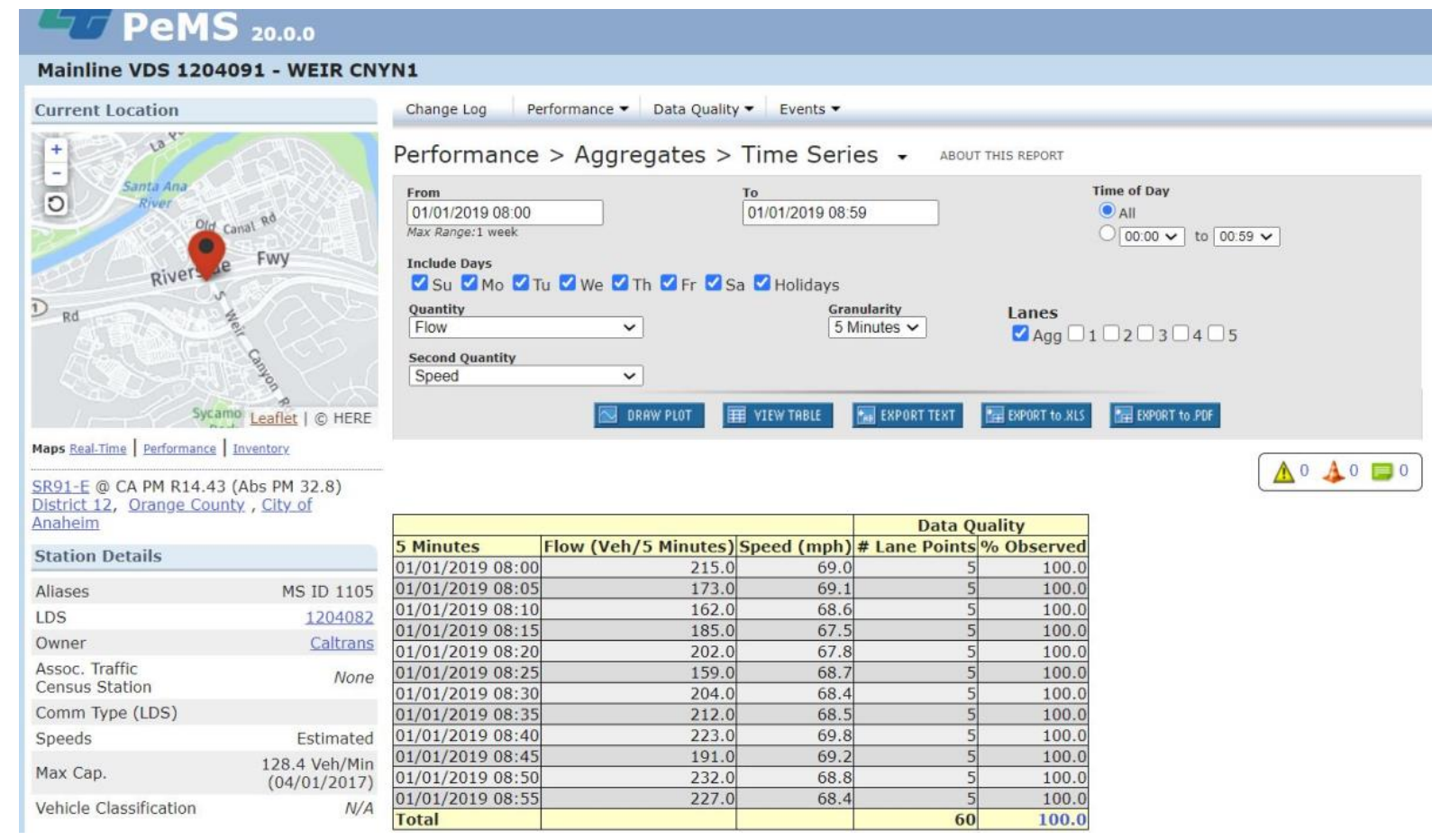

Figure 9: PeMS Data Showing Traffic Flows at 5-Minute Granularity in the Mainline (GPLs)

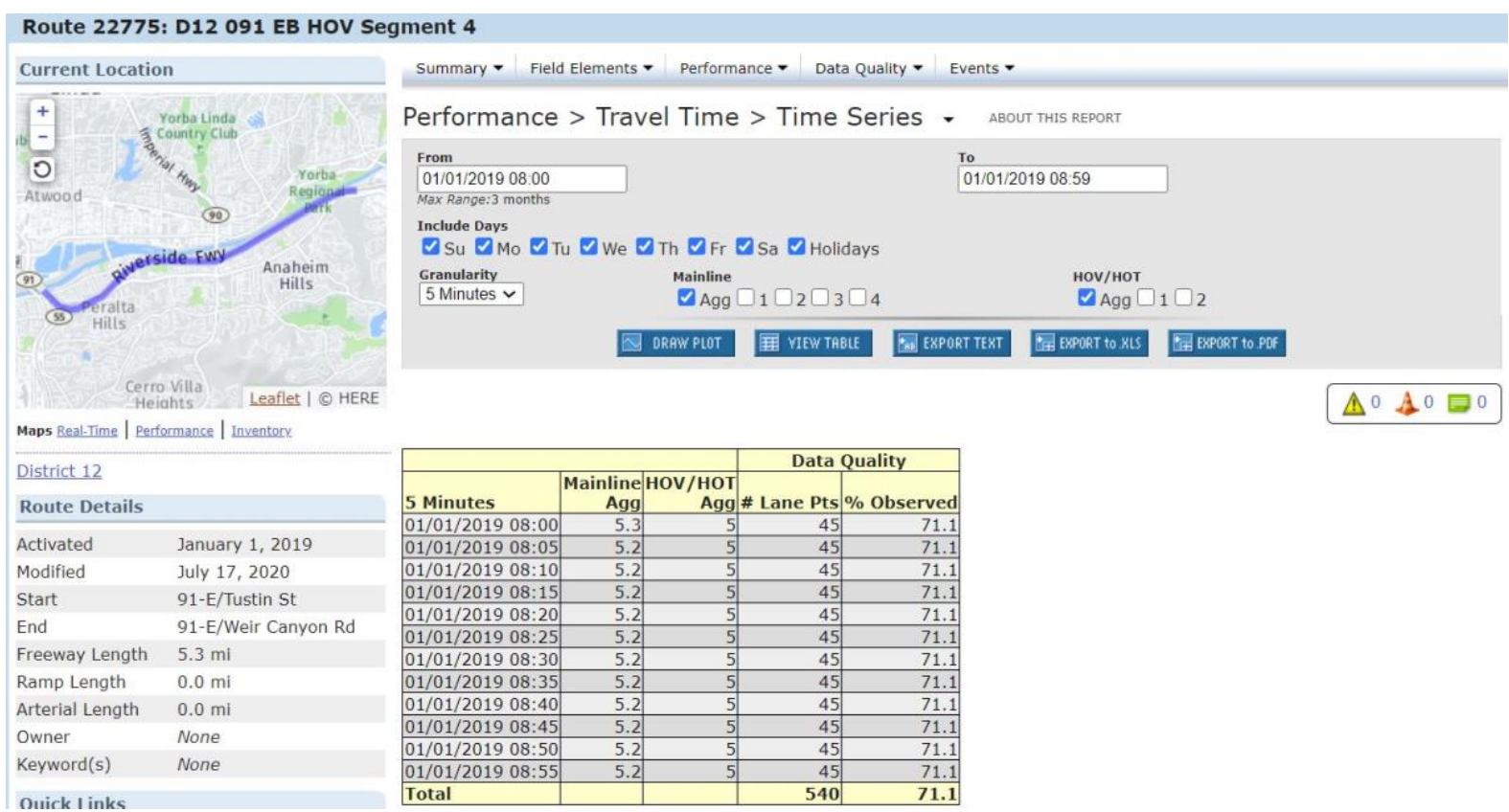

Figure 10: PeMS Data Showing Travel Times in the Mainline (GPLs) and the HOV/HOT Lanes (MLs)

\section{Performance Metrics}

Travel Time Savings

The TTS is the difference in travel times between the GPL and the ML. The TTS was calculated using Equation 13. The travel time (TT) data for each 5-minute period for the four routes were 
extracted from PeMS, and the TTS was calculated. The TTS was weighted by the average volume of traffic in the MLs. The TTS was calculated for peak periods ( 7 to 9 a.m. and 4 to 6 p.m. on weekdays), off-peak periods, and overall (Table 11).

Table 11: Travel Time Savings for SR-91 Routes

\begin{tabular}{|l|l|c|c|c|c|}
\hline \multirow{2}{*}{ Metric } & \multirow{2}{*}{ Time } & \multicolumn{2}{c|}{ Eastbound } & \multicolumn{2}{c|}{ Westbound } \\
\cline { 3 - 6 } & & Route 22775 & Route 22776 & Route 22779 & Route 22778 \\
\hline \multirow{3}{*}{ TTS (minutes) } & Peak & -0.402 & 1.197 & 0.627 & 0.074 \\
\cline { 2 - 6 } & Off-peak & 0.249 & 0.704 & 0.673 & 0.162 \\
\cline { 2 - 6 } & Total & 0.118 & 0.801 & 0.663 & 0.144 \\
\hline
\end{tabular}

The TTS obtained for each of the routes is again weighted by the average volume of traffic in the MLs, and a single value is obtained for the facility. Travelers saved an average of 0.45 minutes by traveling on the 91 Express Lanes.

\section{Variability Benefit}

The variability benefit is defined as the ratio of the standard deviation (国) of travel times in the GPLs to that in the MLs. It represents the variability in travel times experienced by a traveler in the MLs relative to the GPLs. The variability benefit was calculated using Equation 14.

The of travel times are calculated for all the distinct 5-minute time periods available. The variability benefit is then calculated and finally weighted by the volume of traffic in the MLs to obtain the final value for the facility (Table 12).

Table 12: Variability Benefit for SR-91Routes

\begin{tabular}{|l|l|c|c|c|c|}
\hline \multirow{2}{*}{ Metric } & \multirow{2}{*}{ Time } & \multicolumn{2}{c|}{ Eastbound } & \multicolumn{2}{c|}{ Westbound } \\
\cline { 2 - 6 } & & Route 22775 & Route 22776 & Route 22779 & Route 22778 \\
\hline Variability benefit & Peak & 2.224 & 1.499 & 1.788 & 1.544 \\
\cline { 2 - 6 } & Off-peak & 1.729 & 1.534 & 1.449 & 1.228 \\
\cline { 2 - 6 } & Total & 1.776 & 1.535 & 1.514 & 1.288 \\
\hline
\end{tabular}

The variability benefit for the facility is 1.53 , indicating that the travel time variation in the GPLs is higher than in the MLs.

\section{Planning Time Index Benefit}

The planning time index benefit is obtained by subtracting the PTI of the MLs from the PTI of the GPLs. The planning time index benefit was calculated using Equation 16.

The PTI is calculated for both the MLs and the GPLs separately. The FFS is determined to calculate the free-flow travel time. A reasonable estimate of the FFS is obtained by taking the average of observed speeds for the MLs and the GPLs from midnight to 4 a.m. for the data available. The FFS is calculated separately for each of the four routes (Table 13). 
Table 13: Free-Flow Speed for SR-91 Routes

\begin{tabular}{|c|c|c|}
\hline Route & FFS for ML (mph) & FFS for GPL (mph) \\
\hline 22775 & 65.7 & 62.2 \\
\hline 22776 & 70.2 & 68.6 \\
\hline 22779 & 75.7 & 75.5 \\
\hline 22778 & 68.3 & 68.1 \\
\hline
\end{tabular}

The TT for every 5-minute interval for the MLs and the GPLs is obtained from PeMS. Next, the average volumes of traffic in the MLs and the GPLs were found for each 5-minute interval. The average volumes were rounded off to the nearest integer. The TTs were then duplicated by the volume of traffic for each type of lane separately. For example, if the TT in the MLs from 10:00 to $10: 05$ is 4 minutes and the average volume obtained from the detectors is 20 vehicles, the TT is duplicated 20 times. Finally, the 95th percentile TT was found, and the PTI was calculated (Table 14 and Table 15).

Table 14: Calculated Planning Time Indexes for the MLs in SR-91

\begin{tabular}{|l|l|c|c|c|c|}
\hline \multirow{2}{*}{ PTI } & \multirow{2}{*}{ Time } & \multicolumn{2}{c|}{ Eastbound } & \multicolumn{2}{c|}{ Westbound } \\
\cline { 3 - 6 } & & Route 22775 & Route 22776 & Route 22779 & Route 22778 \\
\hline \multirow{3}{*}{ MLs } & Peak & 1.729 & 1.974 & 1.436 & 1.152 \\
\cline { 2 - 6 } & Off-peak & 1.594 & 1.795 & 1.481 & 1.235 \\
\cline { 2 - 6 } & Total & 1.646 & 1.845 & 1.472 & 1.218 \\
\hline
\end{tabular}

Table 15: Calculated Planning Time Indexes for the GPLs in SR-91

\begin{tabular}{|l|l|c|c|c|c|}
\hline \multirow{2}{*}{ PTI } & \multirow{2}{*}{ Time } & \multicolumn{2}{c|}{ Eastbound } & \multicolumn{2}{c|}{ Westbound } \\
\cline { 3 - 6 } & & Route 22775 & Route 22776 & Route 22779 & Route 22778 \\
\hline \multirow{3}{*}{ GPLS } & Peak & 1.476 & 2.354 & 1.755 & 1.210 \\
\cline { 2 - 6 } & Off-peak & 1.357 & 2.099 & 1.887 & 1.283 \\
\cline { 2 - 6 } & Total & 1.375 & 2.177 & 1.868 & 1.275 \\
\hline
\end{tabular}

The PTI for the facility for the GPL users was 1.67, and for the ML users was 1.56. Therefore, the planning time index benefit for the facility was 0.11 (see Table 16).

Table 16: Planning Time Index Benefit for SR-91 Routes

\begin{tabular}{|l|l|c|c|c|c|}
\hline \multirow{2}{*}{ Metric } & \multirow{2}{*}{ Time } & \multicolumn{2}{c|}{ Eastbound } & \multicolumn{2}{c|}{ Westbound } \\
\cline { 3 - 6 } & & Route 22775 & Route 22776 & Route 22779 & Route 22778 \\
\hline \multirow{2}{*}{$\begin{array}{l}\text { Planning time index } \\
\text { benefit }\end{array}$} & Peak & -0.253 & 0.380 & 0.319 & 0.058 \\
\cline { 2 - 6 } & Off-peak & -0.237 & 0.304 & 0.406 & 0.048 \\
\cline { 2 - 6 } & Total & -0.271 & 0.332 & 0.396 & 0.057 \\
\hline
\end{tabular}

\section{Ability of the Toll to Impact Congestion}

The ability of the toll to impact congestion was measured at the detectors located at the east of Weir in the eastbound direction. This location is on Route 22776 (Figure 11). This location was 
chosen because it is away from any major interchange, weaving sections, and lane drop or add locations. This metric was calculated using Equation 17.

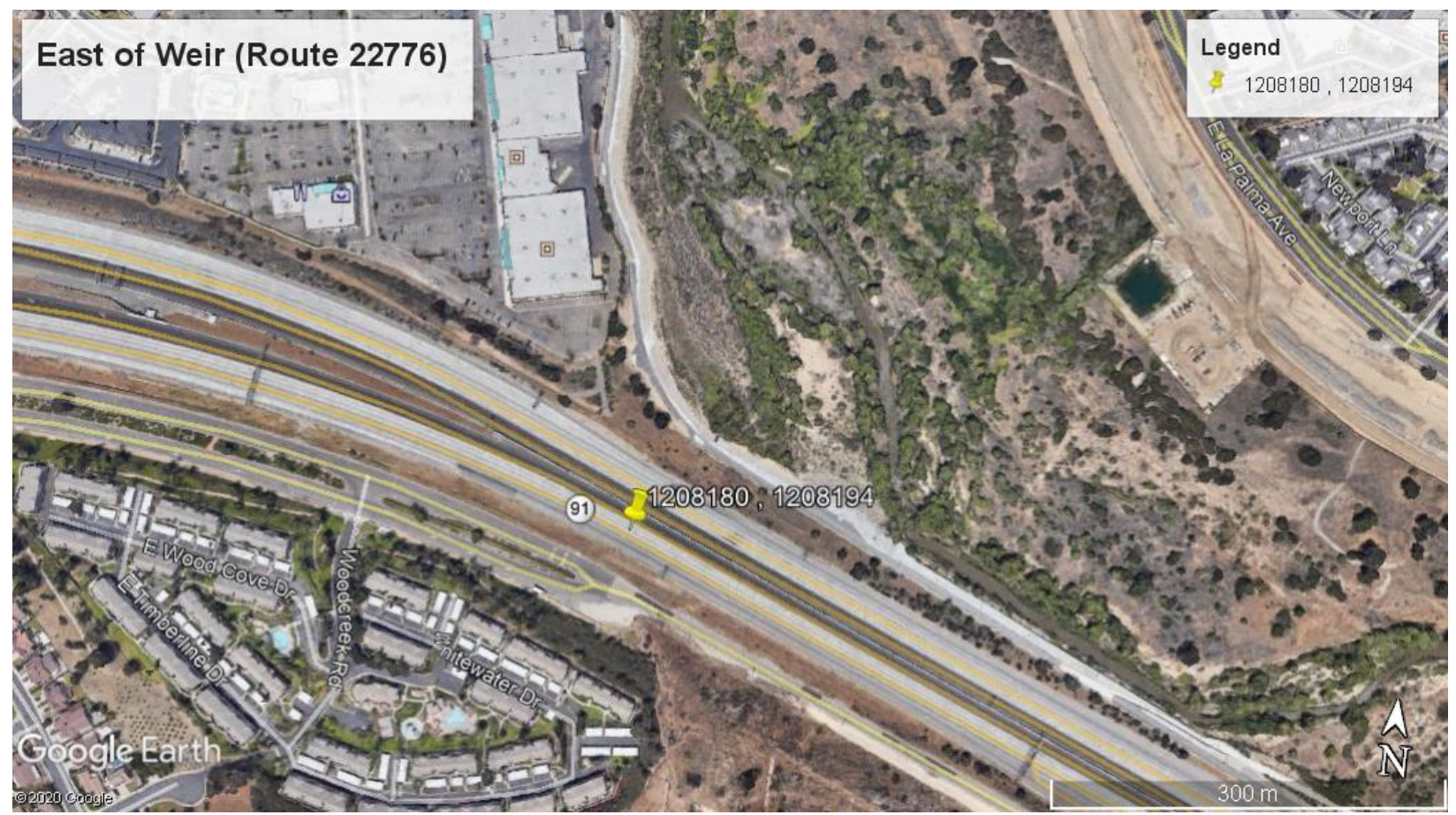

Figure 11: East of Weir, Eastbound Travel (Route 22776)

This metric is calculated for each $\$ 2$ toll bracket. The average toll for each bracket was calculated by taking the weighted average of all the tolls, and the average ML throughput was the mean flow for each toll bracket. It was assumed that the travelers paid the toll for traveling only in Orange County. Table 17 shows the results.

Table 17: Ability of the Toll to Impact Congestion on SR-91

\begin{tabular}{|l|c|c|c|c|c|}
\hline Toll Interval & Average Toll & $\begin{array}{c}\text { Average ML } \\
\text { Throughput } \\
\text { (vph) }\end{array}$ & $\begin{array}{c}\text { Percent Change in } \\
\text { Average Vehicle } \\
\text { Throughput in the } \\
\text { ML }\end{array}$ & $\begin{array}{c}\text { Percent } \\
\text { Increase in } \\
\text { Toll }\end{array}$ & $\begin{array}{c}\text { Toll Ability to } \\
\text { Impact Congestion }\end{array}$ \\
\hline 0 to 2 & 1.69 & 225 & - & - & - \\
\hline 2 to 4 & 3.10 & 1,307 & 479.49 & 83.74 & 5.73 \\
\hline 4 to 6 & 5.40 & 2,220 & 69.92 & 74.42 & 0.94 \\
\hline 6 to 8 & 6.82 & 2,787 & 25.56 & 26.34 & 0.97 \\
\hline 8 to 10 & 8.91 & 2,819 & 1.12 & 30.48 & 0.04 \\
\hline
\end{tabular}

\section{Speed Thresholds}

The primary objective of the MLs is to maintain speeds of at least $45 \mathrm{mph} 90$ percent of the time during peak periods. This criterion is set by FHWA. Similarly, the internal facility goal of the operators is to maintain FFSs of 60 to $65 \mathrm{mph}$ at all times. The speed thresholds were calculated, and Table 18 shows the result. 
Table 18: Percent of Time Speeds Exceeded the Speed Threshold for SR-91

\begin{tabular}{|l|c|c|c|c|}
\hline \multirow{2}{*}{ Speed Threshold and Lanes } & \multicolumn{2}{c|}{ Eastbound } & \multicolumn{2}{c|}{ Westbound } \\
\cline { 2 - 5 } & Route 22775 & Route 22776 & Route 22779 & Route 22778 \\
\hline $\mathrm{ML}>45 \mathrm{mph}$ & 74 & 55 & 99 & 100 \\
\hline $\mathrm{ML}>60 \mathrm{mph}$ & 88 & 76 & 98 & 99 \\
\hline $\mathrm{GPL}>45 \mathrm{mph}$ & 88 & 52 & 92 & 100 \\
\hline $\mathrm{GPL}>60 \mathrm{mph}$ & 90 & 73 & 84 & 99 \\
\hline
\end{tabular}

\section{Speed Graphs}

The average speed in each direction was found by taking the mean speed of both routes for the MLs and the GPLs. The ML and the GPL speeds were plotted together, and the center of the plot was (45mph, 45mph). Figure 12 through Figure 14 show the speeds plots for eastbound and westbound directions for the routes. The plot for Route 22775 is shown in Figure 3.

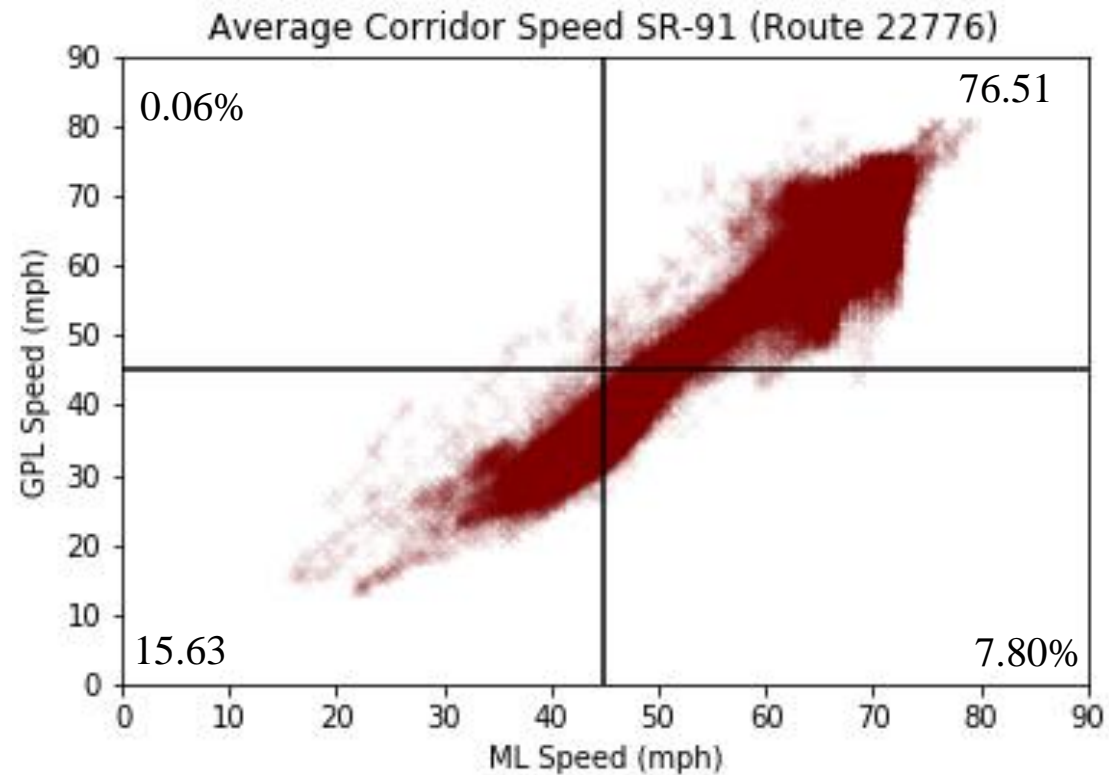

Figure 12: Graphical Display of Performance for Route 22776 in SR-91 


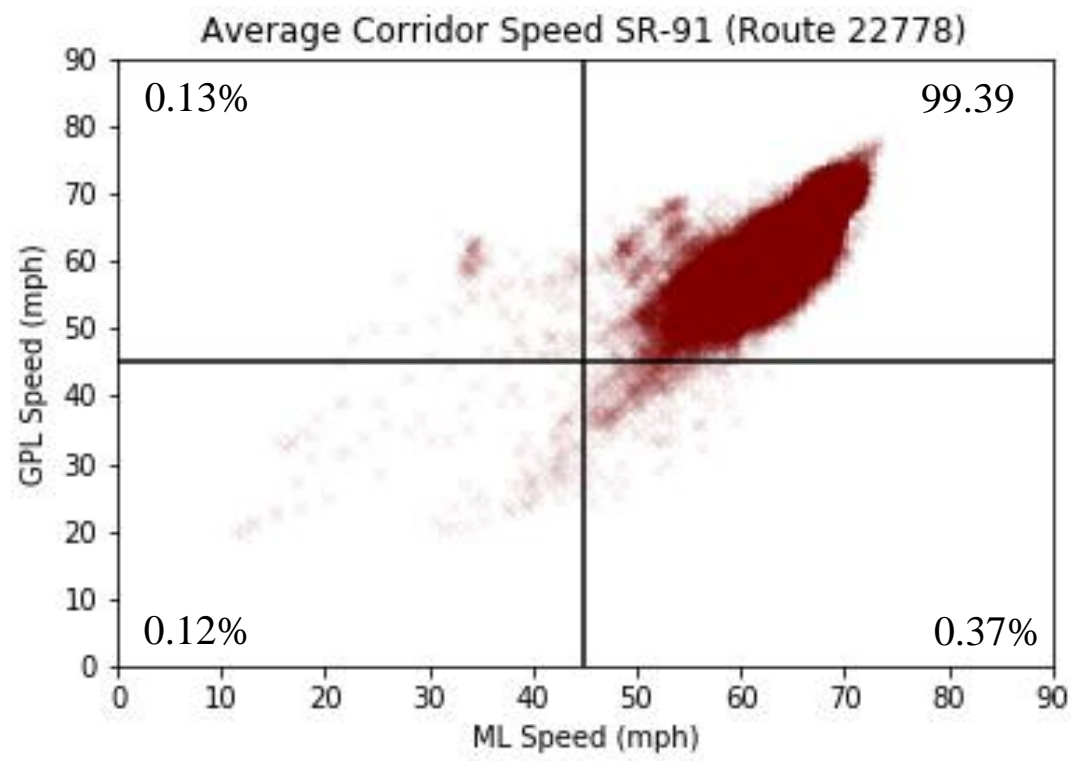

Figure 13: Graphical Display of Performance for Route 22778 in SR-91

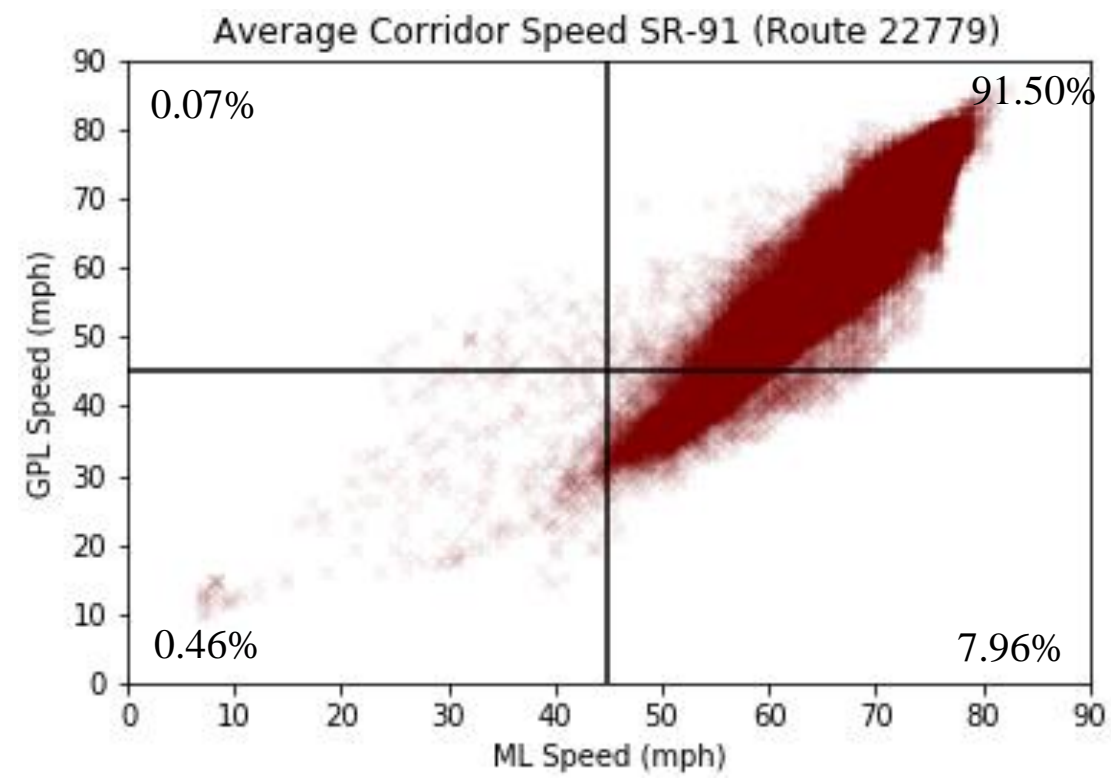

Figure 14: Graphical Display of Performance for Route 22779 in SR-91

\section{Scoring Index}

The scoring index was calculated at all detector locations in both directions. The lane capacity was obtained from the fundamental traffic-flow diagrams. For each detector, the speeds, flows, and densities were extracted, and the flow-density-speed plots were obtained. In the flowspeed diagram (Figure 15), the lane capacity was 1,600 vph, and this value was used for further calculations of the scoring index for westbound. The speed-flow diagram confirms that 1,600 vph is a reasonable capacity for these lanes. For eastbound, the lane capacity was 1,700 vph (see Figure 16). The scoring index was based on the FHWA threshold of $45 \mathrm{mph}$ and the internal facility goal of $60 \mathrm{mph}$. Table 19 and Table 20 show the scores obtained for all detectors on each route. 


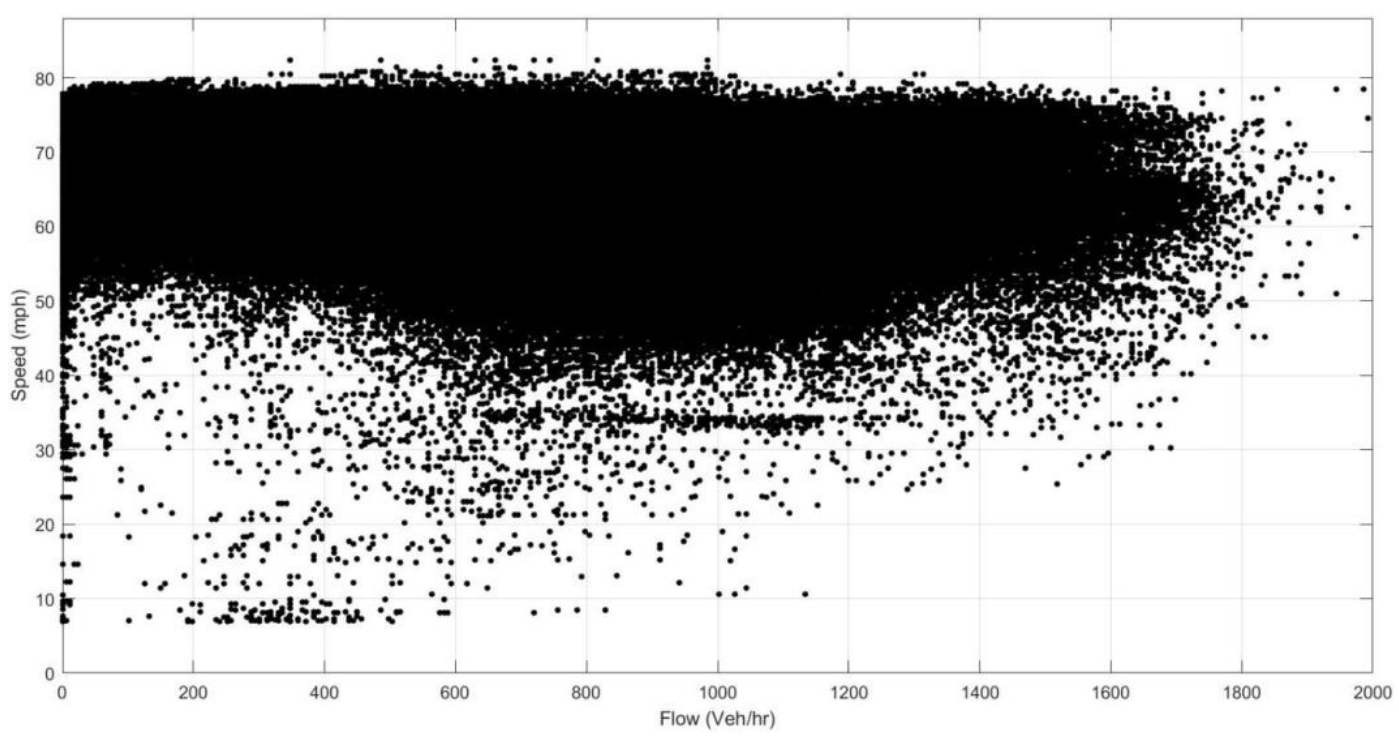

Figure 15: Speed-Flow Plot for SR-91 Westbound

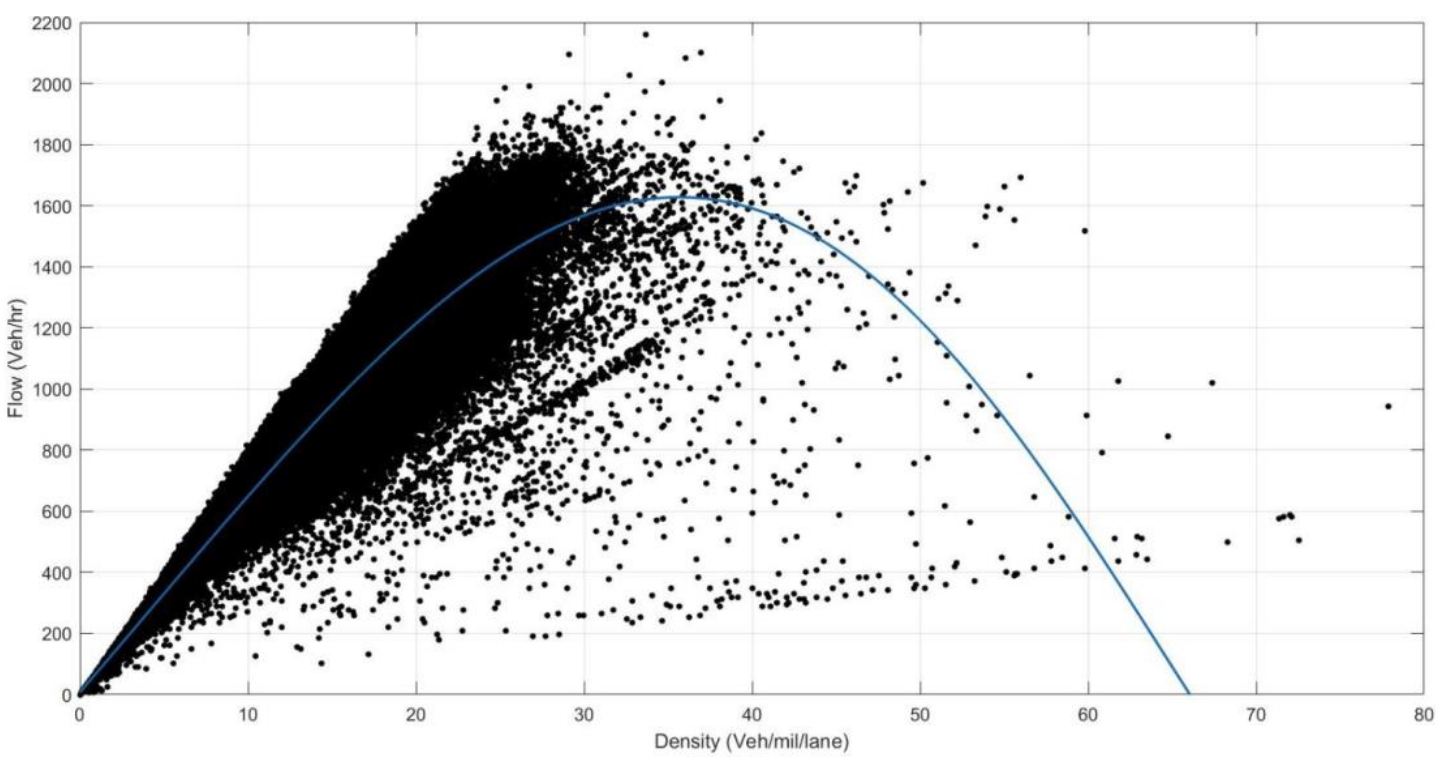

Figure 16: Flow-Density Plot for SR-91 Westbound

Table 19: Score at All Eastbound Locations for SR-91

\begin{tabular}{|c|l|c|c|c|}
\hline Route & \multicolumn{1}{|c|}{ Location } & Scoring Index & ML Volume & Score \\
\hline 22775 & Lakeview 1 & 0.271 & $8,376,670$ & \multirow{2}{*}{0.128} \\
\cline { 2 - 5 } & West of Imperial & 0.249 & $11,274,166$ \\
\cline { 2 - 5 } & Imperial 2 & 0.060 & $8,938,162$ \\
\cline { 2 - 5 } & East of Imperial & 0.060 & $8,998,865$ \\
\cline { 2 - 5 } & Midpoint & 0.055 & $8,995,483$ & \\
\cline { 2 - 5 } & West of Scales & 0.049 & $8,990,889$ & \\
\hline \multirow{3}{*}{2776} & East of Weir & -0.297 & $9,191,273$ & \\
\cline { 2 - 5 } & West of Gypsum & -0.073 & $10,214,576$ & \\
\cline { 2 - 5 } & East of Gypsum & 0.304 & $12,259,989$ & \\
\hline
\end{tabular}


Table 20: Score at All Westbound Locations for SR-91

\begin{tabular}{|c|l|c|c|c|}
\hline Route & \multicolumn{1}{|c|}{ Location } & Scoring Index & ML Volume & Score \\
\hline \multirow{3}{*}{22779} & West of Imperial & 0.848 & $8,865,049$ & \multirow{2}{*}{0.846} \\
\cline { 2 - 4 } & Imperial 2 & 0.845 & $8,602,358$ & \\
\cline { 2 - 4 } & East of Imperial & 0.845 & $8,642,865$ & \multirow{2}{*}{0.869} \\
\cline { 2 - 4 } & West of Scales & 0.845 & $8,640,754$ & \\
\hline \multirow{3}{*}{22778} & Weir Cnyn 1 & 0.857 & $8,614,924$ & $8,471,391$ \\
\cline { 2 - 5 } & Weir Cnyn 2 & 0.860 & $8,634,963$ & \\
\cline { 2 - 5 } & West of Gypsum & 0.857 & $8,949,386$ & \\
\cline { 2 - 5 } & East of Gypsum & 0.915 & $8,694,395$ & \\
\cline { 2 - 5 } & West of Coal & 0.856 & & \\
\end{tabular}

The overall score is 0.084 for eastbound and 0.859 for westbound. These scores are again weighted by the total flow in the MLs, and the overall score for the facility is 0.450 .

\section{I-25 North Express Lanes}

\section{Facility Overview}

The I-25 North Express Lanes in Denver, CO, are 6 miles long and run between US 36 and 120th Avenue. The MLs are variably priced . Figure 17 is a map of the area where the road segment is located. The I-25 Express Lanes are a north-south facility just north of downtown Denver (shown in black in Figure 17). Figure 18 shows a detail of the lanes. There are three GPLs and one $\mathrm{ML}$ in each direction, for a total of eight lanes across, except near freeway entrances and exits. 


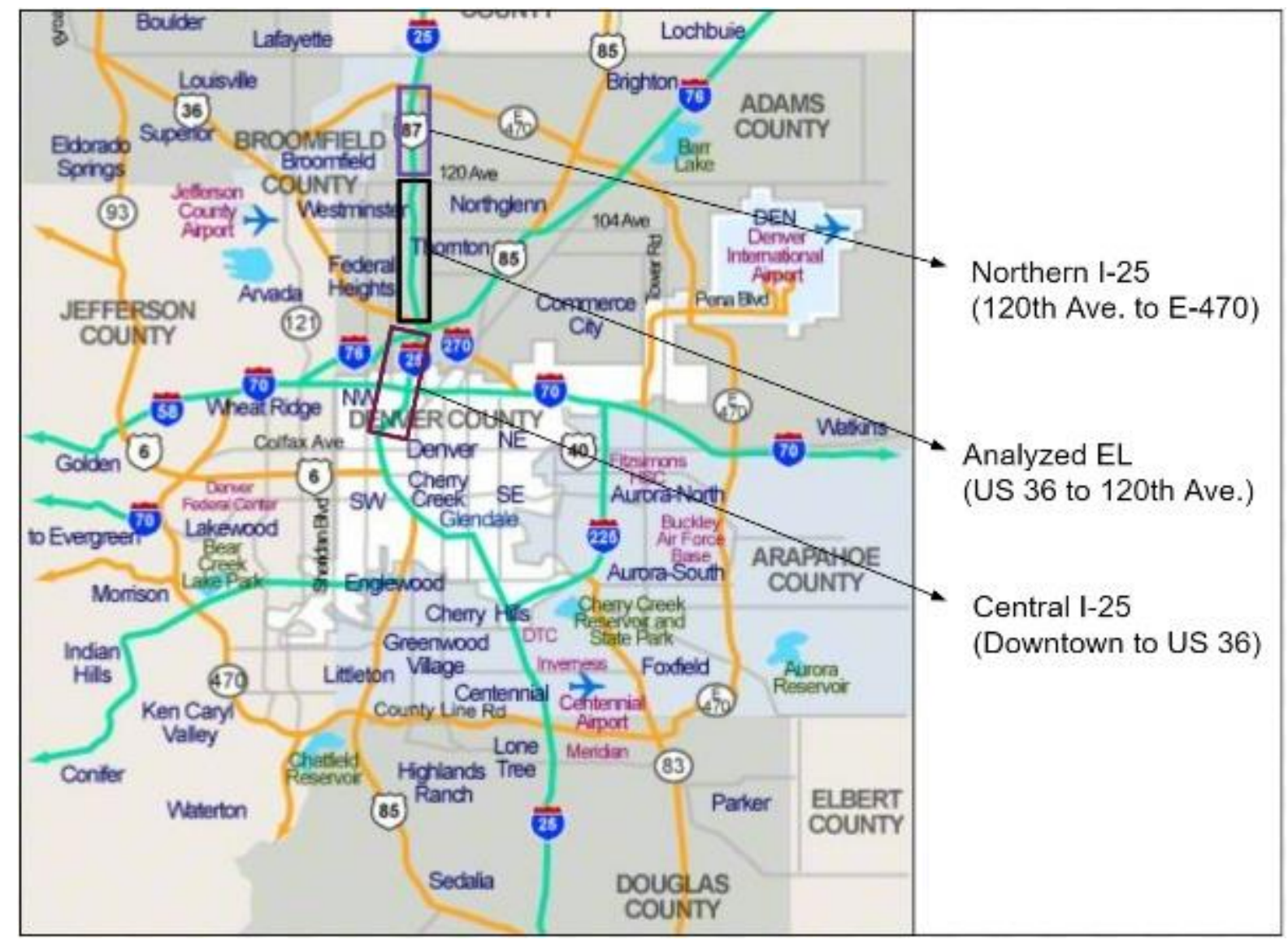

Figure 17: I-25 Express Lanes Map 


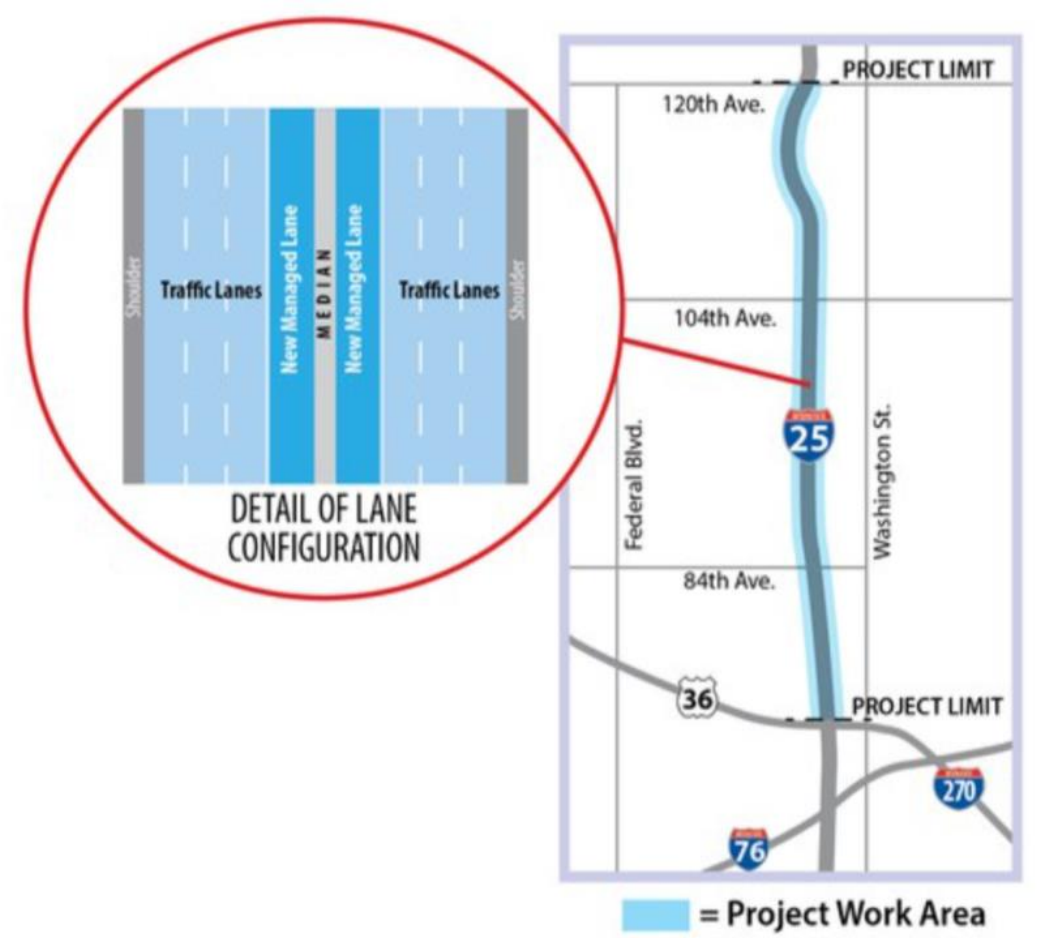

Figure 18: I-25 Lane Schematic (Source: https://www.kristalsellsdenver.com/denvermap/)

\section{Other ELs in the Area}

The two other ELs in the area include:

- The northern segment of I-25 from 120th Avenue to E-470: One lane runs in each direction between 120th Avenue and Northwest Parkway/E-470, alongside the GPLs, and connects with I-25 North: US 36 to 120th Avenue ELs. There are three entry/exit points, but drivers pay the toll only once.

- The central segment of I-25 from downtown Denver to US 36: Two reversible lanes are barrier separated from the GPLs. The I- 25 central ELs in downtown Denver allow travel in the southbound direction in the morning from 5:00 to 11:00 a.m., and travel in the northbound direction from 12:00 p.m. to 3:00 a.m. The ELs allow travelers to connect to both other ELs.

\section{Data}

The average speed for each hour and hourly flow of vehicles in both the ELs and GPLs was obtained from the Colorado Department of Transportation (CDOT). These data are from January 1, 2019, to April 7, 2019. The toll rates were found on CDOT's website as shown in Figure 19. Since these toll rates could vary during a given hour, a weighted average toll rate was found in order to assign a toll rate to each hour (see the next subsection). 


\section{I-25N Seg 2 (US36 to 120th Ave) Toll Rates Effective 7/20/2018}

\begin{tabular}{|c||c|c|c|c|}
\cline { 2 - 5 } \multicolumn{1}{c|}{} & \multicolumn{3}{c|}{ Toll Rates for 2 and 3 axle vehicles } \\
\hline \multirow{2}{*}{$\begin{array}{c}\text { Monday through Friday } \\
\text { Time-of-Day Toll Rate } \\
\text { Schedule }\end{array}$} & \multicolumn{2}{c|}{ NORTHBOUND } & \multicolumn{2}{c|}{ SOUTHBOUND } \\
\cline { 2 - 6 } & Transponder & LPT & Transponder & LPT \\
\hline 5:00 AM - 6:00 AM & $\$ 1.05$ & $\$ 3.79$ & $\$ 1.05$ & $\$ 3.79$ \\
\hline 6:00 AM - 6:45 AM & $\$ 1.05$ & $\$ 3.79$ & $\$ 1.05$ & $\$ 3.79$ \\
\hline 6:45 AM - 7:15 AM & $\$ 1.05$ & $\$ 3.79$ & $\$ 1.30$ & $\$ 4.22$ \\
\hline 7:15 AM - 8:15 AM & $\$ 1.05$ & $\$ 3.79$ & $\$ 2.35$ & $\$ 5.89$ \\
\hline 8:15 AM - 8:45 AM & $\$ 1.05$ & $\$ 3.79$ & $\$ 1.55$ & $\$ 4.64$ \\
\hline 8:45 AM - 10:00 AM & $\$ 1.05$ & $\$ 3.79$ & $\$ 1.30$ & $\$ 4.22$ \\
\hline 10:00 AM - 12:00 PM & $\$ 1.05$ & $\$ 3.79$ & $\$ 1.05$ & $\$ 3.79$ \\
\hline 12:00 PM - 3:00 PM & $\$ 1.05$ & $\$ 3.79$ & $\$ 1.05$ & $\$ 3.79$ \\
\hline 3:00 PM - 3:30 PM & $\$ 1.30$ & $\$ 4.22$ & $\$ 1.05$ & $\$ 3.79$ \\
\hline 3:30 PM - 4:30 PM & $\$ 1.55$ & $\$ 4.64$ & $\$ 1.05$ & $\$ 3.79$ \\
\hline 4:30 PM - 6:00 PM & $\$ 3.15$ & $\$ 7.15$ & $\$ 1.05$ & $\$ 3.79$ \\
\hline 6:00 PM - 8:00 PM & $\$ 1.30$ & $\$ 4.22$ & $\$ 1.05$ & $\$ 3.79$ \\
\hline 8:00 PM - 5:00 AM & $\$ 1.05$ & $\$ 3.79$ & $\$ 1.05$ & $\$ 3.79$ \\
\hline \hline Weekend Toll Rate & $\$ 1.30$ & $\$ 4.22$ & $\$ 1.30$ & $\$ 4.22$ \\
\hline
\end{tabular}

Figure 19: I-25 Express Lane Toll Rates (Source:

https://www.codot.gov/programs/expresslanes/copy of toll-rates/toll-rates-effective-july20-2018-for-i-25-north-us-36-to-120th-seg-2.pdf)

The toll rate was different for travelers paying using a transponder versus those using license plate tolling (LPT). To get the average rate, it was assumed 70 percent paid using a transponder and 30 percent paid by LPT. Similarly, there were no data regarding what percentage of the ML flow was HOV traffic. It was assumed that all ML flow was from toll-paying single-occupant vehicles (SOVs) for the calculations. The data were obtained for vehicles in both the northbound and southbound directions.

\section{Toll Rate Description}

Because the toll rates change hourly, a weighted average was taken to determine the combined toll rate to be assigned for each particular hour. It was assumed that the volume of cars was evenly distributed throughout that hour. In the northbound direction, the time slots of 3:00:00 to 3:59:59 p.m. and 4:00:00 to 4:59:59 p.m. were the only time slots that were affected.

It was assumed that 70 percent of vehicles paid using transponder and 30 percent paid by LPT. Using the transponder and LPT tolls in Table 21, an example calculation for the new toll prices per hour as shown in the "Combined" column in Table 21 is as follows for the northbound direction:

- Toll at 3:00 p.m. $=\$ 1.43(70 \%)+\$ 4.43(30 \%)=\$ 2.33$ 
- Toll at 4:00 p.m. $=\$ 2.35(70 \%)+\$ 5.90(30 \%)=\$ 3.42$

Table 21: Express Lane Toll Rates-Weighted Average for I-25

\begin{tabular}{|c|c|c|c|c|c|c|c|}
\hline \multicolumn{4}{|c|}{ Northbound } & \multicolumn{4}{|c|}{ Southbound } \\
\hline Time & Transponder & LPT & Combined & Time & Transponder & LPT & Combined \\
\hline $\begin{array}{l}\text { 12:00 a.m.- } \\
\text { 2:00 pm }\end{array}$ & $\$ 1.05$ & $\$ 3.79$ & $\$ 1.87$ & $\begin{array}{l}\text { 12:00- } \\
\text { 5:00 a.m. }\end{array}$ & $\$ 1.05$ & $\$ 3.79$ & $\$ 1.87$ \\
\hline 3:00 p.m. & $\$ 1.43$ & $\$ 4.43$ & $\$ 2.33$ & 6:00 a.m. & $\$ 1.11$ & $\$ 3.90$ & $\$ 1.95$ \\
\hline 4:00 p.m. & $\$ 2.35$ & $\$ 5.90$ & $\$ 3.42$ & 7:00 a.m. & $\$ 2.09$ & $\$ 5.47$ & $\$ 3.10$ \\
\hline 5:00 pm & $\$ 3.15$ & $\$ 7.15$ & $\$ 4.35$ & 8:00 a.m. & $\$ 1.69$ & $\$ 4.85$ & $\$ 2.64$ \\
\hline $\begin{array}{l}\text { 6:00- } \\
\text { 7:00 p.m. }\end{array}$ & $\$ 1.30$ & $\$ 4.22$ & $\$ 2.18$ & 9:00 a.m. & $\$ 1.30$ & $\$ 4.22$ & $\$ 2.18$ \\
\hline $\begin{array}{l}8: 00- \\
11: 00 \text { p.m. }\end{array}$ & $\$ 1.05$ & $\$ 3.79$ & $\$ 1.87$ & $\begin{array}{l}\text { 10:00 a.m.- } \\
\text { 11:00 p.m. }\end{array}$ & $\$ 1.05$ & $\$ 3.79$ & $\$ 1.87$ \\
\hline Weekends & $\$ 1.30$ & $\$ 4.22$ & $\$ 2.18$ & Weekends & $\$ 1.30$ & $\$ 4.22$ & $\$ 2.18$ \\
\hline
\end{tabular}

Note: Time slot 12:00 a.m. means 12:00:00 a.m.-12:59:59 a.m.

\section{Performance Metrics}

\section{Travel Time Savings}

The TTS is the difference in travel times between the GPL and the ML, as seen in Equation 13. TTS is calculated for peak periods (7 to 10 a.m. in SB and 3 to 7 p.m. in NB), off-peak periods, and overall. Table 22 shows the results. Table 23 shows the performance measures for I- 25 .

Table 22: Travel Time Savings for I-25

\begin{tabular}{|l|l|c|c|}
\hline \multirow{2}{*}{ Metric } & \multirow{2}{*}{ Time } & \multicolumn{2}{c|}{ Direction } \\
\cline { 3 - 4 } & & Northbound & Southbound \\
\hline \multirow{3}{*}{ TTS (minutes) } & Peak & 6.97 & 1.60 \\
\cline { 2 - 4 } & Off-peak & 3.17 & 1.53 \\
\cline { 2 - 4 } & Total & 3.97 & 1.54 \\
\hline
\end{tabular}

Table 23: Performance Measures for I-25

\begin{tabular}{|l|l|l|}
\hline \multicolumn{1}{|c|}{ Performance Measure } & \multicolumn{1}{|c|}{ Northbound } & \multicolumn{1}{c|}{ Southbound } \\
\hline TTS (overall) & 3.97 minutes & 1.54 minutes \\
\hline Variability benefit & 3.16 & 1.61 \\
\hline Planning time index benefit & 1.0 & 0.25 \\
\hline Ability of toll to impact congestion & See Table 24 & See Table 25 \\
\hline $\begin{array}{l}\text { Do MLs maintain speeds (45) at least 90 percent of the time } \\
\text { during peak periods (including weekends)? }\end{array}$ & Yes & Yes \\
\hline Scoring Index & 1.02 & 0.93 \\
\hline
\end{tabular}

\section{Variability Benefit}

The variability benefit was calculated using Equation 14, and the results are shown in Table 23

\section{Planning Time Index Benefit}

The planning time index benefit is the difference between the PTI for the GPLs and the MLs, as seen in Equation 16. 
The PTI is calculated for the MLs and the GPLs separately. First, the TT for each hour of each day for both the MLs and GPLs in the northbound and southbound direction was calculated for all data points where the EL flow of vehicles was more than zero. Next, all TTs for each hour were separated. For example, there were 97 days' worth of data, so all 97 of the 12:00 a.m. TTs were used to determine the 95th percentile $\Pi$ for that hour. Since there were nearly 100 hours of data, this resulted in a value close to the 94th worst travel time in any given hour. Each of those TTs were then divided by the free-flow travel time (see Equation 15 and Equation 20), resulting in a PTI for each hour.

Free-Flow Travel Time = average EL travel time in the off-peak period

Where:

- Off-peak period = hours when travelers can drive at their desired speed within the legal limit, in this case, from 12:00 a.m. to 4:00 a.m. in the northbound direction, and from 10:00 to 5:00 a.m. in the southbound direction.

A weighted average PTI was calculated using Equation 21.

Planning Time Index (PTI95) $=\frac{\sum_{1}^{n} P T I_{n} x A V G \text { EL } f l o w \_n}{\sum_{1}^{n} A V G E L \text { flow } \_n}$

Where:

- $\mathrm{n}=1$ to 24 (the number of hours per day).

The planning time index benefit can then be calculated according to Equation 16, resulting in 1.0 for northbound and 0.25 for southbound.

\section{Ability of Toll to Impact Congestion}

This metric can be defined as shown in Equation 17.

First, the average ML flow per hour was calculated. For each combined toll rate, the average $\mathrm{ML}$ flow was calculated per Equation 22.

$$
\text { Avg EL flow for specific Toll }=\frac{\sum_{1}^{n} E L \text { flow for specific Toll }}{n}
$$

Where:

- $\mathrm{n}=$ number of times the toll was that specific toll rate.

Next, the percent change between the average ML flows per toll was found using Equation 23 .

$$
\% \text { Change in Flow }=\frac{(A V G \text { EL flow for specific toll })_{2}-(\text { AVG EL flow for specific toll })_{-} 1}{(A V G \text { EL flow for specific } \text { toll })_{-} 1}
$$


Where:

- 1 = average EL flow for toll rate 1.

- 2 = average EL flow for toll rate 2 .

Similarly, the percent change in the tolls was calculated using Equation 24.

$$
\% \text { Change in Toll }=\frac{\text { Toll }_{2}-\text { Toll_}_{\_} 1}{\text { Toll_} \_} \times 100
$$

Where:

- 1 = first toll rate (in ascending order).

- 2 = second toll rate.

Finally, the percent change in flow was divided by the percent change in toll (Equation 17) to get the results shown in Table 24 for the northbound direction, and Table 25 for the southbound direction.

Table 24: Results from Performance Measure-Ability of Toll to Impact Congestion (Northbound)

\begin{tabular}{|c|c|c|c|c|}
\hline Toll & $\begin{array}{c}\text { Avg. ML Flow per } \\
\text { Toll }\end{array}$ & $\begin{array}{c}\text { Percent Change in } \\
\text { Flow }\end{array}$ & $\begin{array}{c}\text { Percent Change } \\
\text { in Toll }\end{array}$ & $\begin{array}{c}\text { Percent Change in Flow/Percent } \\
\text { Change in Toll }\end{array}$ \\
\hline$\$ 1.87$ & 83.85 & - & - & - \\
\hline$\$ 2.18$ & 305.58 & $264 \%$ & $17 \%$ & 15.95 \\
\hline$\$ 2.33$ & 749.58 & $145 \%$ & $7 \%$ & 21.12 \\
\hline$\$ 3.42$ & 882.38 & $18 \%$ & $47 \%$ & 0.38 \\
\hline$\$ 4.35$ & 800.37 & $-9 \%$ & $27 \%$ & -0.34 \\
\hline
\end{tabular}

Table 25: Results from Performance Measure-Ability of Toll to Impact Congestion (Southbound)

\begin{tabular}{|c|c|c|c|c|}
\hline Toll & $\begin{array}{c}\text { Avg ML Flow } \\
\text { per Toll }\end{array}$ & $\begin{array}{c}\text { Percent Change in } \\
\text { Flow }\end{array}$ & $\begin{array}{c}\text { Percent Change } \\
\text { in Toll }\end{array}$ & $\begin{array}{c}\text { Percent Change in Flow/Percent } \\
\text { Change in Toll }\end{array}$ \\
\hline$\$ 1.87$ & 179.36 & - & - & - \\
\hline$\$ 1.95$ & 829.01 & $362 \%$ & $4 \%$ & 84.66 \\
\hline$\$ 2.18$ & 437.10 & $-47 \%$ & $12 \%$ & -4.01 \\
\hline$\$ 2.64$ & 720.97 & $65 \%$ & $21 \%$ & 3.08 \\
\hline$\$ 3.10$ & 876.15 & $22 \%$ & $17 \%$ & 1.24 \\
\hline
\end{tabular}

\section{Threshold 95th Percentile Peak-Period Travel Time (Including Weekends)}

First, the TTs for each hour of each day for both the MLs and GPLs in both northbound and southbound directions were calculated for all data points where the EL flow of vehicles was more than zero. Only peak-period TTs were used in this calculation. A 95th percentile was then found for the collective peak-hour travel times. Peak hours are 3:00 to 7:00 p.m. for the northbound direction and 7:00 to 10:00 a.m. for the southbound direction. 
Do MLs Maintain Speeds (> $45 \mathrm{mph}$ ) at Least 90 Percent of the Time during Peak Periods

(Including Weekends)?

During peak periods, the percentage of time that the EL speed was at least 45 miles per hour is shown in Equation 25.

$\%$ time EL Speed $\geq 45 \mathrm{mph}$ in peak $=\frac{\# \text { of times EL Speed } d_{\text {peak }}-h r s \geq 45 \mathrm{mph}}{n} \times 100$

Where:

- $\mathrm{n}=$ total number of peak period data available, in this case 480 hours' worth going northbound and 385 hours' worth going southbound.

Table 26 shows the results of this calculation.

Table 26: Results for EL Operating Speeds Meeting Threshold Speeds

\begin{tabular}{|l|l|l|}
\hline \multicolumn{1}{|c|}{ Measure } & Northbound & South bound \\
\hline Do MLs maintain speeds? & Yes & Yes \\
\hline Percent of time ML speed $\geq 45 \mathrm{mph}$ & $98 \%$ & $97 \%$ \\
\hline
\end{tabular}

\section{Speed Graphs}

Figure 20 and Figure 21 illustrate the GPL speed versus the EL speed in a four-quadrant format. They give a visual representation of the overall amount of times that the EL is at least $45 \mathrm{mph}$ in both peak and non-peak periods. The percentages in each corner of the quadrants are the percentage of total data points in that quadrant, not including ones that lie on the axis.

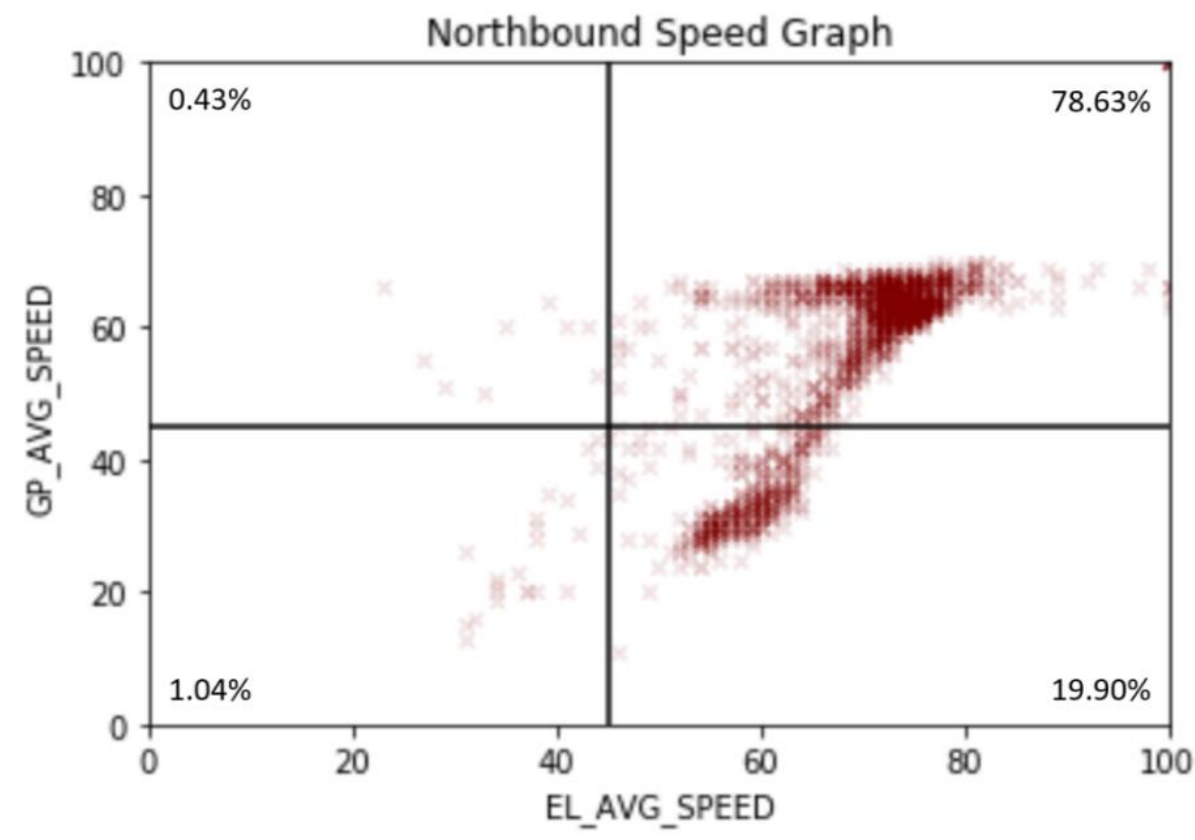

Figure 20: Graphical Display of Performance for I-25 Northbound 


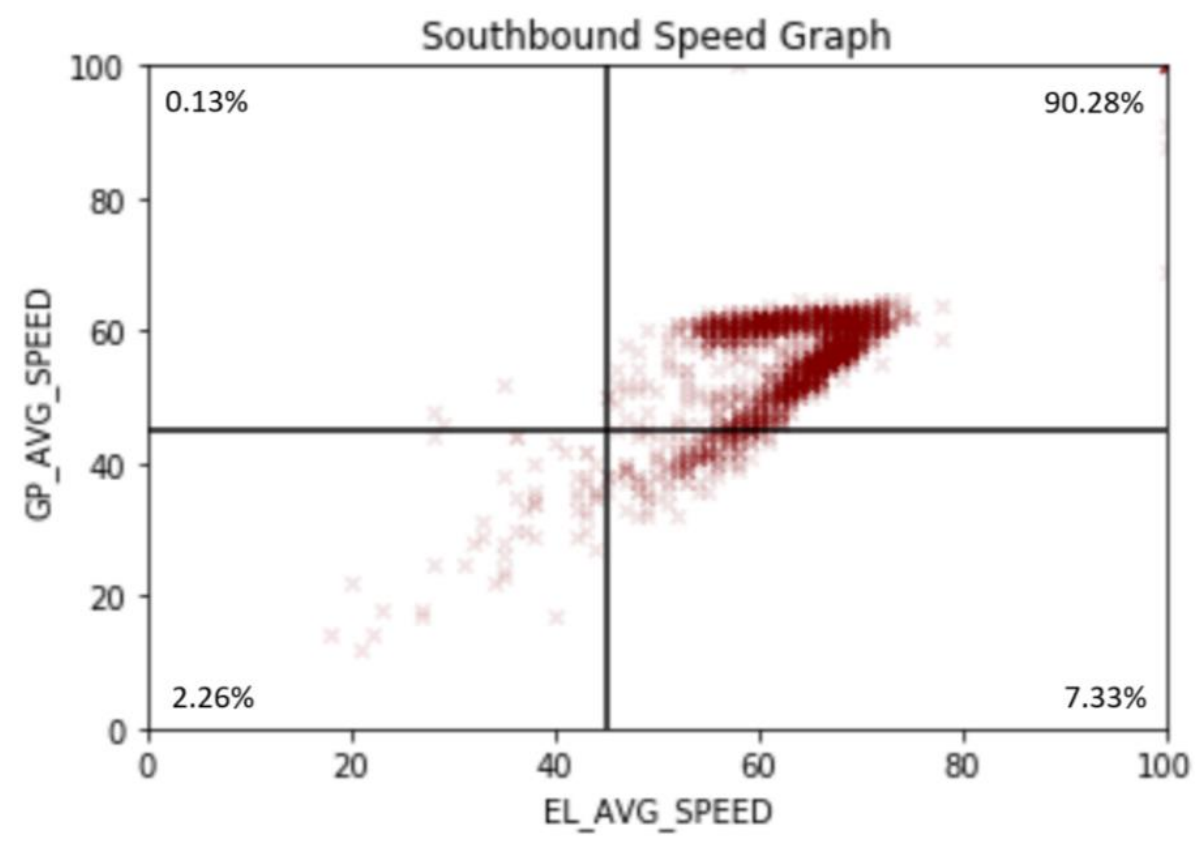

Figure 21: Graphical Display of Performance for I-25 Southbound

\section{Scoring Index}

First, the lane capacity needs to be found according to the fundamental traffic speed-flow and flow-density diagrams. Figure 4 and Figure 5 show examples of these diagrams. The lane capacity for northbound is $1200 \mathrm{vph}$ and for southbound is $1500 \mathrm{vph}$. Each time interval is given a raw score. Figure 6 shows how each raw score is determined. Table 27 and Table 28 summarize the results.

Table 27: Summary of Index Results for I-25 Northbound

\begin{tabular}{|c|c|c|c|c|c|c|c|c|c|c|c|}
\hline $\begin{array}{c}\text { Combined } \\
\text { Toll }\end{array}$ & Frequency & +3 & +2 & +1 & $\begin{array}{c}0 \\
\left(M L \_F=0\right)\end{array}$ & 0 & -1 & -2 & -3 & $\sum$ Points & $\begin{array}{c}\sum \text { Points * } \\
\text { Flow }\end{array}$ \\
\hline$\$ 1.87$ & 1,311 & 9 & 0 & 1,088 & 175 & 22 & 1 & 10 & 6 & 1,076 & 113,254 \\
\hline$\$ 2.18$ & 810 & 36 & 1 & 706 & 44 & 12 & 0 & 8 & 3 & 791 & 200,534 \\
\hline$\$ 2.33$ & 69 & 59 & 1 & 7 & 1 & 0 & 1 & 0 & 0 & 185 & 162,520 \\
\hline$\$ 3.42$ & 69 & 46 & 14 & 6 & 1 & 0 & 2 & 0 & 0 & 170 & 179,141 \\
\hline$\$ 4.35$ & 69 & 31 & 27 & 9 & 1 & 0 & 0 & 1 & 0 & 154 & 153,625 \\
\hline Total & 2,328 & 181 & 43 & 1,816 & 222 & 34 & 4 & 19 & 9 & 2,376 & 809,074 \\
\hline
\end{tabular}

Table 28: Summary of Index Results for I-25 Southbound

\begin{tabular}{|c|c|c|c|c|c|c|c|c|c|c|c|}
\hline $\begin{array}{c}\text { Combined } \\
\text { Toll }\end{array}$ & Frequency & +3 & +2 & +1 & $\begin{array}{c}0 \\
(M L / F=0)\end{array}$ & 0 & -1 & -2 & -3 & $\Sigma$ Points & $\begin{array}{l}\sum \text { Points * } \\
\text { Flow }\end{array}$ \\
\hline$\$ 1.87$ & 1,311 & 6 & 9 & 1,326 & 16 & 45 & 1 & 21 & 4 & 1,307 & 388,975 \\
\hline$\$ 1.95$ & 69 & 12 & 42 & 5 & 0 & 1 & 8 & 1 & 0 & 115 & 144,697 \\
\hline$\$ 2.18$ & 810 & 20 & 16 & 611 & 6 & 23 & 2 & 14 & 1 & 670 & 46,914 \\
\hline$\$ 2.64$ & 69 & 8 & 48 & 8 & 1 & 0 & 4 & 0 & 0 & 124 & 128,075 \\
\hline$\$ 3.10$ & 69 & 6 & 51 & 7 & 1 & 0 & 3 & 1 & 0 & 122 & 161,912 \\
\hline Total & 2,328 & 52 & 166 & 1,957 & 24 & 69 & 18 & 37 & 5 & 2,338 & 870,573 \\
\hline
\end{tabular}


The final score is calculated by Equation 19. The northbound final index score is 1.02 , and the southbound final index score is 0.93 . The overall score is 0.97 .

\section{I-15 Express Lanes}

\section{Facility Overview}

The I-15 Expressway runs from SR-78 in Escondido, CA, to SR-163 in San Diego, CA. The I-15 Expressway is approximately 20 miles long with five GPLs and two MLs in either direction. The freeway PeMS, which is sponsored by Caltrans, collected real-time traffic data from sensors such as vehicle flow and speed. These data were used in the analysis in the following subsections.

\section{HOV and GPL Sensor Acquisition}

There are approximately 20 to 22 HOV lane sensors in both directions on the I-15 Expressway and approximately 40 to $45 \mathrm{GPL}$ sensors in both directions, according to PeMS. To determine which sensors to use, a weeks' worth of speed and flow data were downloaded from PeMS. Sensors were eliminated from consideration if the sensor had reliable data less than 50 percent of the time. The data (flow per hour) for the remaining HOV and GPL sensors were plotted. Sensors were eliminated from consideration if their data contrasted with the majority of other sensors and if their physical location was not representative of typical travel speeds/flow on the lanes.

Finally, sensor pairs that were close to each other (on the MLs and GPLs) and sensors away from any major/minor exits were selected for analysis. Speed and flow data from the four sensor pairs chosen were examined. For three of the sensor pairs, the ML speed was always slower than the GPL speed. The other sensor pair (located in section 3 in Figure 22) had MLs faster for only 30 percent of the time. The travel time data were collected from PeMS and used to calculate the ML and GPL speeds. PeMS offered the data in three sections, as shown in Figure 22, each section having a northbound and southbound direction dataset. Table 29 shows the percentage of time that the MLs were faster for each section.

Section 3 is the only section where the MLs were generally faster than the GPLs. Therefore, PeMS speed data and travel time data could not be used. 


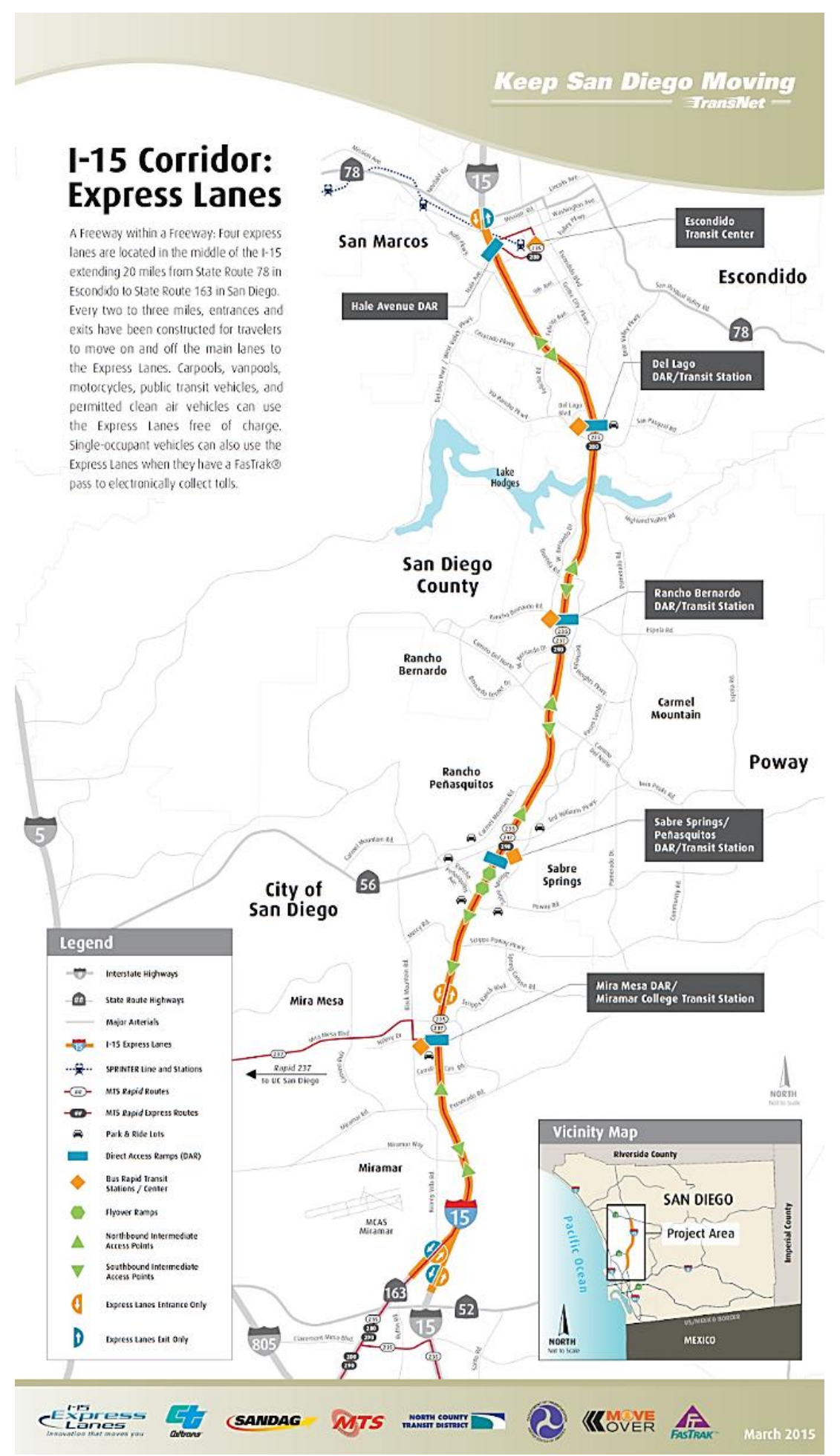

Section 1: SR-163 to SR-56 (7.4 miles).

Section 2: SR-56 to Centre City Parkway (8.2 miles).

Section 3: Centre City Parkway to SR-78 (3.9 miles).

Figure 22: Sections of I-15 Expressway (Source: https://511sd.com/fastrak511sd/how-to-usethe-I-15-Express-Lanes). 
Table 29: Percentage of Time MLs Were Faster Based on Travel-Time Data for I-15

\begin{tabular}{|l|c|c|}
\hline \multirow{2}{*}{$\begin{array}{c}\text { EL } \\
\text { Section }\end{array}$} & \multicolumn{2}{|c|}{ Direction } \\
\cline { 2 - 3 } & Northbound & Southbound \\
\hline 1 & $0.08 \%$ & $0.08 \%$ \\
\hline 2 & $46.13 \%$ & $9.24 \%$ \\
\hline 3 & $88.67 \%$ & $89.24 \%$ \\
\hline
\end{tabular}

\section{Alternative Approach}

The total travel time was combined for all sections at each time of day to get the total amount of time it took to travel across the entire length of the I-15 Expressway in either direction. Table 30 shows the percentage of time that the MLs were faster.

Table 30: Alternative Approach-Percentage of Time MLs Were Faster Based on Travel-Time Data for I-15

\begin{tabular}{|l|c|c|}
\hline \multicolumn{1}{|c|}{ Measure } & Northbound & Southbound \\
\hline $\begin{array}{l}\text { Percentage of time MLs are faster } \\
\text { (GPL_TT > ML_TT) }\end{array}$ & $23.53 \%$ & $7.62 \%$ \\
\hline
\end{tabular}

Both directions still have very low percentages of time that the MLs are faster with this approach, so I-15 MLs could not be analyzed.

\section{MoPac Express Lanes}

\section{Facility Overview}

The Loop 1 Express Lanes in Austin, TX, known locally as the MoPac Expressway, are 11 miles long and run between Cesar Chavez Street and Parmer Lane. Figure 23 is a map of the area where the road segment is located, MoPac being labeled as Loop 1 in the center of the map. There are three GPLs and one ML in each direction, for a total of eight lanes across, except near freeway entrances and exits. 


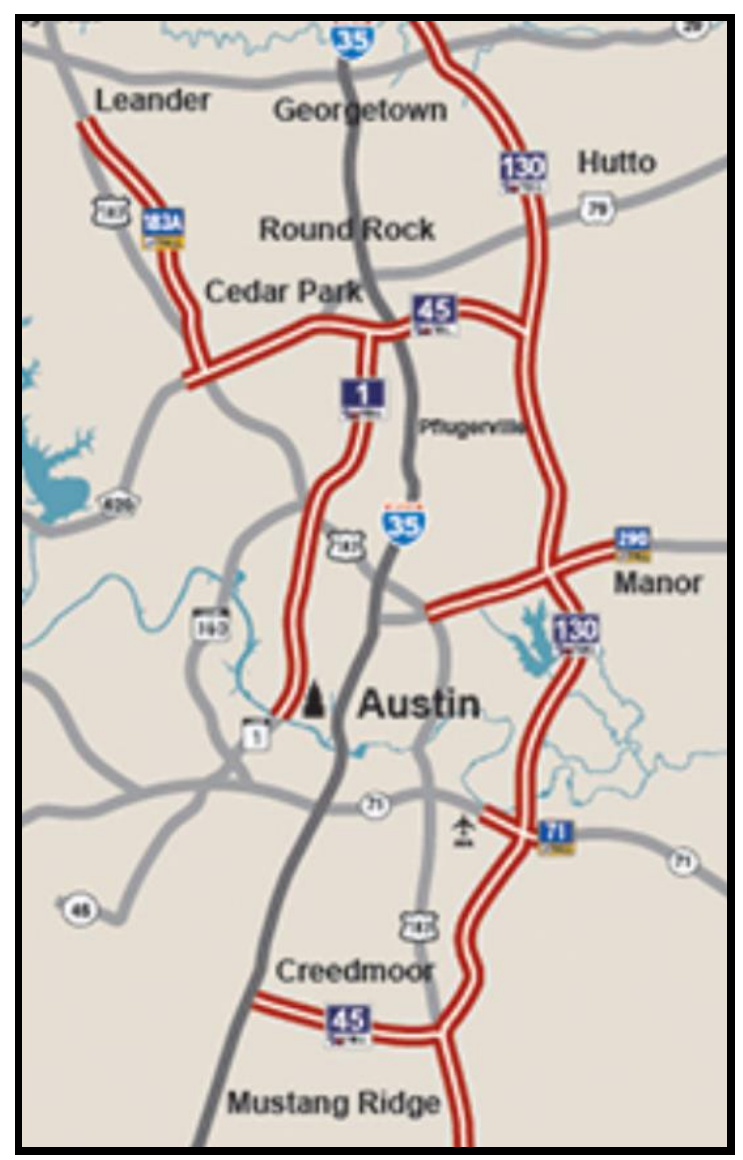

Figure 23: Express Lanes in Austin, TX (Source:

https://www.txtag.org/en/about/tollroad austin area.shtml)

\section{Data}

The speed, flow, travel time, and average/maximum fare of vehicles in both the ELs and the GPLs in 5-minute increments were obtained from the Central Texas Regional Mobility Authority. These data were from January 1, 2018, to December 31, 2018. The data were given in terms of the entire length of road from the beginning of the ELs (Cesar Chavez Street) to the end (Parmer Lane), and in segments (Cesar Chavez Street to 2222 and 2222 to Parmer Lane). The data for the entire length of the road were used for this analysis.

\section{Performance Metrics}

Travel Time Savings

The TTS is the difference in travel times between the GPL and the ML, as seen in Equation 13. Table 31 shows the overall average TTS. 
Table 31: Performance Measures for MoPac

\begin{tabular}{|l|l|l|}
\hline \multicolumn{1}{|c|}{ Performance Measure } & \multicolumn{1}{|c|}{ Northbound } & \multicolumn{1}{c|}{ Southbound } \\
\hline TTS & 1.67 minutes & 1.68 minutes \\
\hline Variability benefit & 1.46 & 0.82 \\
\hline Planning time index benefit & 0.55 & 0.46 \\
\hline Ability of toll to impact congestion & See Table 32 & See Table 33 \\
\hline $\begin{array}{l}\text { Do MLs maintain speeds (45-55 mph) at least 90 percent } \\
\text { of the time during peak periods (including weekends)? }\end{array}$ & Yes & No \\
\hline Index & 0.84 & 0.87 \\
\hline
\end{tabular}

\section{Variability Benefit}

First, the standard deviation for each 4-minute interval in a 24-hour period was calculated for both the GPL and ML travel times. Next, the unweighted variability metric was calculated according to Equation 26 for each 4-minute interval $n$.

$$
\text { Unweighted Variability }_{n}=\frac{\text { Standard Deviation of GPL travel time }}{n}
$$

The total ML flow at a specific 4-minute interval $\mathrm{n}$ is then multiplied by the unweighted variability metric at specific 4-minute interval $n$. The overall weighted variability metric is calculated by Equation 27.

$$
\text { Variability }=\frac{\sum \text { Unweighted Reliability } \times \text { ML Flow }}{\sum M L \text { Flow }}
$$

\section{Planning Time Index Benefit}

The planning time index benefit is the difference between the PTI for the GPLs and the MLs as seen in Equation 15. The PTI is calculated for the MLs and the GPLs separately. First, the FFS was found by averaging the ML speed in the off-peak period (12:00 to 5:00 a.m.). Next, the 95th percentile travel times were calculated for the MLs and GPLs. The PTI for GPLs and MLs is calculated using Equation 15, and the planning time index benefit is the difference between $P T I_{G P L}$ and $P T I_{M L}$, as seen in Equation 16.

\section{Ability of Toll to Impact Congestion}

This metric is calculated for each $\$ 2$ toll bracket. The average toll for each bracket was calculated by taking the weighted average of all the tolls, and the average ML throughput was the mean flow for each toll bracket. Table 32 summarizes the results for the northbound direction, and Table 33 summarizes the results for the southbound direction. 
Table 32: Results from Performance Measure-Ability of Toll to Impact Congestion (Northbound)

\begin{tabular}{|l|c|c|c|c|c|}
\hline Toll Interval & Avg. Toll & $\begin{array}{c}\text { Avg. ML } \\
\text { Throughput }\end{array}$ & $\begin{array}{c}\text { Percent Change in } \\
\text { Avg. Vehicle } \\
\text { Throughput }\end{array}$ & $\begin{array}{c}\text { Percent } \\
\text { Increase } \\
\text { in Toll }\end{array}$ & $\begin{array}{c}\text { Toll Ability to Impact } \\
\text { Congestion }\end{array}$ \\
\hline 0 to 2 & $\$ 0.60$ & 34.5 & - & - & - \\
\hline 2 to 4 & $\$ 2.97$ & 51.8 & $50.2 \%$ & $398.4 \%$ & 0.13 \\
\hline 4 to 6 & $\$ 5.06$ & 58.6 & $13.0 \%$ & $70.0 \%$ & 0.19 \\
\hline 6 to 8 & $\$ 7.03$ & 61.7 & $5.3 \%$ & $39.0 \%$ & 0.14 \\
\hline 8 to 10 & $\$ 9.02$ & 59.1 & $-4.2 \%$ & $28.4 \%$ & -0.15 \\
\hline 10 to $12+$ & $\$ 10.93$ & 85.1 & $44.0 \%$ & $21.1 \%$ & 2.08 \\
\hline
\end{tabular}

Table 33: Results from Performance Measure-Ability of Toll to Impact Congestion (Southbound)

\begin{tabular}{|l|c|c|c|c|c|}
\hline Toll Interval & Avg. Toll & $\begin{array}{c}\text { Avg. ML } \\
\text { Throughput }\end{array}$ & $\begin{array}{c}\text { Percent Change in } \\
\text { Avg. Vehicle } \\
\text { Throughput }\end{array}$ & $\begin{array}{c}\text { Percent } \\
\text { Increase in } \\
\text { Toll }\end{array}$ & $\begin{array}{c}\text { Toll Ability to Impact } \\
\text { Congestion }\end{array}$ \\
\hline 0 to 2 & $\$ 0.66$ & 22.3 & - & - & - \\
\hline 2 to 4 & $\$ 3.00$ & 31.6 & $41.9 \%$ & $355.4 \%$ & 0.12 \\
\hline 4 to 6 & $\$ 5.04$ & 39.8 & $26.0 \%$ & $67.9 \%$ & 0.38 \\
\hline 6 to 8 & $\$ 6.84$ & 50.6 & $27.0 \%$ & $35.8 \%$ & 0.75 \\
\hline 8 to 10 & $\$ 8.74$ & 36.5 & $-27.8 \%$ & $27.7 \%$ & -1.00 \\
\hline 10 to 12 & $\$ 10.86$ & 42.5 & $16.4 \%$ & $24.3 \%$ & 0.67 \\
\hline $12+$ & $\$ 12.83$ & 16 & $-62.4 \%$ & $18.2 \%$ & -3.43 \\
\hline
\end{tabular}

\section{Threshold 95th Percentile Peak-Period TT (Including Weekends)}

A 95th percentile was found for the ML and GPL travel times during peak hours. Peak hours are from 4:00 to 7:00 p.m. for the northbound direction and 7:00 to 9:00 a.m. for the southbound direction.

\section{Do MLs Maintain Speeds at Least 90 Percent of the Time during Peak Periods (Including Weekends)?}

During peak periods, the percentage of time that the EL speed was at least $45 \mathrm{mph}$ is shown in Equation 25. Table 34 shows the results.

Table 34: Results for EL Operating Speeds Meeting Threshold Speeds for MoPac

\begin{tabular}{|l|l|l|}
\hline \multicolumn{1}{|c|}{ Measure } & \multicolumn{1}{|c|}{ Northbound } & Southbound \\
\hline Do MLs maintain speeds? & Yes & No \\
\hline Percent of time ML speed $\geq 45 \mathrm{mph}$ & $90 \%$ & $85 \%$ \\
\hline
\end{tabular}

\section{Speed Graphs}

Figure 24 and Figure 25 illustrate the GPL speed versus the EL speed in a four-quadrant format. The figures give a visual representation of the overall amount of times that the EL is at least $45 \mathrm{mph}$, in both peak and non-peak periods. The percentage in each corner of the quadrants is the percentage of total data points in that quadrant. 


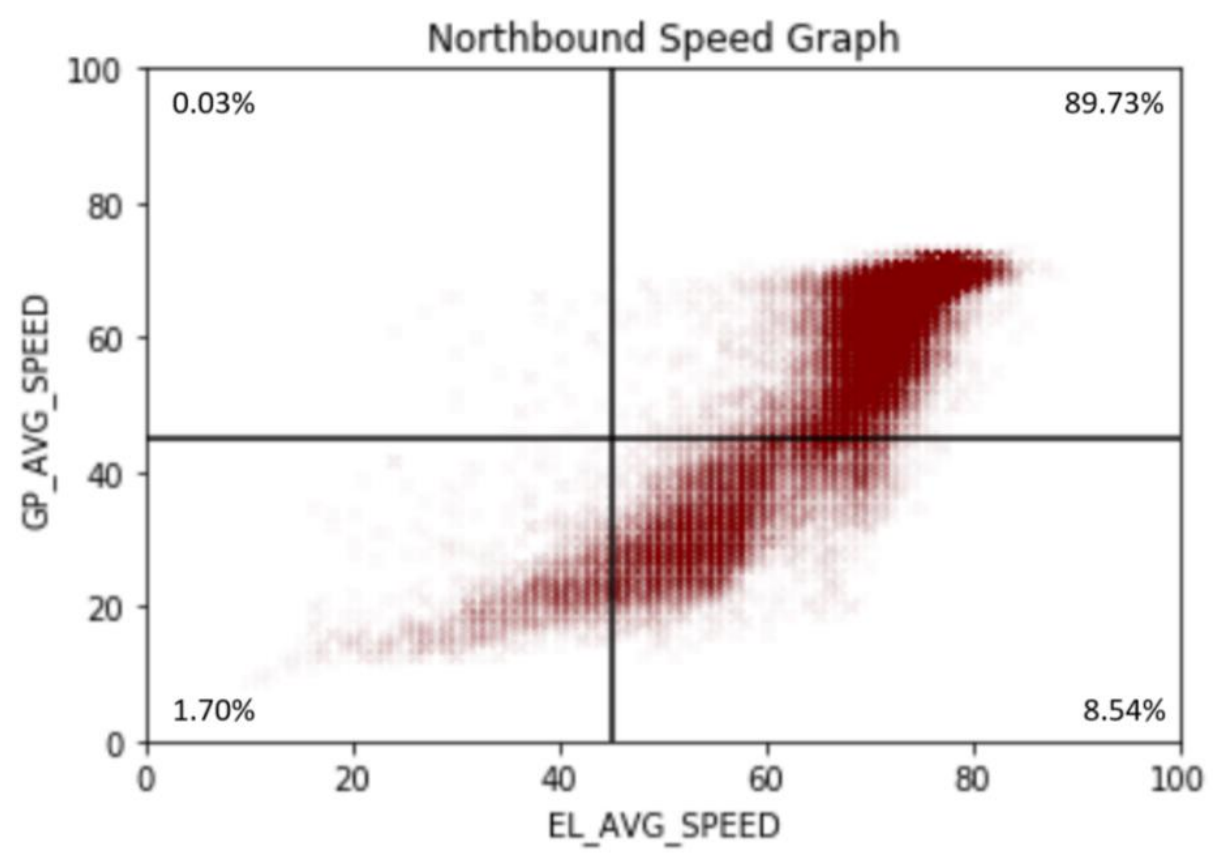

Figure 24: Graphical Display of Performance for MoPac Northbound

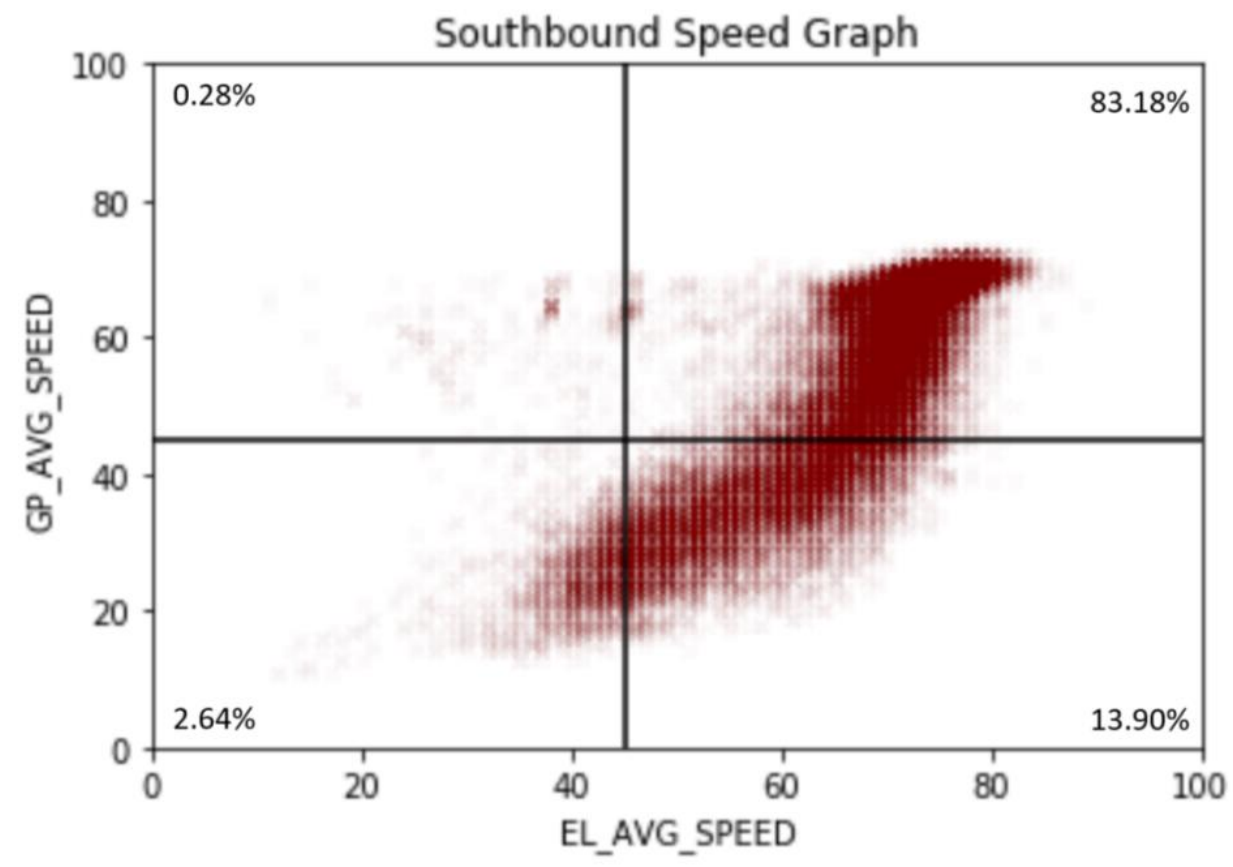

Figure 25: Graphical Display of Performance for MoPac Southbound

\section{Scoring Index}

First, the lane capacity needs to be found according to the fundamental traffic speed-flow and flow-density diagrams. Figure 4 and Figure 5 show examples of these diagrams. The lane capacity for northbound is $1500 \mathrm{vph}$ and for southbound is $1700 \mathrm{vph}$. Each time interval is given a raw score. Figure 6 shows how each raw score is determined. Table 35 and Table 36 summarize the results. 
Table 35: Summary of Index Results for MoPac Northbound

\begin{tabular}{|c|c|c|r|}
\hline Score & Frequency & Total ML Flow & Score $\times$ Total ML Flow \\
\hline-3 & 36 & 467 & -1401 \\
\hline-2 & 2,081 & 78,750 & $-157,500$ \\
\hline-1 & 2 & 225 & -225 \\
\hline 0 & 118 & 6,069 & 0 \\
\hline 1 & 106,190 & $1,732,792$ & $1,732,792$ \\
\hline 2 & 126 & 13,251 & 26,502 \\
\hline 3 & 75 & 8,752 & 26,256 \\
\hline
\end{tabular}

Table 36: Summary of Index Results for MoPac Southbound

\begin{tabular}{|c|c|c|r|}
\hline Score & Frequency & Total ML Flow & Score $\times$ Total ML Flow \\
\hline-3 & 309 & 6,933 & $-20,799$ \\
\hline-2 & 3,026 & 123,536 & $-247,072$ \\
\hline-1 & 2 & 242 & -242 \\
\hline 0 & 261 & 13,201 & 0 \\
\hline 1 & 92,827 & $1,454,965$ & $1,454,965$ \\
\hline 2 & 156 & 17,417 & 34,834 \\
\hline 3 & 77 & 9,619 & 28,857 \\
\hline
\end{tabular}

The final score is calculated by Equation 19 . The northbound final index score is 0.84 , and the southbound final index score is 0.87 . The overall score is 0.86 .

\section{MnPASS Express Lanes}

There are three EL facilities in Minnesota. They are located along I-35W, I-35E, and I-394, as shown in Figure 26 . The lanes are dynamically priced, with the toll rates varying from $\$ 0.25$ to $\$ 8.00$. The tolls can change every 3 minutes depending on the speed and the number of vehicles using the lanes and the change in traffic density at the most congested downstream segment. The tolling algorithm adopted for these lanes has been discussed in depth previously. The tolls charged are in multiples of $\$ 0.25$. The MLs generally operate only on weekdays and in the peak hours in the morning ( 6 to 10 a.m.) and evening ( 3 to 7 p.m.). Outside of the operating hours, the MLs are open to all users, and no toll is charged.

The MLs are always free for motorcycles, transit, and vehicles with two or more occupants. The tolls are only charged to SOVs, which must have a MnPASS tag with a MnPASS account to facilitate electronic toll collection. 


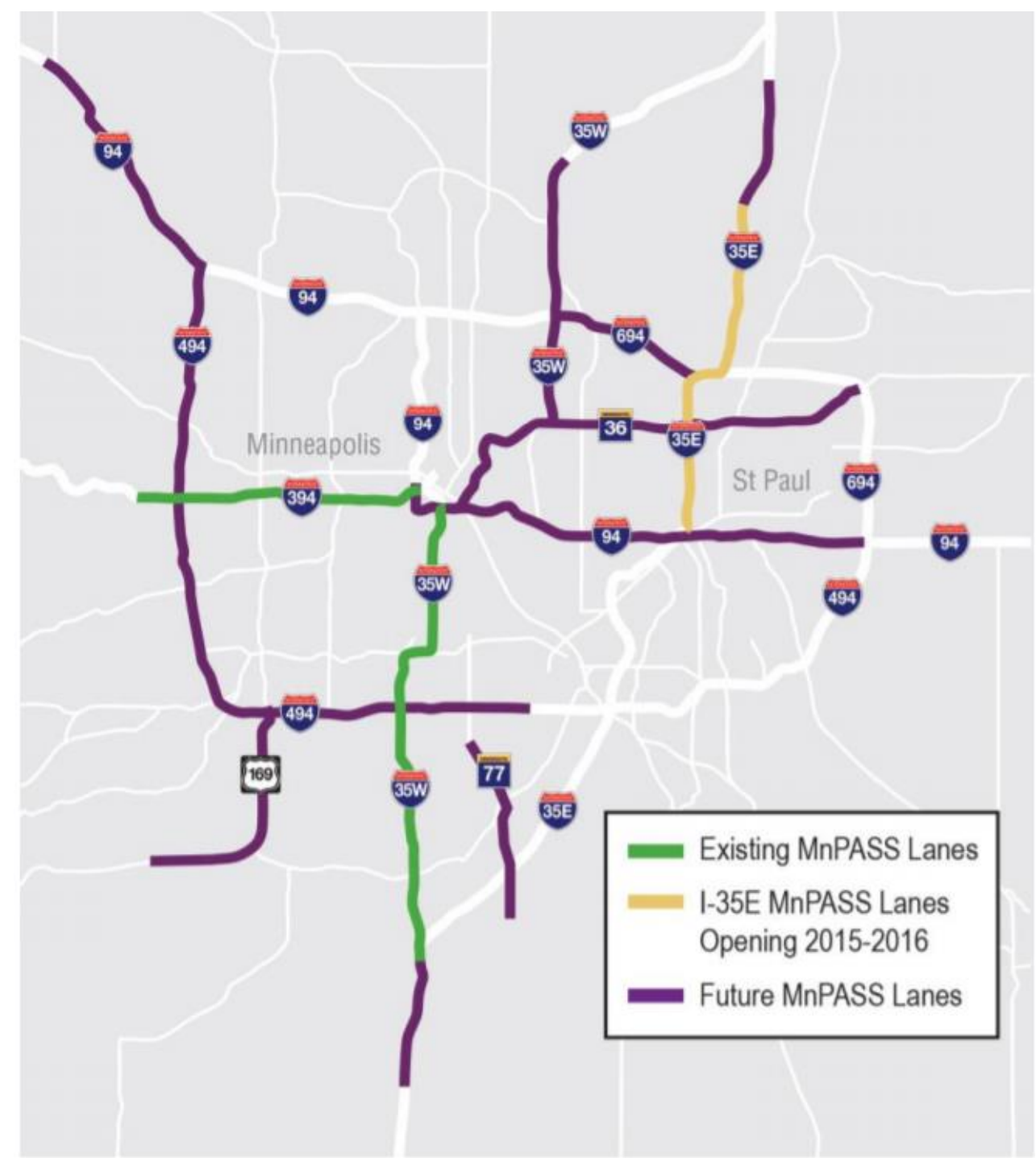

Figure 26: MnPASS Express Lanes in Minnesota (Source: www.Mnpass.org)

\section{Data}

The traffic data were obtained from the open-source tool known as DataExtract developed by the Minnesota Department of Transportation (MnDOT), downloaded from http://data.dot.state.mn.us/datatools/dataextract.html This tool contains archived traffic data for the freeway system throughout the Twin Cities metro area in Minnesota. The loop detector data were extracted for various detectors in both the GPLs and the MLs throughout the facilities. The traffic data extracted included speed, flow, density, and volume. The data were obtained at 3-minute granularity for all weekdays in 2016 and 2017. Figure 27 shows the process of extracting traffic data. 


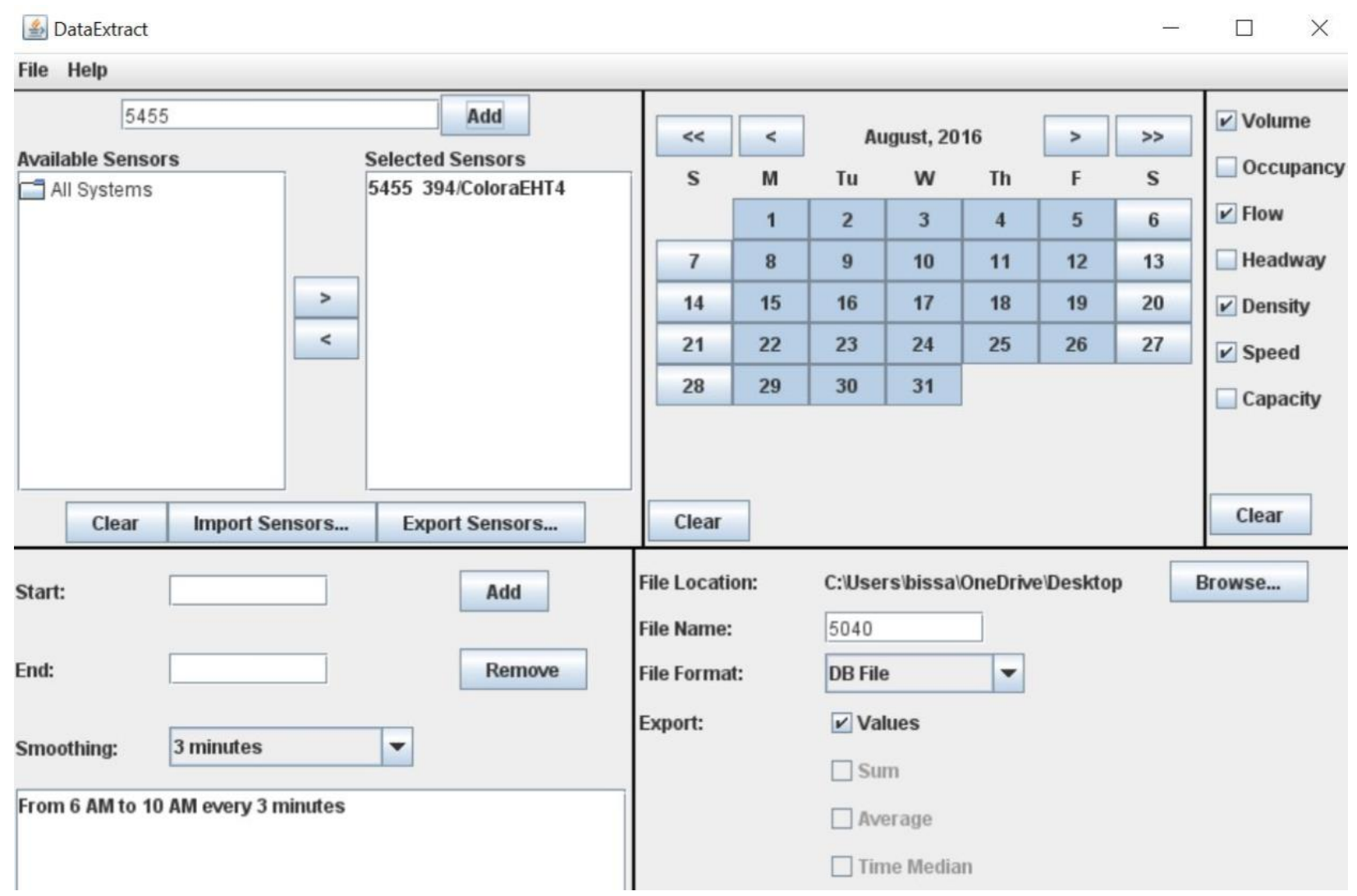

Figure 27: Sample Loop Detector Data Extracted at ML Detector 5455 Located on I-394

After extraction of the traffic data, data cleaning was performed to remove any erroneous data. Speeds and volume less than zero were considered an error and were removed before conducting further analysis. Speeds greater than $100 \mathrm{mph}$ were also considered unrealistic and hence removed. Further, traffic densities greater than 250 vehicles/mile/lane were considered unreasonable and removed. The cleaning process resulted in around 3 percent of the $\mathrm{ML}$ detector data removed for I-35W. Around 13 percent of the data were removed for the $\mathrm{ML}$ detectors located on I-394 and I-35E. The cleaned traffic data were further used for calculating the performance measures.

MnDOT provided the toll data. The dataset consisted of all the toll transactions that occurred in the MLs in facilities I-35W, I-35E, and I-394 from January 1, 2016, to December 31, 2017. The toll transaction data were received from MnDOT in the form of an Excel Worksheet file. Each row denotes a unique trip and contains the time when a vehicle was first detected at a tolling location. The first and last tolling locations where a vehicle was detected were also available. Lastly, the toll charged for each transaction was also available. Table 37 shows a sample of toll transaction data. 
Table 37: Sample Toll Transaction Data for I-35W

\begin{tabular}{|l|l|l|l|l|l|c|}
\hline S. No. & Entry Time & Road & Direction & Entry Location & Exit Location & Toll Amount (\$) \\
\hline 1 & $\begin{array}{l}01-01-2016 \\
06: 51: 45\end{array}$ & I-35W & NB & Cliff Road & 66 th Street & 0.25 \\
\hline 2 & $\begin{array}{l}05-02-2016 \\
08: 06: 40\end{array}$ & I-35W & NB & Burnsville & Cliff Road & 3 \\
\hline 3 & $\begin{array}{l}02-02-2016 \\
16: 18: 59\end{array}$ & I-35W & SB & 50th Street & Blackdog Road & 8 \\
\hline 4 & $\begin{array}{l}05-01-2016 \\
16: 23: 34\end{array}$ & I-35W & SB & 50th Street & 106th Street & 2.75 \\
\hline
\end{tabular}

Note: NW = northbound; SB = southbound.

Sometimes, the toll for a trip was $\$ 0$, which indicated that either the occupant had the transponder set to HOV mode or drove outside the tolling hours. Table 38 shows the entire tolled trips for the 2 years for each facility.

Table 38: MnPASS Transactions for Each Facility

\begin{tabular}{|l|c|c|}
\hline \multicolumn{1}{|c|}{ Facility } & Transactions (2016) & Transactions (2017) \\
\hline I-35W & 921,688 & 947,042 \\
\hline I-35E & 189,729 & 439,296 \\
\hline I-394 & $1,178,765$ & $1,316,580$ \\
\hline
\end{tabular}

\section{Performance Measures}

\section{Travel Time Savings}

The cleaned data were used for analyzing the facility and computing the performance metrics. The fundamental parameter for estimation is the travel times in both the MLs and GPLs, which were required for several metrics. To estimate travel times, the speeds were calculated. At each 3-minute interval, the speeds obtained from all the detectors were volume-weighted for the MLs and the GPLs. Next, the weighted speeds of all ML detectors were averaged to get an estimate of the average corridor speed at each 3-minute time interval. Next, the travel times were calculated from the average corridor speed and the ML facility length. Also, the average volume of vehicles using the ML facility was calculated by averaging the traffic measured from all the detectors for the 3-minute time interval. The same procedure was applied to the GPLs, and the TTS was calculated using Equation 13.

\section{Variability Benefit}

Next, the variability benefit can be estimated using Equation 14.

\section{Planning Time Index Benefit}

The next metric calculated was the planning time index benefit, calculated from PTI, as discussed in Equation 16 and Equation 15, respectively. To get a reasonable estimate of the free-flow travel times, the FFS was calculated. For distinct segments in a facility, the ML detector speeds were obtained for all the detectors from 12 to 4 a.m. Next, data cleaning was performed to remove negative speeds and speeds greater than $100 \mathrm{mph}$. Finally, the average 
speed obtained during those overnight times was taken as the FFS for that segment in the facility.

\section{Ability of Toll to Impact Congestion}

The ability of the toll to impact the congestion metric is calculated from Equation 17. From the toll transaction data, the entry tolling locations were available for all trips. The flow of traffic coming from the nearest detectors was taken as the flow rate for whenever a toll transaction occurred. In the case of two detectors near the location, one upstream and the other downstream, the downstream one was selected for the volume data. The average flow in the MLs was found for each distinct toll. Unfortunately, this flow includes all the tolled trips, that is, the SOVs plus the toll-exempt vehicles, primarily HOVs.

\section{Speed Thresholds}

Next, for the speed threshold metric, the internal speed goal was taken as $50 \mathrm{mph}$ because the objective of the MnPASS lanes is to keep traffic flowing between 50 and $55 \mathrm{mph}$.

\section{Scoring Index}

The speed of $50 \mathrm{mph}$ was also taken in the scoring index criteria, which is shown in Figure 6. The lane capacity was calculated for all directions of traffic in the facilities separately. The average $\mathrm{ML}$ flow was found using Equation 18. The speed, flow, and density from all the available detectors in a segment were used in the fundamental traffic-flow diagrams to obtain a reasonable lane capacity. Each of the three ML facilities is discussed in detail in the next sections, and the performance measures are computed.

\section{I-35W Express Lanes}

\section{Facility Overview}

The I-35W MnPASS Express Lanes opened on September 30, 2009. The MLs connect downtown Minneapolis with the city of Burnsville. There is one ML in each direction of traffic. The northbound route starts near County Road 42 and extends to 26th Street in the downtown. The southbound route starts south of 42 nd Street and ends near Cliff Road. The MLs are concurrent flow and are the leftmost lane in each direction of traffic. Figure 28 shows the I-35W facility. 


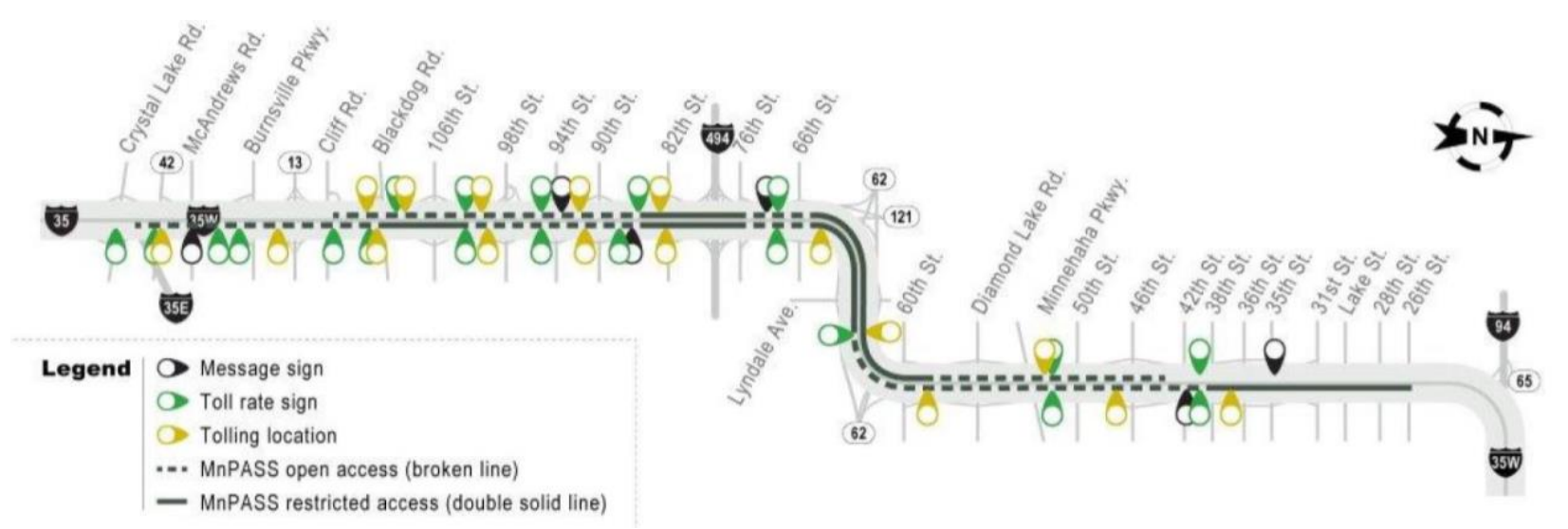

Figure 28: Map of MnPASS I-35W Express Lanes (Source: www.mnpass.org)

The users are allowed to enter and exit from the ML whenever the pavement markings are broken lines. In contrast, the travelers are restricted to enter and exit the lanes whenever there is a double solid line. The complete northbound route is accessible from 6 to 10 a.m. on weekdays, while the entire southbound route operates from 3 to 7 p.m. on weekdays. However, a short segment in both directions also operates at a different time than its respective complete route. The facility is analyzed as four different routes, as shown in Table 39.

Table 39: Analyzed Routes for I-35W Express Lanes

\begin{tabular}{|l|l|c|l|}
\hline \multicolumn{1}{|c|}{ Route } & \multicolumn{1}{|c|}{ Location } & Distance (Miles) & \multicolumn{1}{c|}{ Operating Hours } \\
\hline NB segment 1 & Crystal Lake Road to 26th Street & 16 & 6 to 10 a.m. \\
\hline NB segment 2 & Highway 62 to 26th Street & 4.9 & 3 to 7 p.m. \\
\hline SB segment 1 & 42nd Street to Cliff Road & 10.6 & 3 to 7 p.m. \\
\hline SB segment 2 & 42nd Street to I-494 & 4.9 & 6 to 10 a.m. \\
\hline
\end{tabular}

There are 16 and $20 \mathrm{ML}$ and GPL detector stations in the southbound and northbound directions, respectively. Further, the ML and GPL detectors were present together at all locations where they are observed. There are one ML and two to four GPLs for each direction of traffic. Table 40 and

Table 41 show the location of the northbound and southbound detectors, respectively. 
Table 40: Northbound Detectors on I-35W

\begin{tabular}{|l|l|l|c|}
\hline \multicolumn{1}{|c|}{ Location } & \multicolumn{1}{c|}{$\begin{array}{c}\text { ML Detector } \\
\text { Number }\end{array}$} & \multicolumn{1}{|c|}{ GPL Detector Number } & $\begin{array}{c}\text { Distance } \\
\text { (Miles) }\end{array}$ \\
\hline Crystal Lake Road Entrance & - & - & - \\
\hline County Road 42 & 7040 & 360,359 & 0.5 \\
\hline Timberland Drive & 7042 & 132,131 & 1 \\
\hline Burnsville Parkway & 461 & 259,258 & 0.6 \\
\hline Cliff Road & 500 & 265,264 & 1 \\
\hline North Cliff Road & 6907 & 6906,6905 & 0.4 \\
\hline Blackdog road & 496 & 495,494 & 0.6 \\
\hline 102nd & 541 & 272,271 & 1.4 \\
\hline 98th & 545 & 274,273 & 0.3 \\
\hline 94th & 577 & 276,275 & 0.8 \\
\hline 88th & 579 & 278,277 & 0.7 \\
\hline 82nd & 729 & 282,281 & 0.9 \\
\hline 70th & 3935 & 290,289 & 1.3 \\
\hline 66th & 3938 & 292,291 & 0.4 \\
\hline Nicollet Avenue & 5923 & 5922,299 & 1.4 \\
\hline 60th & 6935 & $6934,6933,6931,6931$ & 0.4 \\
\hline 48th & 6945 & $6944,6943,6942,6941$ & 1.4 \\
\hline 42nd & 6791 & $318,317,316,315$ & 0.8 \\
\hline 37th & 6954 & $330,329,328,327$ & 0.6 \\
\hline 31st & 6794 & $6962,6961,6960,6959$ & 0.8 \\
\hline 28th & 6963 & - & 0.5 \\
\hline 26th Street Exit & - & & 0.2 \\
\hline
\end{tabular}

Table 41: Southbound Detectors on I-35W

\begin{tabular}{|l|l|l|c|}
\hline \multicolumn{1}{|c|}{ Location } & \multicolumn{1}{|c|}{$\begin{array}{c}\text { ML Detector } \\
\text { Number }\end{array}$} & \multicolumn{1}{|c|}{ GPL Detector Number } & $\begin{array}{c}\text { Distance } \\
\text { (Miles) }\end{array}$ \\
\hline 42nd Street Entrance & - & - & - \\
\hline 48th Street & 6940 & $6939,6938,6937,6936$ & 0.6 \\
\hline Diamond Lake Road & 5940 & $5939,221,220,219$ & 1 \\
\hline 58th Street & 224 & 223,222 & 0.4 \\
\hline Lyndale Avenue & 229 & 228,227 & 0.9 \\
\hline 66th Street & 3944 & 233,232 & 0.9 \\
\hline 70th Street & 3945 & 235,234 & 0.4 \\
\hline 76th Street & 351 & 239,238 & 0.7 \\
\hline 82nd Street & 355 & 243,242 & 0.6 \\
\hline 85th Street & 582 & 245,244 & 0.7 \\
\hline 88th Street & 583 & 247,246 & 0.2 \\
\hline 92nd Street & 999 & 249,248 & 0.5 \\
\hline 98th Street & 1000 & 251,250 & 1 \\
\hline 106th Street & 6910 & 6909,6908 & 0.4 \\
\hline 110th Street & 1003 & $257,256,6803$ & 0.6 \\
\hline Blackdog Road & 1008 & $1007,1006,6804$ & 0.7 \\
\hline
\end{tabular}




\begin{tabular}{|l|l|l|l|}
\hline Cliff Road & 1013 & $1012,1011,6829$ & 0.9 \\
\hline Cliff Road Exit & - & - & 0.1 \\
\hline
\end{tabular}

There are 10 tolling locations northbound and seven tolling locations southbound. Table 42 shows the tolling locations and the nearest $\mathrm{ML}$ detectors chosen for analysis.

Table 42: Tolling Locations and ML Detectors on I-35W

\begin{tabular}{|l|l|l|l|}
\hline \multicolumn{1}{|c|}{$\begin{array}{c}\text { Northbound Tolling } \\
\text { Location }\end{array}$} & $\begin{array}{c}\text { Northbound ML Detector } \\
\text { Number }\end{array}$ & \multicolumn{1}{|c|}{$\begin{array}{c}\text { Southbound Tolling } \\
\text { Location }\end{array}$} & $\begin{array}{c}\text { Southbound ML Detector } \\
\text { Number }\end{array}$ \\
\hline Burnsville Parkway & 7040 & 48th Street & 6940 \\
\hline Highway 13 & 461 & Nicollet Avenue & 229 \\
\hline Cliff Road & 496 & 82 nd Street & 355 \\
\hline 98th Street & 545 & 90 th Street & 999 \\
\hline 90th Street & 579 & 98 th Street & 1000 \\
\hline 82nd Street & 729 & 106th Street & 1003 \\
\hline 66th Street & 3938 & Blackdog Road & 1008 \\
\hline 60th Street & 6935 & - & - \\
\hline 46th Street & 6945 & - & - \\
\hline 38th Street & 6954 & - & - \\
\hline
\end{tabular}

\section{Performance Metrics}

The performance metrics for the I-35W facility were calculated for all four routes for all 2016 and 2017 data. The results are discussed as follows.

Travel Time Savings: The weighted average TTS was calculated for the routes, as shown in Table 43. The weighted TTS for using the I-35W facility was 1.44 minutes.

Table 43: Performance Metrics on I-35W

\begin{tabular}{|l|c|c|c|c|}
\hline \multicolumn{1}{|c|}{ Route } & NB Segment 1 & NB Segment 2 & SB Segment 1 & SB Segment 2 \\
\hline TTS (minutes) & 2.52 & 1.38 & 0.85 & 0.73 \\
\hline Variability benefit & 1.79 & 2.28 & 2.18 & 2.10 \\
\hline PTI for GPL & 1.67 & 2.14 & 1.41 & 1.66 \\
\hline PTI for ML & 1.37 & 1.66 & 1.18 & 1.30 \\
\hline $\begin{array}{l}\text { Planning time index } \\
\text { benefit }\end{array}$ & 0.30 & 0.48 & 0.23 & 0.36 \\
\hline
\end{tabular}

Variability Benefit: Table 43 shows the variability benefit for using the MLs compared to the GPLs. The overall variability benefit for I-35W was 2.08 .

Planning Time Index Benefit: The FFS was estimated to be $67 \mathrm{mph}$ in the northbound direction and $62.7 \mathrm{mph}$ in the southbound direction. The PTI was then computed for both the ML and the GPLs, as shown in Table 43. Finally, the planning time index benefit was calculated. The planning time index benefit for the entire facility was 0.34 .

Ability of the Toll to Impact Congestion: This metric was calculated considering traffic and tolls for all routes. Table 44 shows the results for the I-35W facility. 
Table 44: Ability of the Toll to Impact Congestion for Entire I-35W Facility

\begin{tabular}{|l|c|c|c|c|c|}
\hline Toll Interval & $\begin{array}{c}\text { Average } \\
\text { Toll (\$) }\end{array}$ & $\begin{array}{c}\text { Average } \mathbf{M L} \\
\text { Throughput } \\
\text { (vph) }\end{array}$ & $\begin{array}{c}\text { Percent Change in } \\
\text { Average Vehicle } \\
\text { Throughput in the } \mathbf{M L}\end{array}$ & $\begin{array}{c}\text { Percent } \\
\text { Increase in } \\
\text { Toll }\end{array}$ & $\begin{array}{c}\text { Toll Ability to } \\
\text { Impact Congestion }\end{array}$ \\
\hline 0.25 to 1 & 0.702 & 549 & - & - & - \\
\hline 1.25 to 2 & 1.586 & 927 & $68.97 \%$ & $125.74 \%$ & 0.549 \\
\hline 2.25 to 3 & 2.540 & 956 & $3.10 \%$ & $60.16 \%$ & 0.052 \\
\hline 3.25 to 4 & 3.562 & 1,017 & $6.44 \%$ & $40.24 \%$ & 0.160 \\
\hline 4.25 to 5 & 4.601 & 1,045 & $2.72 \%$ & $29.18 \%$ & 0.093 \\
\hline 5.25 to 6 & 5.600 & 1,018 & $-2.54 \%$ & $21.71 \%$ & -0.117 \\
\hline 6.25 to 7 & 6.601 & 1,017 & $-0.07 \%$ & $17.88 \%$ & -0.004 \\
\hline 7.25 to 8 & 7.839 & 985 & $-3.23 \%$ & $18.75 \%$ & -0.172 \\
\hline
\end{tabular}

The toll transaction data showed that the I-35W facility had the maximum number of $\$ 8$ toll cap transactions when compared to I-35E and I-394. The maximum number of toll transactions originated from the Burnsville Parkway tolling location in the northbound direction. The ability of the toll metric was again calculated for the trips originating from this location. Table 45 shows the results.

Table 45: Ability of the Toll Metric for Trips Originating at Burnsville in I-35W

\begin{tabular}{|l|c|c|c|c|c|}
\hline Toll Interval & $\begin{array}{c}\text { Average } \\
\text { Toll (\$) }\end{array}$ & $\begin{array}{c}\text { Average } \mathbf{M L} \\
\text { Throughput } \\
\text { (vph) }\end{array}$ & $\begin{array}{c}\text { Percent Change in } \\
\text { Average Vehicle } \\
\text { Throughput in the } \text { ML }\end{array}$ & $\begin{array}{c}\text { Percent } \\
\text { Increase in } \\
\text { Toll }\end{array}$ & $\begin{array}{c}\text { Toll Ability to } \\
\text { Impact Congestion }\end{array}$ \\
\hline 0.25 to 1 & 0.720 & 389 & - & - & - \\
\hline 1.25 to 2 & 1.615 & 583 & $49.84 \%$ & $124.16 \%$ & 0.401 \\
\hline 2.25 to 3 & 2.537 & 690 & $18.20 \%$ & $57.10 \%$ & 0.319 \\
\hline 3.25 to 4 & 3.572 & 668 & $-3.12 \%$ & $40.78 \%$ & -0.077 \\
\hline 4.25 to 5 & 4.600 & 663 & $-0.78 \%$ & $28.80 \%$ & -0.027 \\
\hline 5.25 to 6 & 5.622 & 671 & $1.20 \%$ & $22.22 \%$ & 0.054 \\
\hline 6.25 to 7 & 6.623 & 671 & $0.06 \%$ & $17.80 \%$ & 0.003 \\
\hline 7.25 to 8 & 7.851 & 692 & $3.14 \%$ & $18.54 \%$ & 0.170 \\
\hline
\end{tabular}

The users continue to pay the high tolls to use the facility, which could result in congestion in the ML.

Speed Thresholds: The percent of the time that the MLs and the GPLs maintain the FHWA external speed criterion of $45 \mathrm{mph}$ was estimated. Similarly, the percent of the time the lanes maintain the MnPASS internal criterion of $50 \mathrm{mph}$ was estimated (see Table 46).

Table 46: Percent of Time Speeds Exceeded the Speed Threshold for I-35W

\begin{tabular}{|l|c|c|c|c|}
\hline \multirow{2}{*}{$\begin{array}{c}\text { Speed Threshold and } \\
\text { Lanes }\end{array}$} & \multicolumn{4}{|c|}{ Route } \\
\cline { 2 - 5 } & NB Segment 1 & NB Segment 2 & SB Segment 1 & SB Segment 2 \\
\hline $\mathrm{ML}>45 \mathrm{mph}$ & 98 & 93 & 99 & 98 \\
\hline $\mathrm{ML}>50 \mathrm{mph}$ & 95 & 86 & 98 & 95 \\
\hline $\mathrm{GPL}>45 \mathrm{mph}$ & 85 & 68 & 94 & 88 \\
\hline $\mathrm{GPL}>50 \mathrm{mph}$ & 73 & 55 & 87 & 80 \\
\hline
\end{tabular}

Speed Graphs: Figure 29 through Figure 32 show the plotted speed graphs for the four routes. 




Figure 29: Graphical Display of Performance for Northbound Segment 1 in I-35W

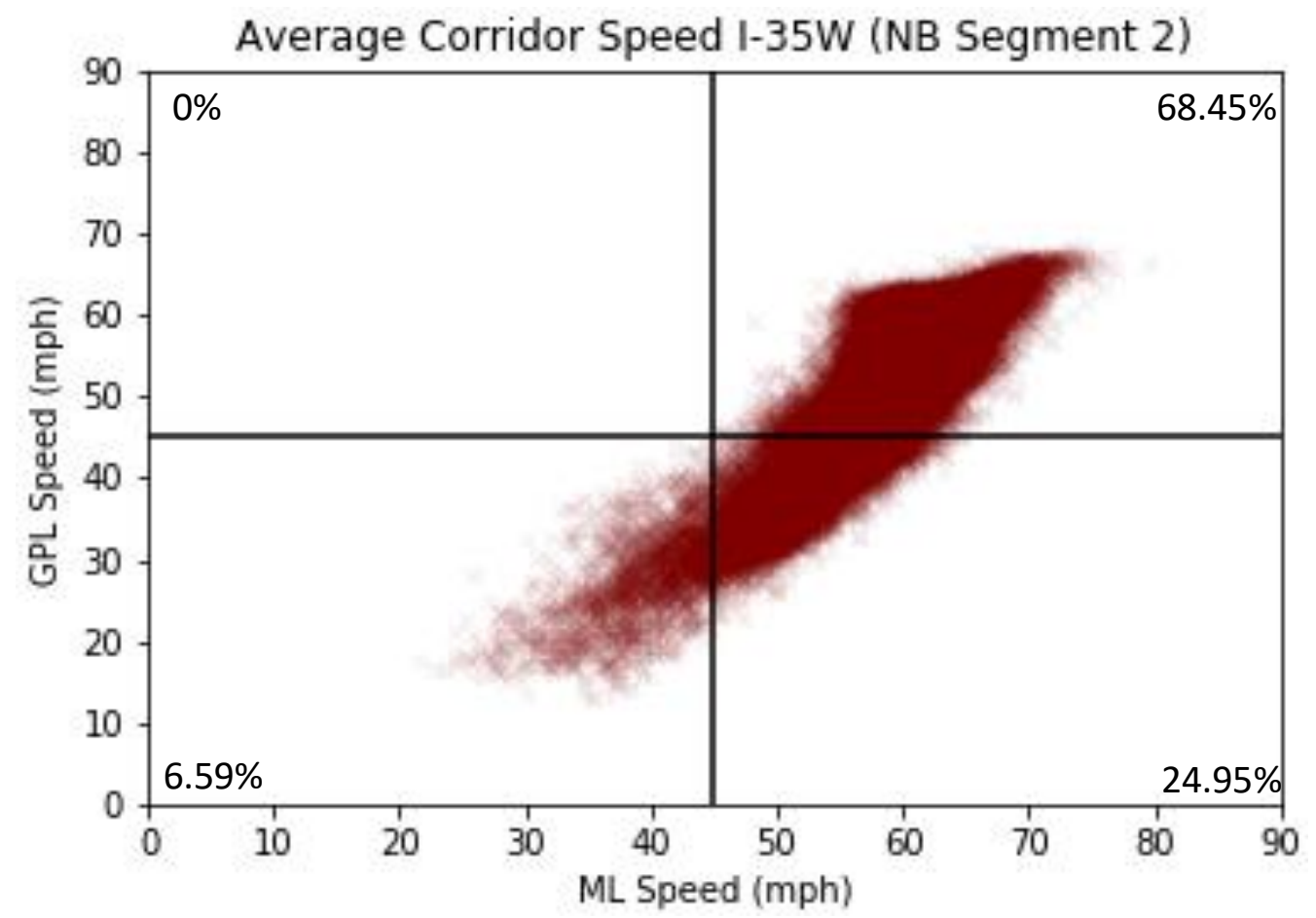

Figure 30: Graphical Display of Performance for Northbound Segment 2 in I-35W 


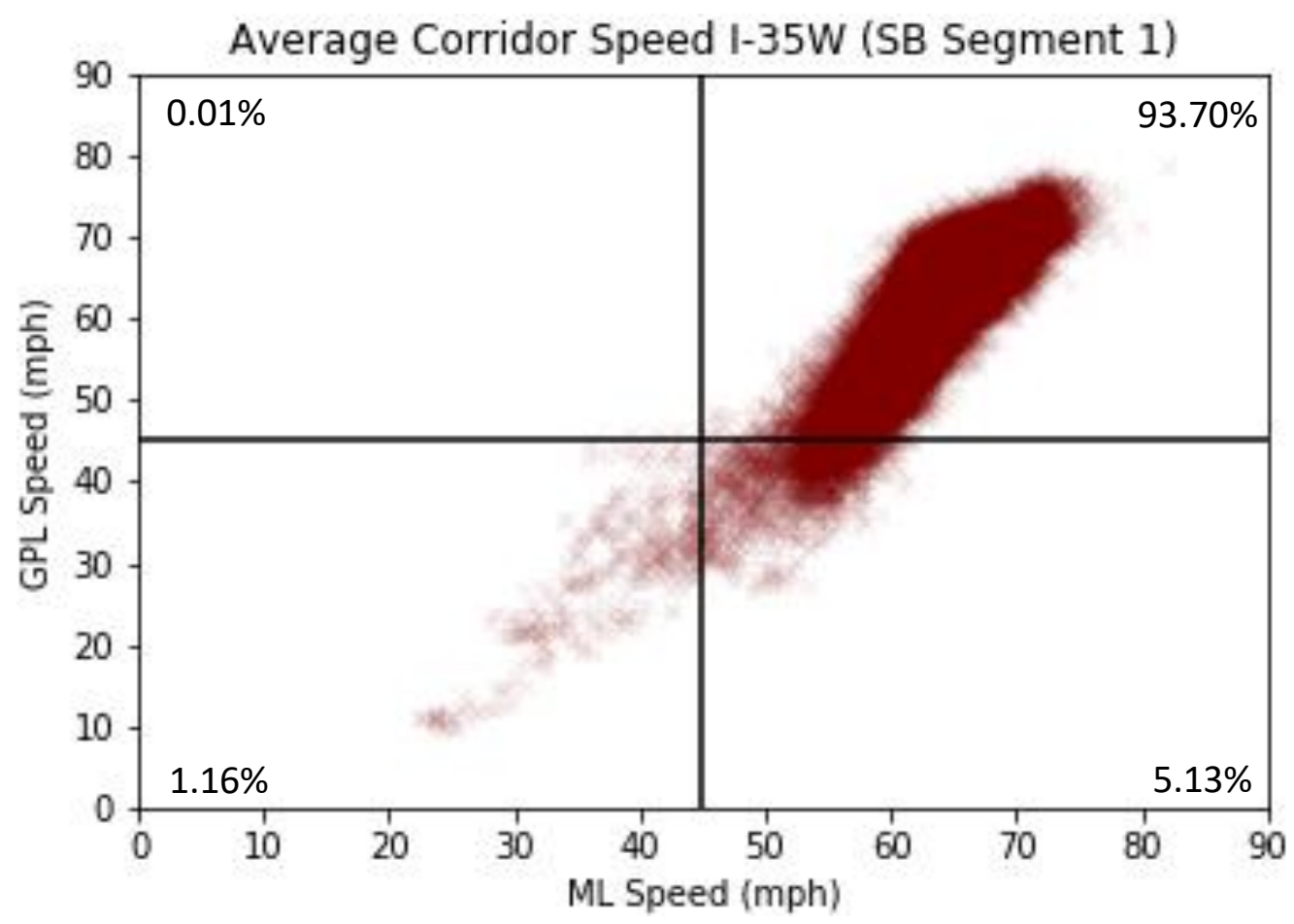

Figure 31: Graphical Display of Performance for Southbound Segment 1 in I-35W

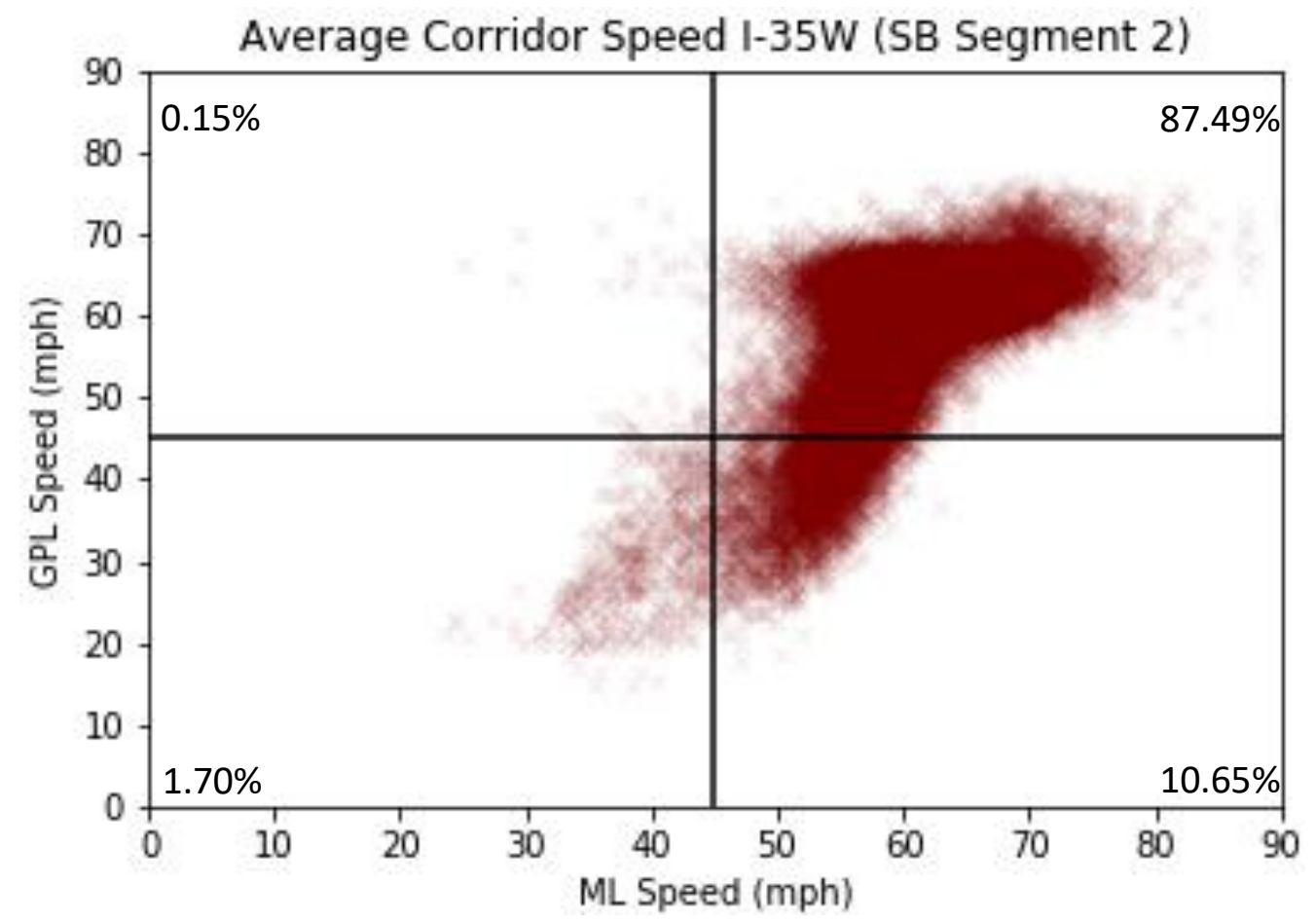

Figure 32: Graphical Display of Performance for Southbound Segment 2 in I-35W

Scoring Index The scoring index was calculated at the detectors near the tolling locations. The approximate lane capacity was found for the northbound and the southbound directions separately. Figure 33 and Figure 34 show the flow-density and flow-speed fundamental 
diagrams, respectively, for northbound. It was confirmed that the lane capacity is approximately $2,000 \mathrm{vph}$. Similarly, the lane capacity for southbound was $1,800 \mathrm{vph}$. Figure 35 and

Figure 36 show the fundamental flow-density and flow-speed plots for southbound, respectively.

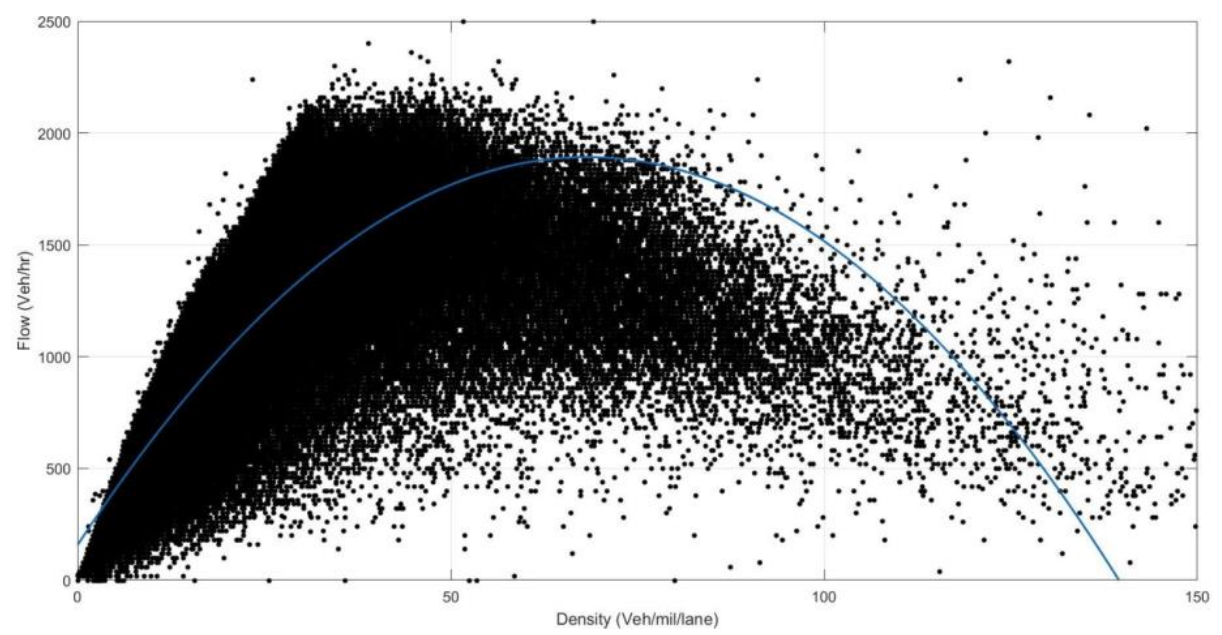

Figure 33: Flow-Density Plot for I-35W Northbound

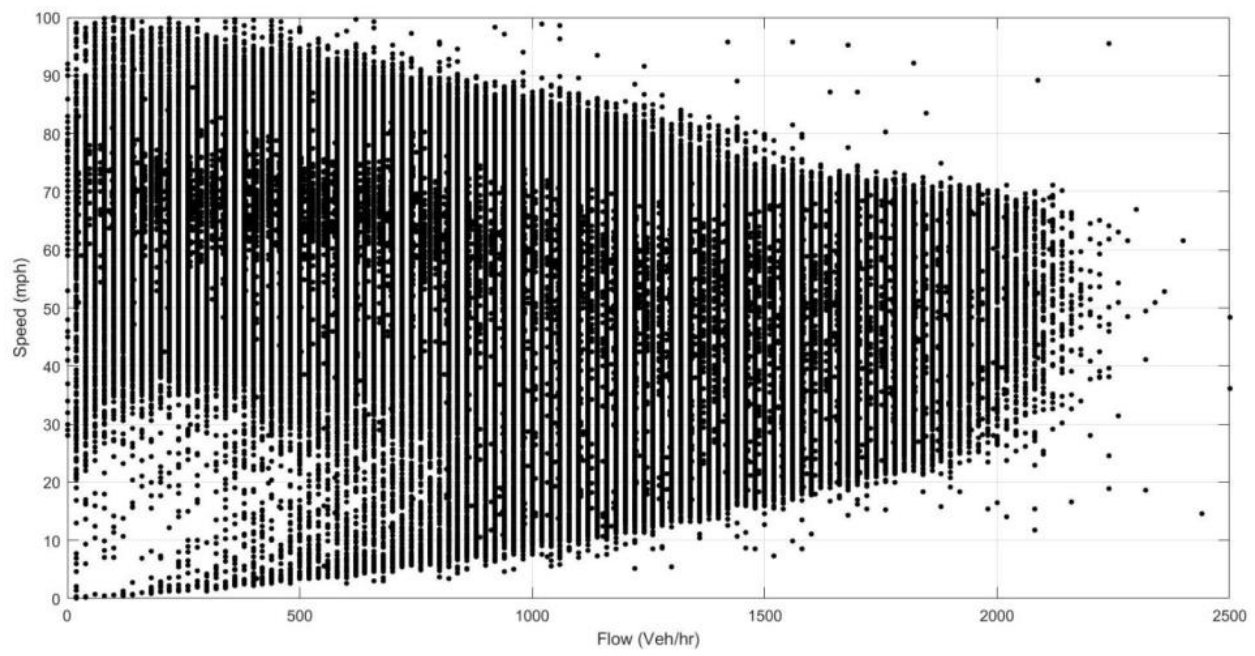

Figure 34: Flow-Speed Plot for I-35W Northbound 


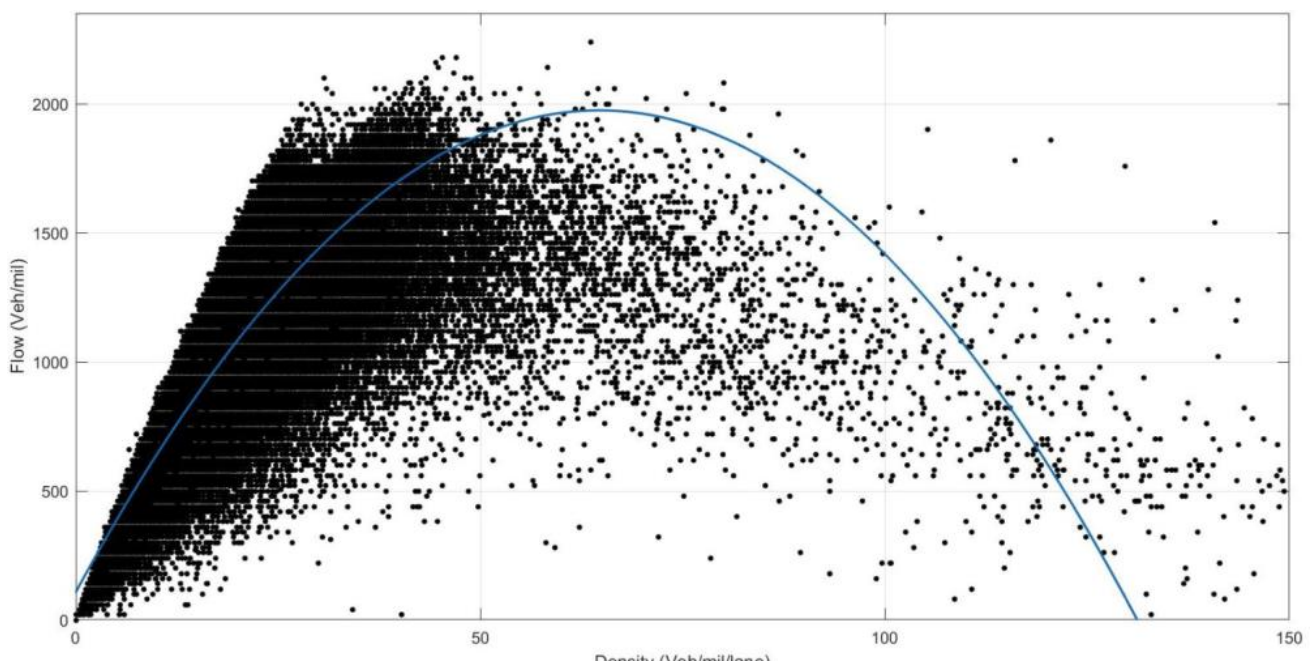

Figure 35: Flow-Density Plot for I-35W Southbound

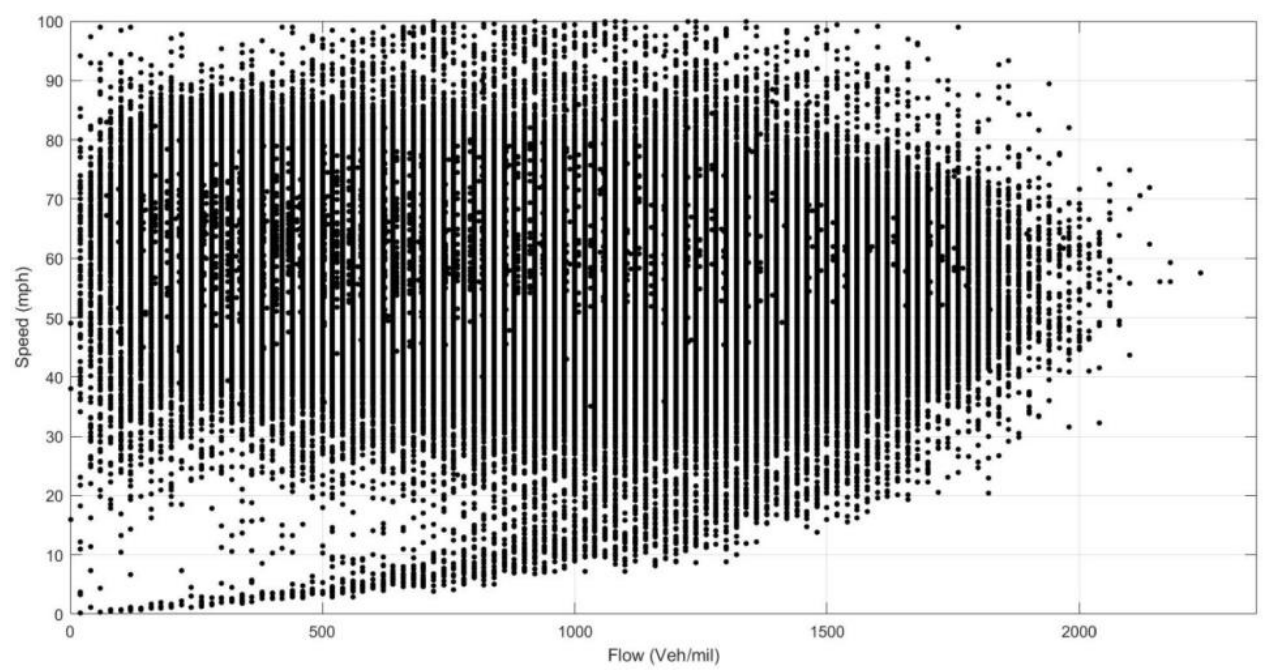

Figure 36: Flow-Speed Plot for I-35W Southbound

Table 47 shows the scoring index obtained near the tolling locations for both northbound and southbound. The overall weighted score for northbound and southbound was 0.72 and 0.80 , respectively. Again, these were weighed by direction, and the final score for I-35W was 0.75 .

Table 47: Scoring Index for I-35W

\begin{tabular}{|l|c|l|l|c|c|}
\hline \multicolumn{3}{|c|}{ Northbound } & \multicolumn{3}{c|}{ Southbound } \\
\hline \multicolumn{1}{|c|}{ Tolling Location } & ML Volume & Score & \multicolumn{1}{|c|}{ Tolling Location } & ML Volume & Score \\
\hline Burnsville Parkway & 934,167 & 0.88 & Blackdog Road & $1,859,747$ & 0.95 \\
\hline Highway 13 & $1,588,968$ & 0.49 & 106th Street & $1,947,066$ & 0.95 \\
\hline Cliff Road & $2,212,961$ & 0.92 & 98th Street & $2,027,439$ & 0.90 \\
\hline 98th Street & $1,922,649$ & 0.96 & 90th Street & $1,874,796$ & 0.80 \\
\hline 90th Street & $1,612,652$ & 0.89 & 82nd Street & $1,297,865$ & 0.91 \\
\hline 82nd Street & $1,334,155$ & 0.99 & Nicollet Ave & $1,935,164$ & 0.20 \\
\hline 66th Street & $1,018,561$ & 0.97 & 48th Street & $1,562,226$ & 0.97 \\
\hline 60th Street & $2,455,574$ & 0.87 & - & - & - \\
\hline
\end{tabular}




\begin{tabular}{|l|l|l|l|l|l|} 
46th Street & $3,002,461$ & 0.56 & - & - & - \\
\hline 38th Street & $3,184,480$ & 0.25 & - & - & - \\
\hline
\end{tabular}

\section{I-394 Express Lanes}

\section{Facility Overview}

The I-394 MnPASS Express Lanes opened in May 2005. They were the first ELs to begin operations in Minnesota. The lanes were converted from HOV lanes, and the goal was to better optimize the capacity of the existing HOV lanes. The lanes are around 11 miles long and connect the city of Wayzata with downtown Minneapolis. The eastbound lane starts near Wayzata Boulevard and end near Highway 100. The westbound lanes start near Highway 100 and end at Carlson Parkway. The eastbound ML operates from 6 to 10 a.m., while the westbound ML operates from 3 to 7 p.m. on weekdays. One more segment of two reversible MLs operates from Highway 100 to I-94. The lanes are tolled eastbound from 6 a.m. to 1 p.m. and westbound from 2 p.m. to 5 a.m. Between 1 and 2 p.m., the lanes are closed to all traffic, and the traffic direction transition is made. These lanes operate Monday through Friday and also on weekends. The weekend hours of operation vary and depend on events in the community. Figure 37 shows the I-394 facility.



Figure 37: Map of MnPASS I-394 Express Lanes (Source: https://www.dot.state.mn.us/mnpass/)

Similar to the I-35 MLs, users can enter and exit the lanes whenever there is a double broken line. However, crossing the solid, double-white lines is restricted and is a violation. For this analysis, to estimate the performance of the MLs, the entire route was analyzed when they were operational. Therefore, the segments are defined considering the concurrent-flow lanes and the reversible lanes together, assuming that a traveler uses the entire length of I-394. Table 48 shows the routes in the facility for the analysis.

Table 48: Analyzed Routes for I-394 Express Lanes

\begin{tabular}{|l|l|c|l|}
\hline \multicolumn{1}{|c|}{ Route } & \multicolumn{1}{|c|}{ Location } & $\begin{array}{c}\text { Distance } \\
\text { (Miles) }\end{array}$ & \multicolumn{1}{c|}{ Operating Hours } \\
\hline Eastbound segment & County Road 15 to Dunwoody Boulevard & 9.93 & 6 to 10 a.m. \\
\hline Westbound segment & Dunwoody Boulevard to Carlson Parkway & 8.72 & 3 to 7 p.m. \\
\hline
\end{tabular}


There are 16 and $19 \mathrm{ML}$ and GPL detector stations in the westbound and eastbound directions, respectively. Further, the ML and GPL detectors were present together at all the locations where they are observed except at Highway 100 westbound. There are two to four GPLs for each direction of traffic. There is one $\mathrm{ML}$ in each direction of traffic in the concurrent-flow section and two MLs in the reversible section. The reversible MLs run in the median of the facility. Similarly, the concurrent-flow MLs are always the leftmost lanes for each direction. Table 49 and Table 50 show the location of the eastbound and westbound detectors, respectively.

Table 49: Eastbound Detectors on I-394

\begin{tabular}{|l|l|l|c|}
\hline \multicolumn{1}{|c|}{ Location } & \multicolumn{1}{|c|}{ ML Detector Number } & GPL Detector Number & Distance (Miles) \\
\hline County Road 15 Entrance & - & - & - \\
\hline Bushaway Road & 1637 & 1636,1635 & 0.16 \\
\hline Carlson Parkway & 1643 & 1642,1641 & 0.78 \\
\hline West of 494 & 1647 & 1646,1645 & 0.39 \\
\hline I-494 & 1653 & 1652,1651 & 0.59 \\
\hline Plymouth Road & 5447 & 1657,1656 & 0.58 \\
\hline Ridgedale Drive & 5448 & 1661,1662 & 0.57 \\
\hline Hopkins Crossroad & 5449 & 1670,1669 & 0.6 \\
\hline Shelard Parkway & 5450 & $1676,1677,1678$ & 0.5 \\
\hline US 169 & 5451 & 1682,1683 & 0.39 \\
\hline General Mills Boulevard & 5452 & 1687,1686 & 0.64 \\
\hline Winnetka Avenue South & 5453 & $1693,1694,1695$ & 0.33 \\
\hline Louisiana Avenue South & 5454 & 1698,1699 & 0.49 \\
\hline Colorado Avenue South & 5455 & $1702,1703,1704$ & 0.51 \\
\hline Xenia Avenue South & 1710 & 1708,1709 & 0.52 \\
\hline Highway 100 & 1746,1747 & $1719,1720,1721$ & 0.66 \\
\hline West Wirth Parkway & 1733,1734 & $1730,1731,1732$ & 0.52 \\
\hline East Wirth Parkway & 791,792 & $793,794,795$ & 0.39 \\
\hline Penn Avenue & 780,781 & $783,784,785$ & 0.52 \\
\hline Dunwoody Boulevard & 773,774 & $1737,770,771,772$ & 0.37 \\
\hline Dunwoody Boulevard Exit & - & - & 0.42 \\
\hline
\end{tabular}


Table 50: Westbound Detectors on I-35W

\begin{tabular}{|l|l|l|c|}
\hline \multicolumn{1}{|c|}{ Location } & ML Detector Number & GPL Detector Numbers & Distance (Miles) \\
\hline Dunwoody Boulevard Entrance & - & - & - \\
\hline Dunwoody Boulevard & 773,774 & $767,768,769$ & 0.42 \\
\hline Penn Avenue & 780,781 & $778,778,779$ & 0.37 \\
\hline East Wirth Parkway & 791,792 & $788,789,790$ & 0.52 \\
\hline West Wirth Parkway & 1733,1734 & $1740,1741,1742$ & 0.39 \\
\hline Highway 100 & 1746,1747 & - & 0.52 \\
\hline Colorado Avenue South & 5458 & $1760,1761,1762$ & 1.17 \\
\hline Louisiana Avenue South & 5459 & $1765,1766,5848$ & 0.51 \\
\hline Winnetka Avenue South & 5460 & $1771,1772,5849$ & 0.48 \\
\hline General Mills Boulevard & 5461 & 1776,1777 & 0.36 \\
\hline US 169 & 5462 & 1780,1781 & 0.52 \\
\hline Shelard Parkway & 5463 & $1787,1788,1789$ & 0.49 \\
\hline Hopkins Crossroad & 1792,1793 & 0.5 \\
\hline Ridgedale Drive & 5464 & 1797,1798 & 0.6 \\
\hline Plymouth Road & 5465 & 1801,1802 & 0.57 \\
\hline I-494 & 5466 & 1807,1806 & 0.58 \\
\hline West of 494 & 1808 & 1812,1811 & 0.45 \\
\hline Carlson Parkway Exit & 1813 & - & 0.27 \\
\hline
\end{tabular}

There are four tolling locations each in the westbound and eastbound directions. In the reversible section, there is one tolling location. Table 51 shows the tolling locations and the nearest $\mathrm{ML}$ detectors chosen for analysis.

Table 51: Tolling Locations and ML Detectors on I-394

\begin{tabular}{|l|l|l|l|}
\hline \multicolumn{1}{|c|}{$\begin{array}{c}\text { Eastbound Tolling } \\
\text { Location }\end{array}$} & \multicolumn{1}{|c|}{$\begin{array}{c}\text { Eastbound ML } \\
\text { Detectors }\end{array}$} & \multicolumn{1}{|c|}{$\begin{array}{c}\text { Westbound Tolling } \\
\text { Location }\end{array}$} & $\begin{array}{c}\text { Westbound ML } \\
\text { Detectors }\end{array}$ \\
\hline I-494 & 1653 & East Wirth Parkway & 791,792 \\
\hline Ridgedale Drive & 5448 & Colorado Avenue South & 5455 \\
\hline US 169 & 5451 & US 169 & 5462 \\
\hline Colorado Avenue South & 5455 & Ridgedale Drive & 5465 \\
\hline East Wirth Parkway & 791,792 & West of 494 & 1813 \\
\hline
\end{tabular}

\section{Performance Metrics}

The performance metrics for the I-394 facility were calculated for both segments for the entire 2016 and 2017 period. The results are discussed as follows.

Travel Time Savings: The weighted TTS was 3.88 minutes in the eastbound direction and 1.77 in the westbound direction. The overall weighted TTS was 2.74 minutes in I-394.

Variability Benefit: The variability benefit for using the MLs compared to the GPLs was 1.47 in the eastbound direction and 2.21 in the westbound direction. The variability benefit for using I-394 was 1.87 . 
Planning Time Index Benefit: The FFS was estimated to be $62.8 \mathrm{mph}$ in the eastbound direction and 62.2 in the westbound direction. The PTI was then computed for both the ML and the GPLs, as shown in Table 52.

Table 52: PTI Values for GPL and ML for I-394

\begin{tabular}{|l|c|c|}
\hline \multicolumn{1}{|c|}{ Route } & PTI for GPL & PTI for ML \\
\hline Eastbound segment & 1.61 & 1.09 \\
\hline Westbound segment & 1.55 & 1.18 \\
\hline
\end{tabular}

Finally, the planning time index benefit was calculated, as shown in Table 53 . The overall planning time index benefit was 0.44 .

Table 53: Planning Time Index Benefit for I-394

\begin{tabular}{|l|c|c|}
\hline \multicolumn{1}{|c|}{ Route } & Eastbound Segment & Westbound Segment \\
\hline $\begin{array}{l}\text { Planning time index } \\
\text { benefit }\end{array}$ & 0.52 & 0.37 \\
\hline
\end{tabular}

Ability of the toll to impact congestion: This metric was calculated considering traffic and tolls for both routes. Table 54 shows the results for the I-394 facility.

Table 54: Ability of the Toll to Impact Congestion on I-394

\begin{tabular}{|c|c|c|c|c|c|}
\hline $\begin{array}{c}\text { Toll } \\
\text { Interval }\end{array}$ & $\begin{array}{c}\text { Average } \\
\text { Toll } \mathbf{( \$ )}\end{array}$ & $\begin{array}{c}\text { Average } \mathbf{M L} \\
\text { Throughput } \\
\text { (vph) }\end{array}$ & $\begin{array}{c}\text { Percent Change in } \\
\text { Average Vehicle } \\
\text { Throughput in the } \mathbf{M L}\end{array}$ & $\begin{array}{c}\text { Percent } \\
\text { Increase in } \\
\text { Toll }\end{array}$ & $\begin{array}{c}\text { Toll Ability to } \\
\text { Impact Congestion }\end{array}$ \\
\hline 0.25 to 1 & 0.655 & 844 & - & - & - \\
\hline 1.25 to 2 & 1.540 & 1,118 & $32.39 \%$ & $135.30 \%$ & 0.239 \\
\hline 2.25 to 3 & 2.560 & 1,176 & $5.27 \%$ & $66.16 \%$ & 0.080 \\
\hline 3.25 to 4 & 3.510 & 1,161 & $-1.31 \%$ & $37.15 \%$ & -0.035 \\
\hline 4.25 to 5 & 4.585 & 1,077 & $-7.27 \%$ & $22.25 \%$ & -0.238 \\
\hline 5.25 to 6 & 5.605 & 988 & $-8.20 \%$ & $16.94 \%$ & -0.369 \\
\hline 6.25 to 7 & 6.555 & 968 & $-2.05 \%$ & $18.83 \%$ & -0.121 \\
\hline 7.25 to 8 & 7.789 & 926 & $-4.35 \%$ & & -0.231 \\
\hline
\end{tabular}

Speed Thresholds: Table 55 shows the results of the speed thresholds.

Table 55: Percent of Time Speeds Exceeded the Speed Threshold for I-394

\begin{tabular}{|l|c|c|}
\hline \multirow{2}{*}{ Speed Threshold and Lanes } & \multicolumn{2}{|c|}{ Route } \\
\cline { 2 - 3 } & Eastbound Segment & Westbound Segment \\
\hline $\mathrm{ML}>45 \mathrm{mph}$ & 98 & 99 \\
\hline $\mathrm{ML}>50 \mathrm{mph}$ & 96 & 87 \\
\hline $\mathrm{GPL}>45 \mathrm{mph}$ & 89 & 98 \\
\hline $\mathrm{GPL}>50 \mathrm{mph}$ & 80 & 75 \\
\hline
\end{tabular}

Speed Graphs: Figure 38 and Figure 39 show the four-quadrant speed graphs for the two routes. 




Figure 38: Graphical Display of Performance for Eastbound Segment in I-394

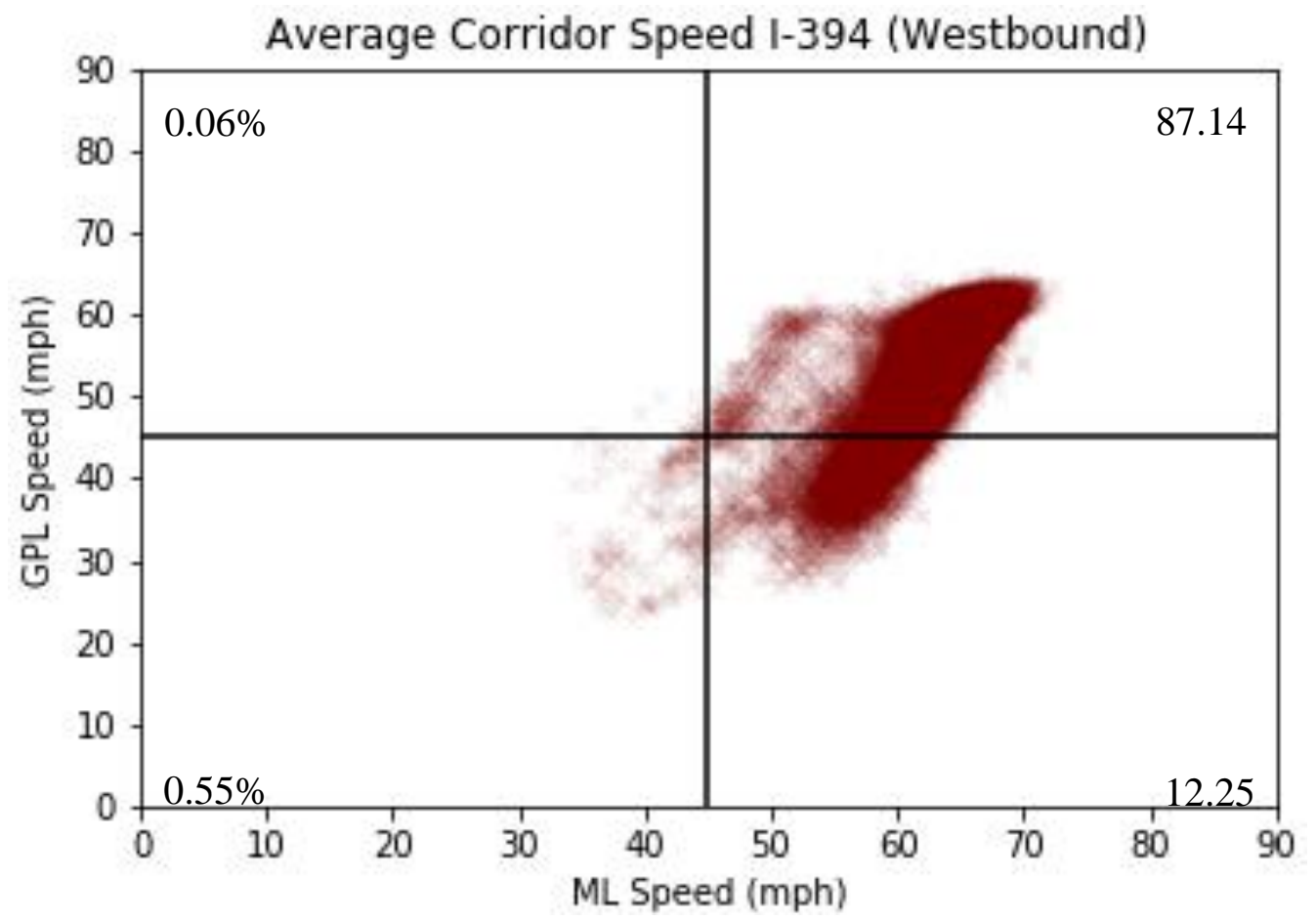

Figure 39: Graphical Display of Performance for Westbound Segment in I-394

Scoring Index: The same procedure as discussed for I-35W was used to calculate the scoring index. Figure 40 and Figure 41 show the flow-density and flow-speed fundamental diagrams, respectively, for eastbound. It was confirmed that the lane capacity is approximately 1,900 vph 
in the eastbound direction. Similarly, the lane capacity in the westbound direction was estimated to be 1,700 vph. Figure 42 and Figure 43 show the fundamental flow-density and flow speed plots, respectively, for southbound.

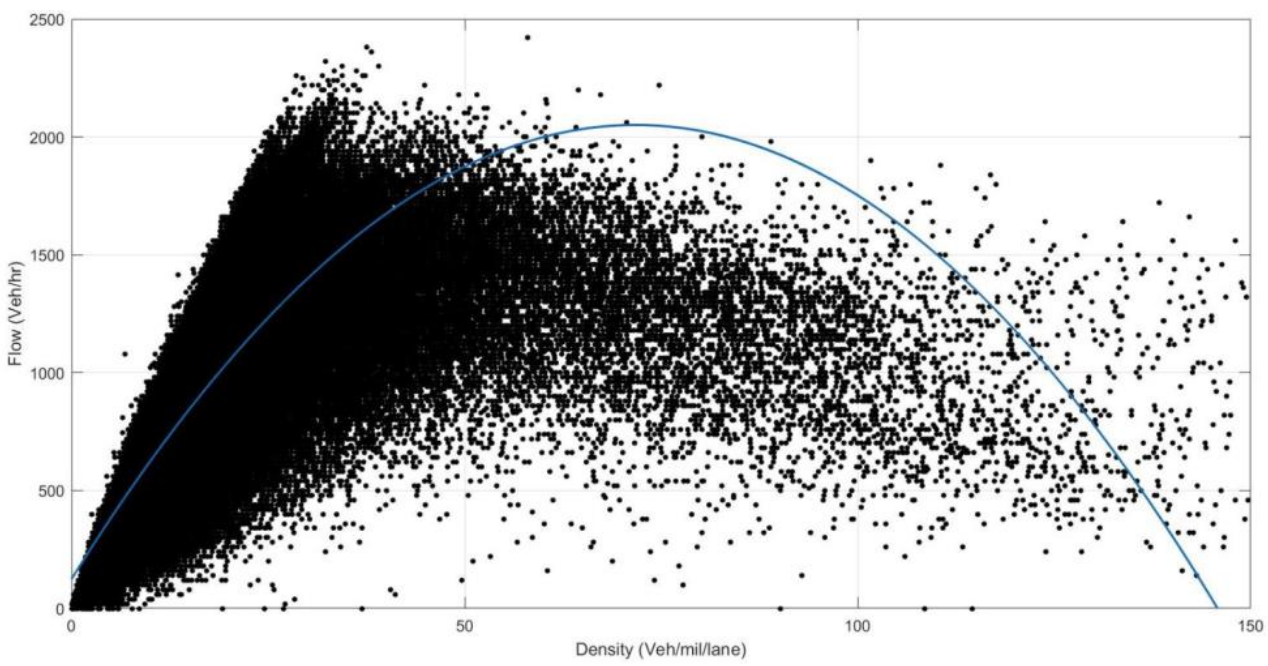

Figure 40: Flow-Density Plot for I-394 Eastbound

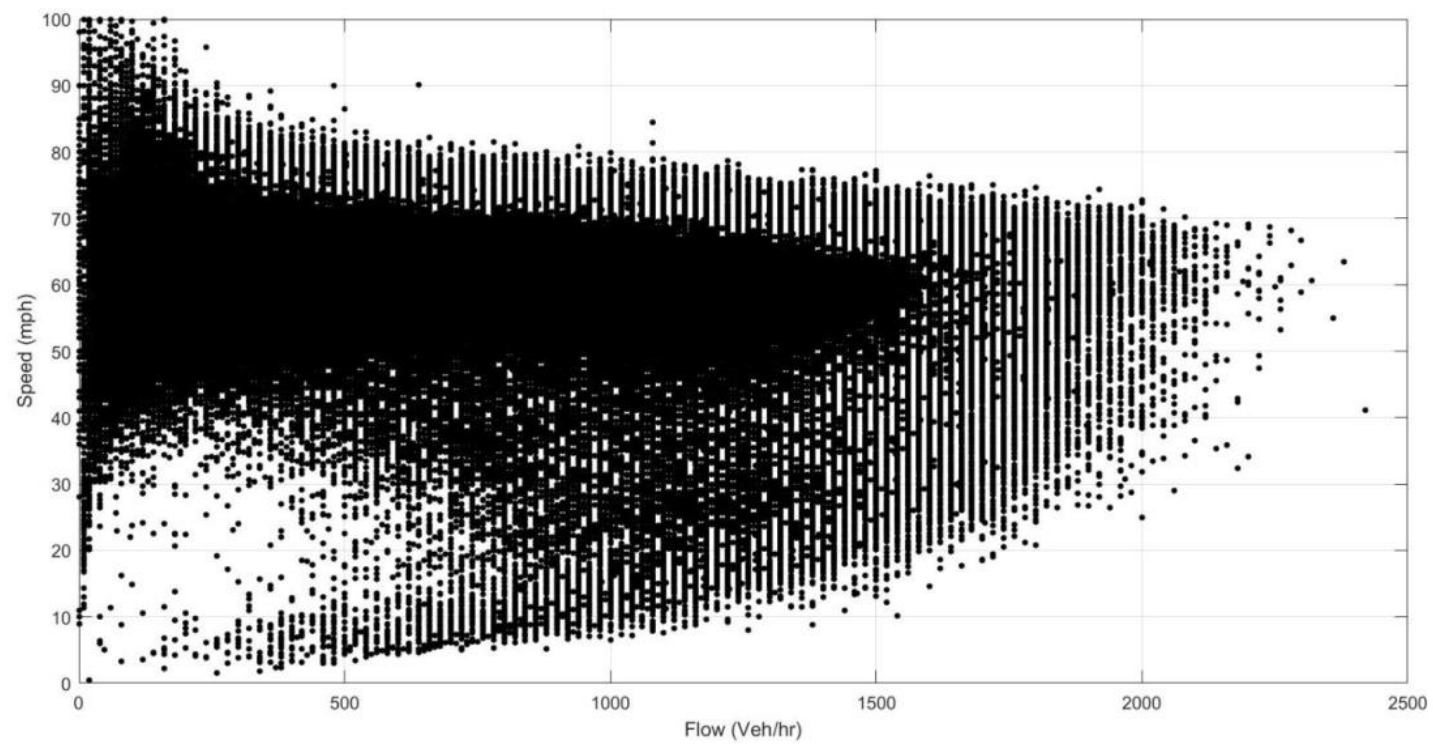

Figure 41: Flow-Speed Plot for I-394 Eastbound 


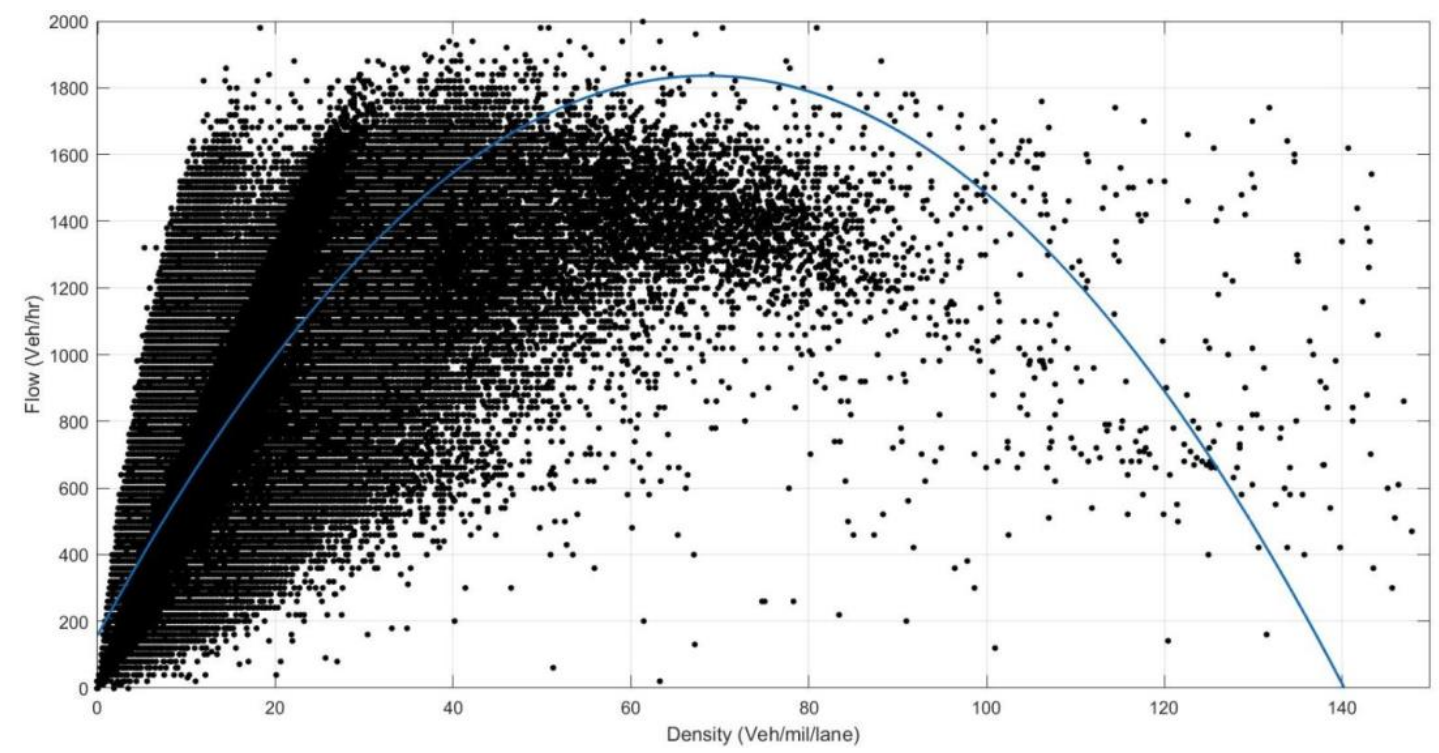

Figure 42: Flow-Density Plot for I-394 Westbound

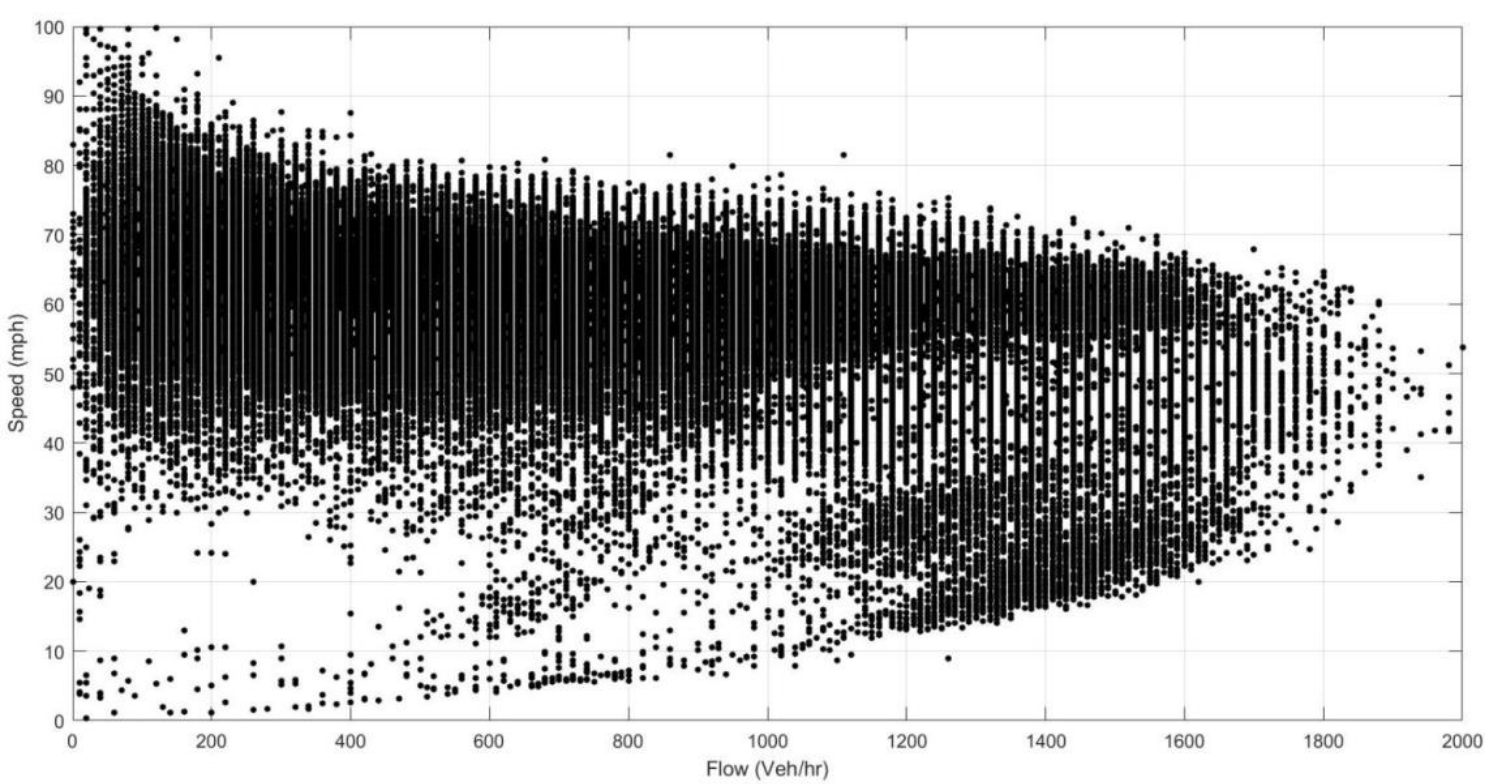

Figure 43: Flow-Speed Plot for I-394 Westbound

The scoring index was calculated near the tolling locations for eastbound and westbound, shown in Table 56. The overall weighted score for eastbound and westbound was 0.85 and 0.94, respectively. Again, these were weighted by direction, and the final score for I-394 was 0.88 . 
Table 56: Scoring Index for I-394

\begin{tabular}{|l|r|r|l|c|c|}
\hline \multicolumn{2}{|c|}{ Eastbound } & \multicolumn{4}{c|}{ Westbound } \\
\hline \multicolumn{1}{|c|}{ Tolling Location } & ML Volume & Score & \multicolumn{1}{c|}{ Tolling Location } & ML Volume & Score \\
\hline West of 494 & 667,611 & 0.94 & East Wirth Parkway & $1,143,097$ & 0.80 \\
\hline Ridgedale Drive & $1,174,356$ & 0.95 & Colorado Avenue South & $1,471,319$ & 0.87 \\
\hline US 169 & $1,501,987$ & 0.70 & US 169 & $1,485,695$ & 0.94 \\
\hline Colorado Avenue South & $1,573,012$ & 0.80 & Ridgedale Drive & $1,147,974$ & 0.99 \\
\hline East Wirth Parkway & $1,386,037$ & 0.96 & West of 494 & 882,257 & 0.99 \\
\hline
\end{tabular}

\section{I-35E Express Lanes}

\section{Facility Overview}

The I-35E Express Lanes opened in 2015 and 2016. The northbound MLs always operate in the afternoon peak from 3 to 7 p.m., while the southbound ML operates in the morning peak from 6 to 10 a.m. The MLs are tolled only on weekdays.

For this research, the southbound segment was analyzed for 2017 because the entire route was operational in 2017. At the same time, the northbound segment was analyzed separately because two distinct routes were available. The northbound segment 1 was analyzed for 2016 and 2017, while the northbound segment 2 was analyzed for only 2017. Table 57 shows the routes. Figure 44 shows a map of the I-35E facility.

Table 57: Analyzed Routes for I-35E Express Lanes

\begin{tabular}{|l|l|c|l|}
\hline \multicolumn{1}{|c|}{ Route } & \multicolumn{1}{|c|}{ Location } & $\begin{array}{c}\text { Distance } \\
\text { (Miles) }\end{array}$ & \multicolumn{1}{c|}{ Operating Hours } \\
\hline NB segment 1 & Cayuga Street to Little Canada Road & 3.85 & 3 to 7 p.m. \\
\hline NB segment 2 & County Road E to County Road J & 5.47 & 3 to 7 p.m. \\
\hline SB segment & County Road 96 to Cayuga Street & 8.87 & 6 to 10 a.m. \\
\hline
\end{tabular}




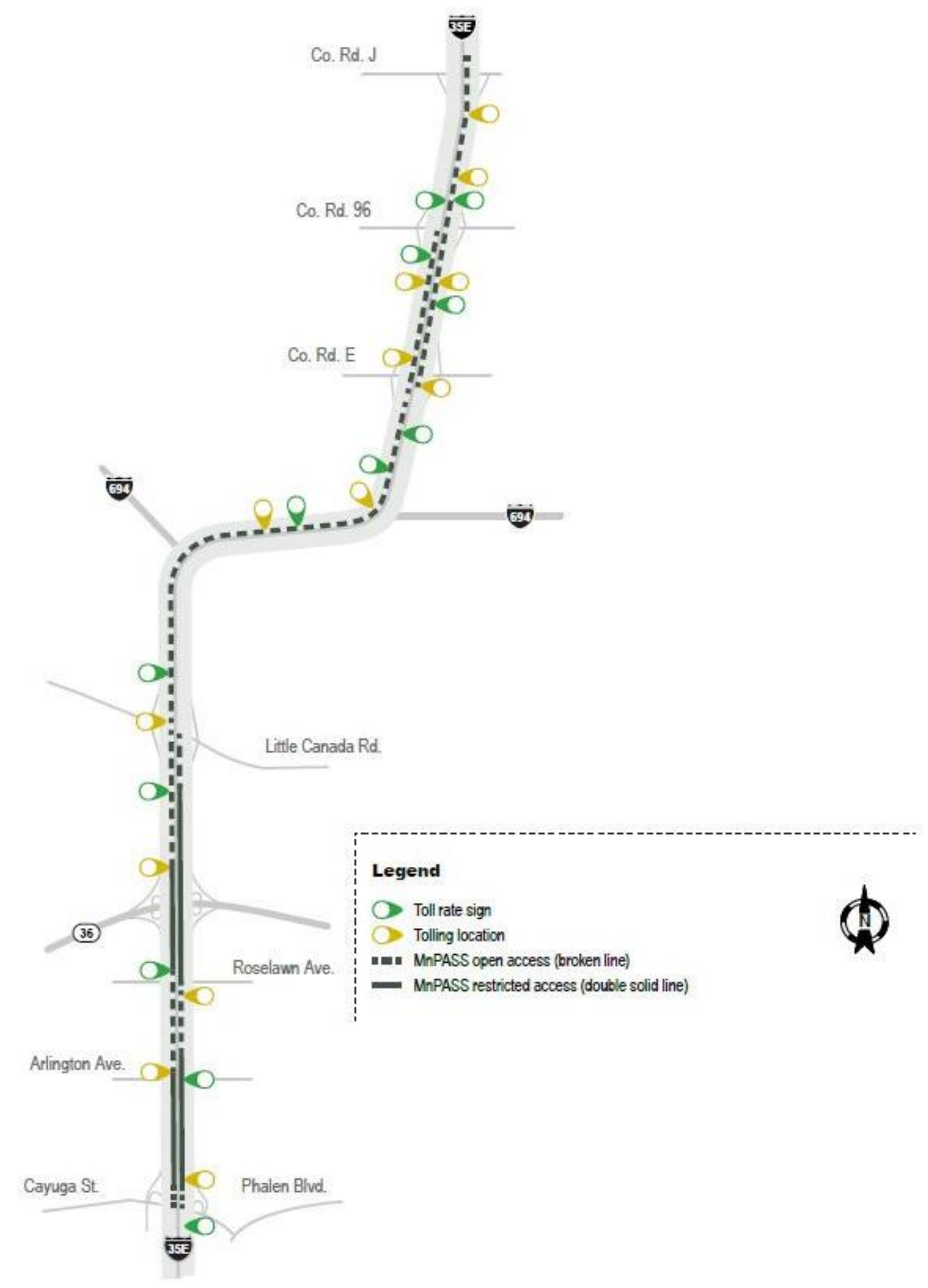

Figure 44: Map of MnPASS I-35E Express Lanes (Source: www.mnpass.org)

There are 7 and $10 \mathrm{ML}$ and GPL detector stations in NB segment 1 and NB segment 2, respectively. There are 13 detector stations in the southbound segment. There are one $\mathrm{ML}$ and two to four GPLs in each direction. Similar to the other MnPASS lanes discussed previously, the $\mathrm{ML}$ is always the leftmost lane in each direction. Table 58 and Table 59 show the location of the northbound detectors. Table 60 shows the location of southbound detectors. 
Table 58: Northbound Segment 1 Detectors on I-35E

\begin{tabular}{|l|l|l|c|}
\hline \multicolumn{1}{|c|}{ Location } & $\begin{array}{c}\text { ML Detector } \\
\text { Number }\end{array}$ & \multicolumn{1}{|c|}{ GPL Detector Number } & $\begin{array}{c}\text { Distance } \\
\text { (Miles) }\end{array}$ \\
\hline Cayuga Street Start & - & - & - \\
\hline Jenks Avenue & 7132 & $7131,2391,2390,2389$ & 0.3 \\
\hline Maryland Avenue & 7133 & $2395,2394,2393$ & 0.49 \\
\hline Wheelock Avenue & 7561 & $2399,2398,2397$ & 0.58 \\
\hline Larpenteur Avenue & 7560 & $2403,2402,2401$ & 0.4 \\
\hline Roselawn Avenue & 7559 & $2408,2407,2406$ & 0.54 \\
\hline Catbird Circle & 7558 & $2412,2411,2410$ & 0.36 \\
\hline T.H. 36 & 7557 & $2416,2415,2414$ & 0.46 \\
\hline Little Canada Road Exit & - & - & 0.72 \\
\hline
\end{tabular}

Table 59: Northbound Segment 2 Detectors on I-35E

\begin{tabular}{|l|l|l|c|}
\hline \multicolumn{1}{|c|}{ Location } & \multicolumn{1}{|c|}{$\begin{array}{c}\text { ML Detector } \\
\text { Number }\end{array}$} & \multicolumn{1}{|c|}{$\begin{array}{c}\text { GPL Detector } \\
\text { Number }\end{array}$} & $\begin{array}{c}\text { Distance } \\
\text { (Miles) }\end{array}$ \\
\hline County Road E Start & - & - & - \\
\hline Co Road East & 5485 & 5484,5483 & 0.22 \\
\hline Goose Lake Road & 7702 & 6359,6358 & 0.59 \\
\hline North of Goose Lake Road & 7703 & 6361,6360 & 0.47 \\
\hline South of CR 96 & 7704 & 6363,6362 & 0.65 \\
\hline North of CR 96 & 7834 & 6369,6368 & 1.1 \\
\hline Constellation Drive & 7835 & 6371,6370 & 0.33 \\
\hline County Road H2 & 7836 & 6373,6372 & 0.71 \\
\hline North of County Road H2 & 7837 & 6375,6374 & 0.3 \\
\hline South of County Road J & 7838 & 6377,6376 & 0.56 \\
\hline County Road J & 7839 & 6380,6379 & 0.5 \\
\hline County Road J Exit & - & - & 0.04 \\
\hline
\end{tabular}

Table 60: Southbound Segment Detectors on I-35E

\begin{tabular}{|l|l|l|c|}
\hline \multicolumn{1}{|c|}{ Location } & \multicolumn{1}{|c|}{$\begin{array}{c}\text { ML Detector } \\
\text { Number }\end{array}$} & \multicolumn{1}{|c|}{$\begin{array}{c}\text { GPL Detector } \\
\text { Number }\end{array}$} & $\begin{array}{c}\text { Distance } \\
\text { (Miles) }\end{array}$ \\
\hline County Road 96 Start & - & - & - \\
\hline South of County Road 96 & 7705 & 6439,6438 & 0.43 \\
\hline North of Goose Lake Road & 7706 & 6441,6440 & 0.63 \\
\hline Goose Lake Road & 7707 & 6443,6442 & 0.52 \\
\hline County Road East & 5491 & 5490,5489 & 0.55 \\
\hline I-694 East Junction & 7830 & 7829,7828 & 0.83 \\
\hline I-694 & 5500 & 5499,5498 & 1.25 \\
\hline Little Canada Road & 5501 & $2426,2427,2428$ & 0.77 \\
\hline T.H. 36 & 7552 & $2430,2431,2432$ & 0.77 \\
\hline Catbird Circle & 7551 & $2437,2436,2435$ & 0.45 \\
\hline Roselawn Avenue & 7550 & $2442,2443,2444$ & 0.36 \\
\hline Larpenteur Avenue & 7549 & $2449,2448,2447$ & 0.54 \\
\hline Wheelock Avenue & 7548 & $2450,2451,2452$ & 0.39 \\
\hline Maryland Avenue & 7134 & $2458,2459,2460$ & 0.82 \\
\hline Cayuga Street End & - & - & 0.56 \\
\hline
\end{tabular}


There are six tolling locations northbound and seven tolling locations southbound. Table 61 shows the tolling locations and the nearest ML detectors chosen for analysis.

Table 61: Tolling Locations and ML Detectors on I-35E

\begin{tabular}{|l|l|l|l|}
\hline \multicolumn{1}{|c|}{$\begin{array}{c}\text { Northbound Tolling } \\
\text { Location }\end{array}$} & Northbound ML Detector & \multicolumn{1}{|c|}{$\begin{array}{c}\text { Southbound Tolling } \\
\text { Location }\end{array}$} & Southbound ML Detector \\
\hline Cayuga Street & 7132 & County Road 96 & 7706 \\
\hline Roselawn & 7559 & County Road East & 5491 \\
\hline County Road East & 5485 & I-694 East Junction & 7830 \\
\hline Goose Lake Road & 7703 & I-694 & 5500 \\
\hline County Road 96 & 7835 & Little Canada Road & 5501 \\
\hline County Road H2 & 7836 & T.H. 36 & 7552 \\
\hline- & - & Arlington Avenue & 7548 \\
\hline
\end{tabular}

\section{Performance Metrics}

The performance metrics for the I-35E facility were calculated for all three routes, and the results are discussed as follows.

Travel Time Savings: The weighted TTS was calculated for the routes, as shown in Table 62. The TTS for using the I-35E facility was 1.03.

Table 62: Performance Metrics for I-35E Routes

\begin{tabular}{|l|c|c|c|}
\hline \multicolumn{1}{|c|}{ Route } & NB Segment 1 & NB Segment 2 & SB Segment \\
\hline TTS (minutes) & 1.00 & 0.41 & 1.72 \\
\hline Variability benefit & 2.30 & 2.34 & 2.19 \\
\hline FFS (mph) & 67.8 & 73.3 & 68.6 \\
\hline PTI for GPL & 1.70 & 1.22 & 1.51 \\
\hline PTI for ML & 1.22 & 1.08 & 1.20 \\
\hline $\begin{array}{l}\text { Planning time index } \\
\text { benefit }\end{array}$ & 0.48 & 0.14 & 0.31 \\
\hline
\end{tabular}

Variability Benefit: Table 62 shows the variability benefit for using the MLs compared to the GPLs. The overall variability benefit was 2.26 .

Planning Time Index Benefit: Table 62 shows the planning time index benefit for the routes. The weighted planning time index benefit for I-35E was 0.36 .

Ability of the toll to impact congestion: This metric was calculated considering traffic and tolls for all the routes. Table 63 shows the results for the I-35E facility. 
Table 63: Ability of the Toll to Impact Congestion for Entire I-35E Facility

\begin{tabular}{|l|c|c|c|c|c|}
\hline $\begin{array}{c}\text { Toll } \\
\text { Interval }\end{array}$ & $\begin{array}{c}\text { Average } \\
\text { Toll } \mathbf{( \$ )}\end{array}$ & $\begin{array}{c}\text { Average } \mathbf{M L} \\
\text { Throughput } \\
\text { (vph) }\end{array}$ & $\begin{array}{c}\text { Percent Change in } \\
\text { Average Vehicle } \\
\text { Throughput in the } \mathbf{M L}\end{array}$ & $\begin{array}{c}\text { Percent } \\
\text { Increase in } \\
\text { Toll }\end{array}$ & $\begin{array}{c}\text { Toll Ability to } \\
\text { Impact Congestion }\end{array}$ \\
\hline 0.25 to 1 & 0.670 & 507 & - & - & - \\
\hline 1.25 to 2 & 1.499 & 867 & $71.11 \%$ & $62.79 \%$ & 0.575 \\
\hline 2.25 to 3 & 2.440 & 944 & $8.87 \%$ & $43.37 \%$ & 0.141 \\
\hline 3.25 to 4 & 3.498 & 849 & $-10.08 \%$ & $30.01 \%$ & -0.232 \\
\hline 4.25 to 5 & 4.547 & 746 & $-12.03 \%$ & $24.23 \%$ & -0.401 \\
\hline 5.25 to 6 & 5.649 & 630 & $-15.55 \%$ & $15.14 \%$ & -0.642 \\
\hline 6.25 to 7 & 6.504 & 593 & $-5.85 \%$ & $17.53 \%$ & -0.819 \\
\hline 7.25 to 8 & 7.645 & 508 & $-14.36 \%$ & & \\
\hline
\end{tabular}

Speed Thresholds: The percent of time, the MLs, and the GPLs maintain the FHWA external goal. Table 64 shows the MnPASS internal goal.

Table 64: Percent of Time that Speeds Exceeded the Speed Threshold for I-35E

\begin{tabular}{|l|c|c|c|}
\hline \multirow{2}{*}{\multicolumn{1}{|c|}{ Speed Threshold and Lanes }} & \multicolumn{3}{c|}{ Route } \\
\cline { 2 - 4 } & NB Segment 1 & NB Segment 2 & SB Segment \\
\hline $\mathrm{ML}>45 \mathrm{mph}$ & 100 & 100 & 99 \\
\hline $\mathrm{ML}>50 \mathrm{mph}$ & 99 & 100 & 98 \\
\hline $\mathrm{GPL}>45 \mathrm{mph}$ & 82 & 100 & 95 \\
\hline $\mathrm{GPL}>50 \mathrm{mph}$ & 62 & 99 & 89 \\
\hline
\end{tabular}

Speed Graphs: Figure 45 through Figure 47 show the plotted speed graphs for the three routes.

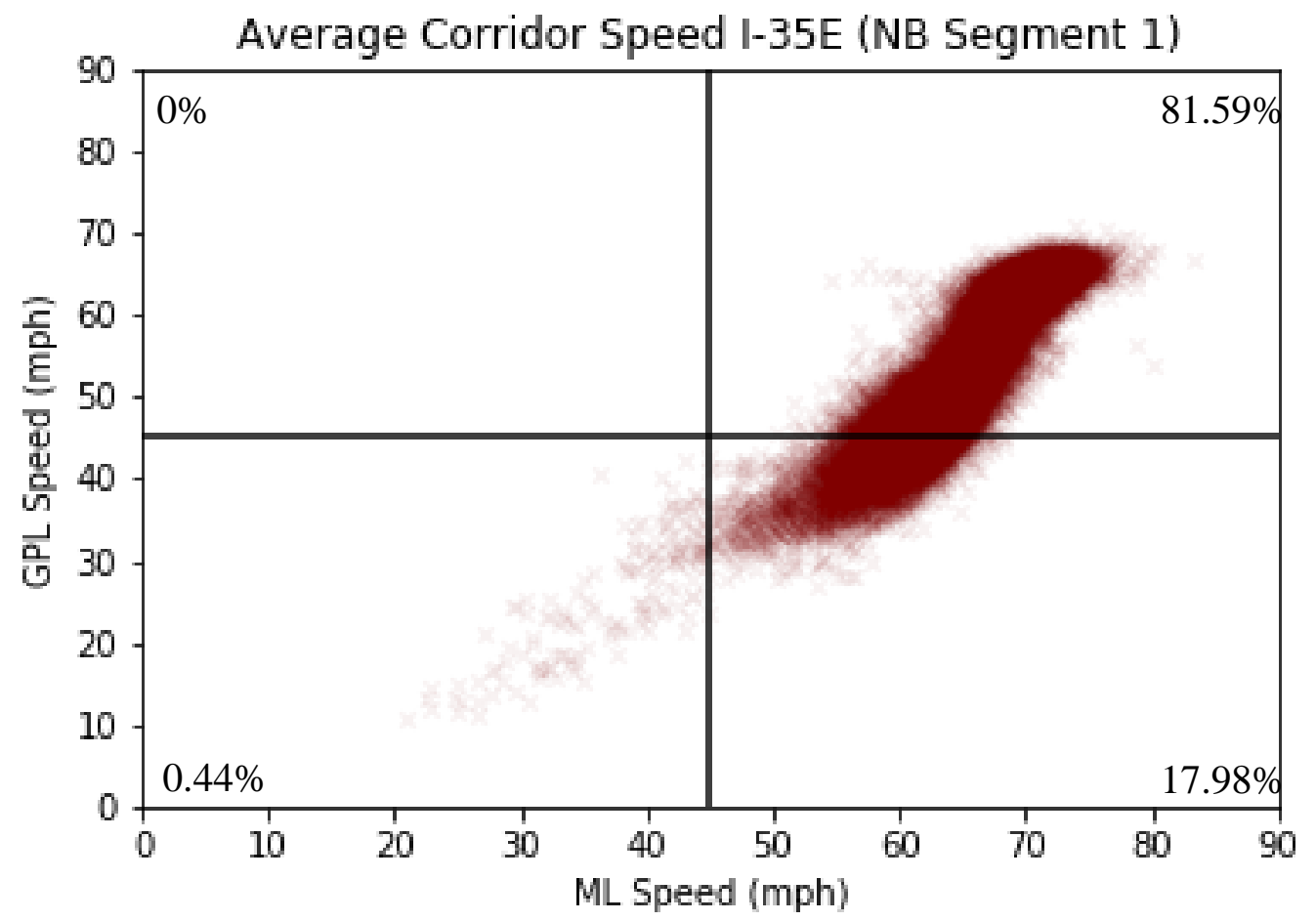

Figure 45: Graphical Display of Performance for Northbound Segment 1 in I-35E 


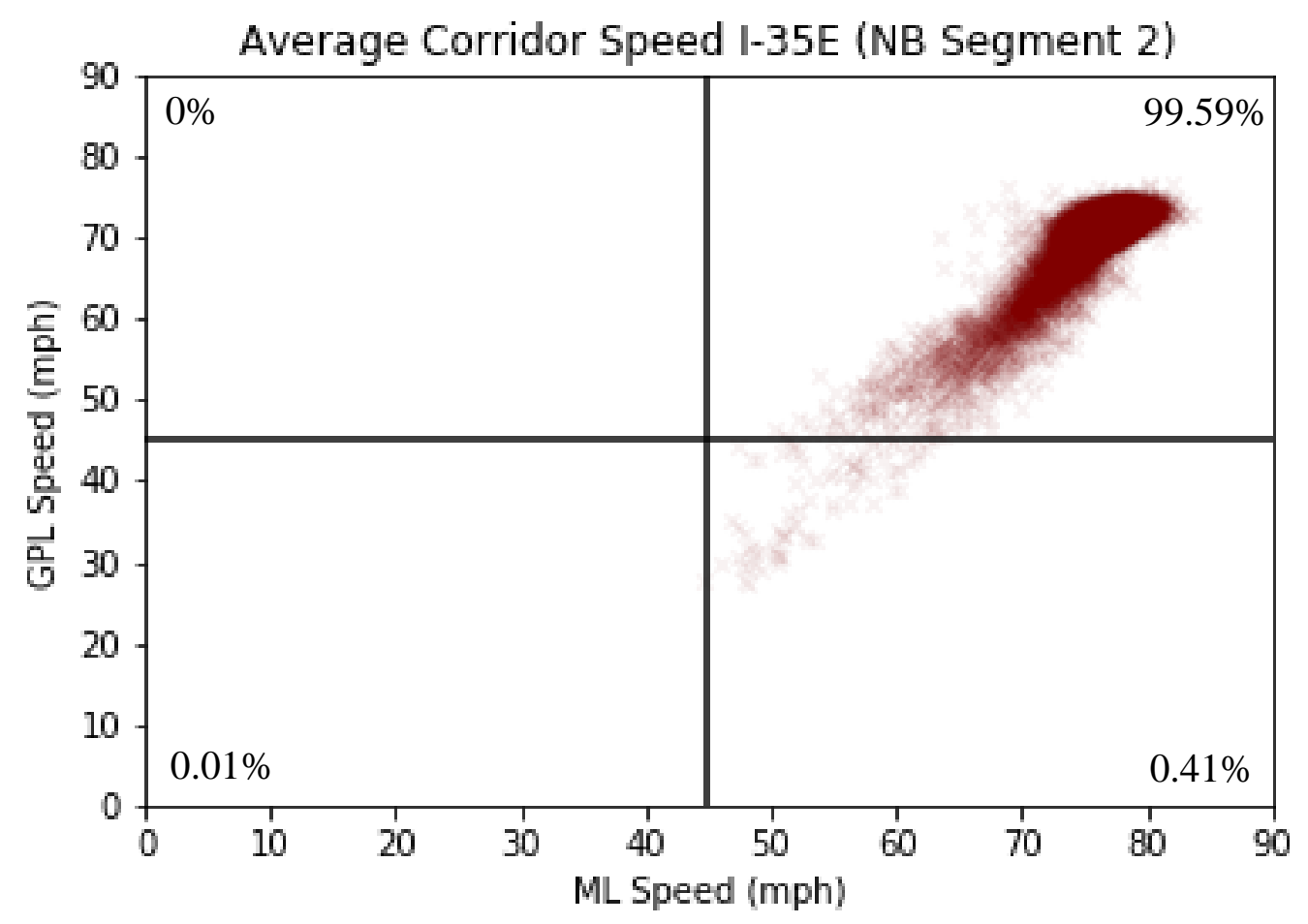

Figure 46: Graphical Display of Performance for Northbound Segment 2 in I-35E

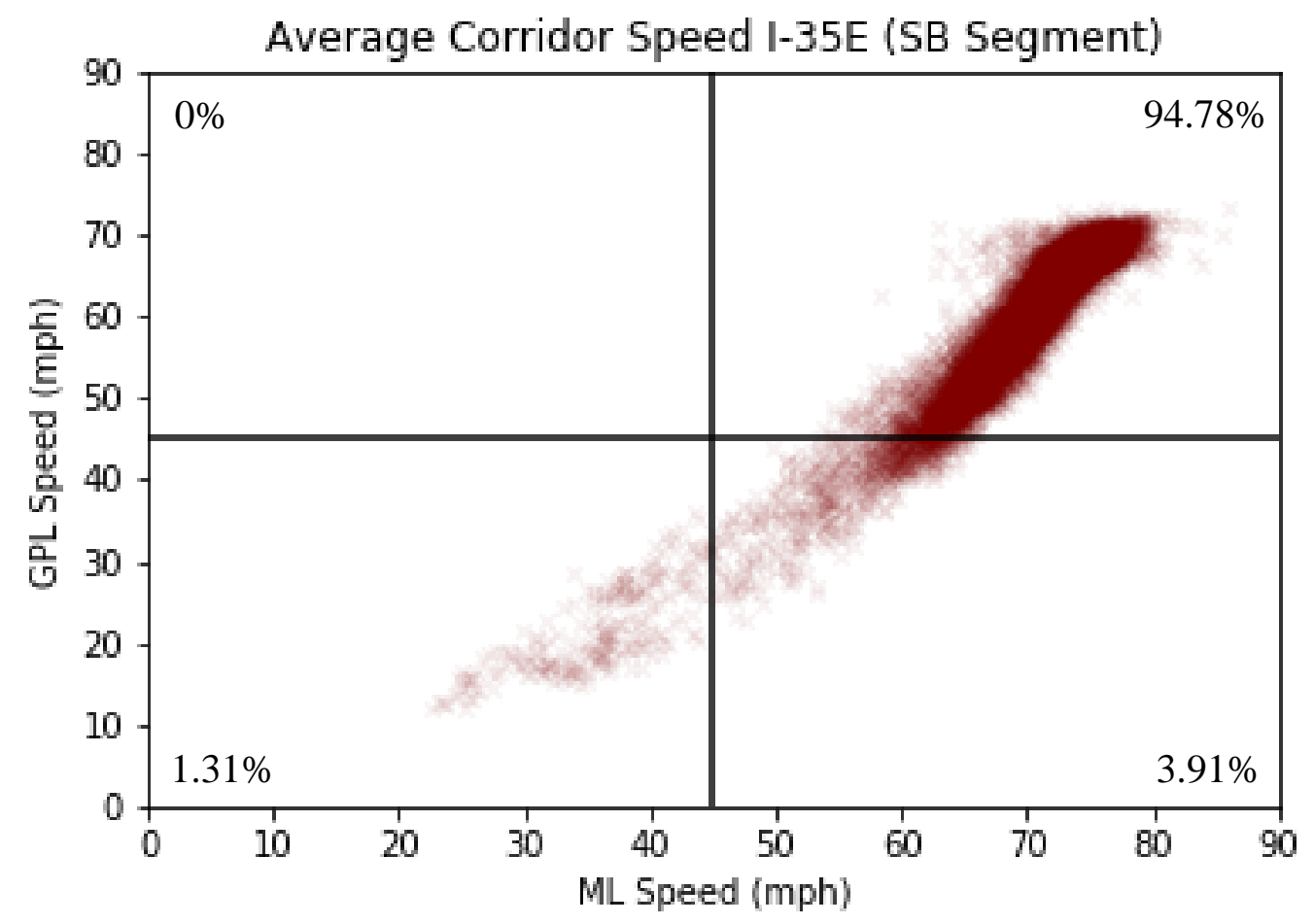

Figure 47: Graphical Display of Performance for Southbound Segment in I-35E

Scoring Index: The scoring index was calculated at some of the detectors for both directions. The approximate lane capacity for northbound was confirmed as $1,500 \mathrm{vph}$. Similarly, the lane 
capacity for southbound was 1,800 vph. Figure 48 through Figure 51 show the fundamental flow-density and flow-speed plots.

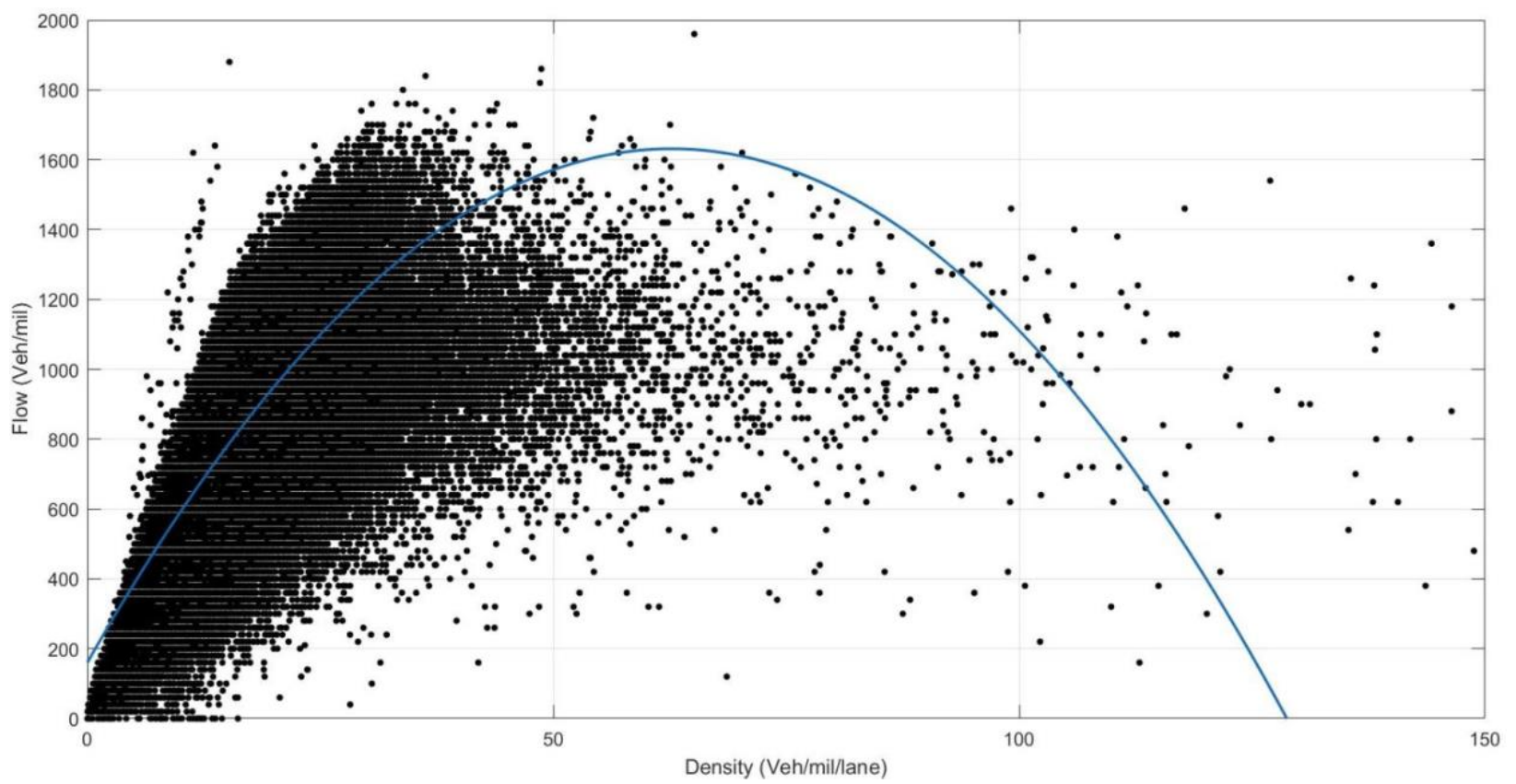

Figure 48: Flow-Density Plot for I-35E Northbound

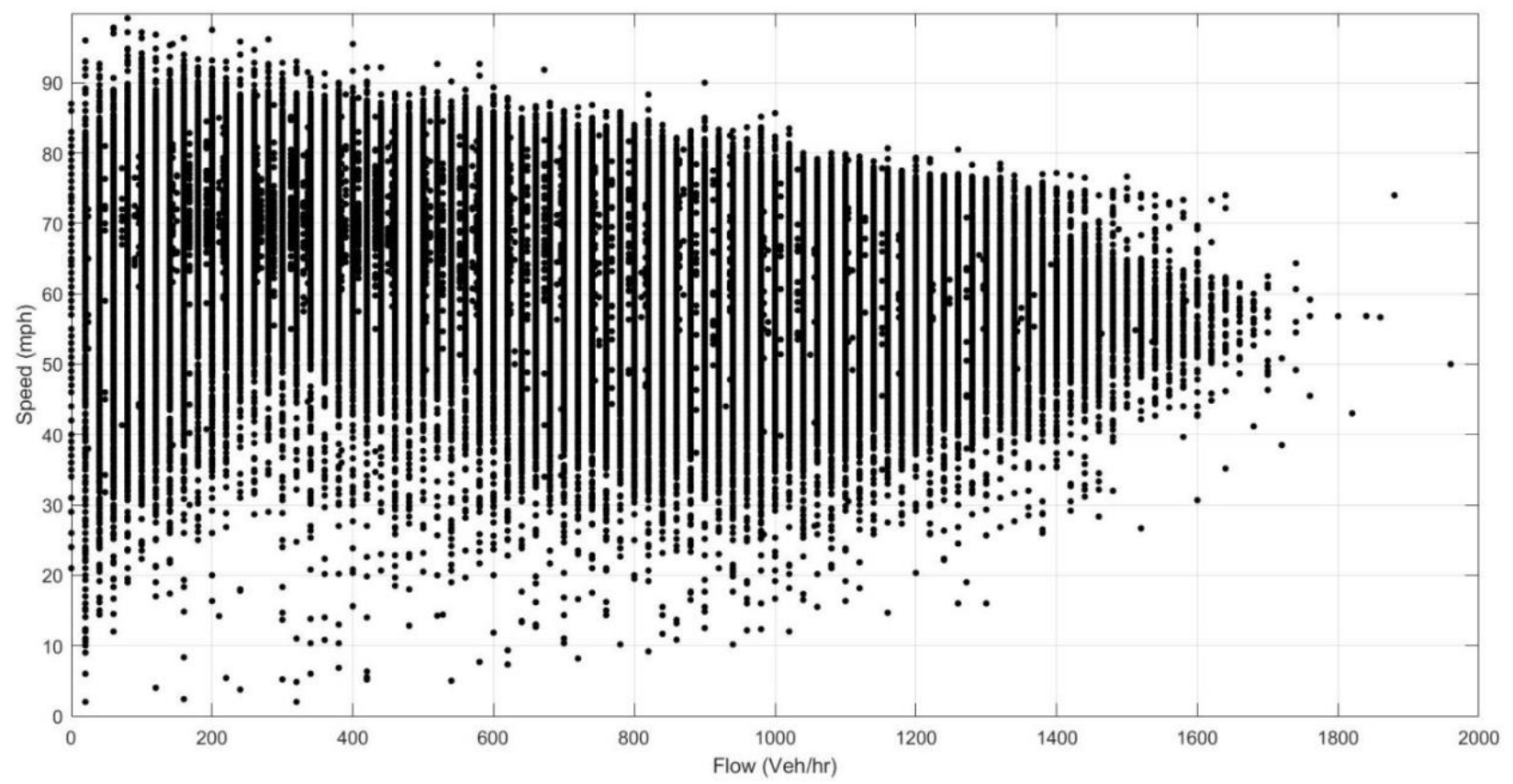

Figure 49: Flow-Speed Plot for I-35E Northbound 


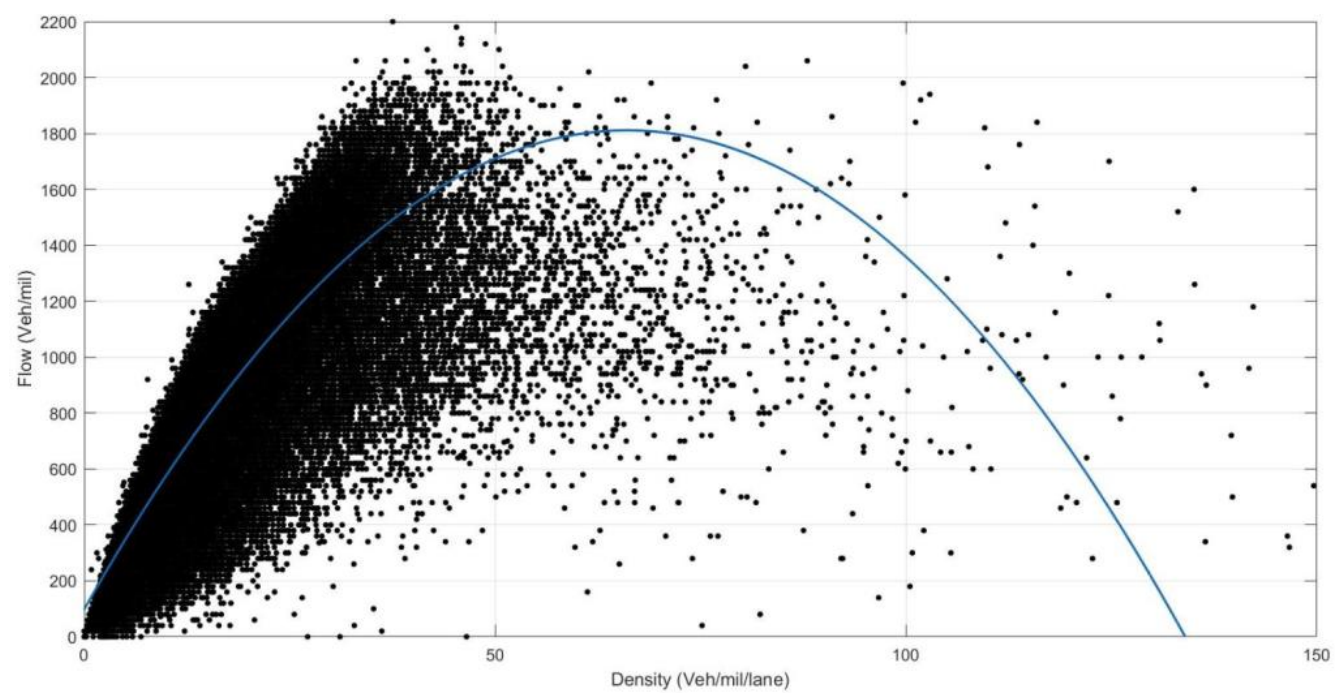

Figure 50: Flow-Density Plot for I-35E Southbound

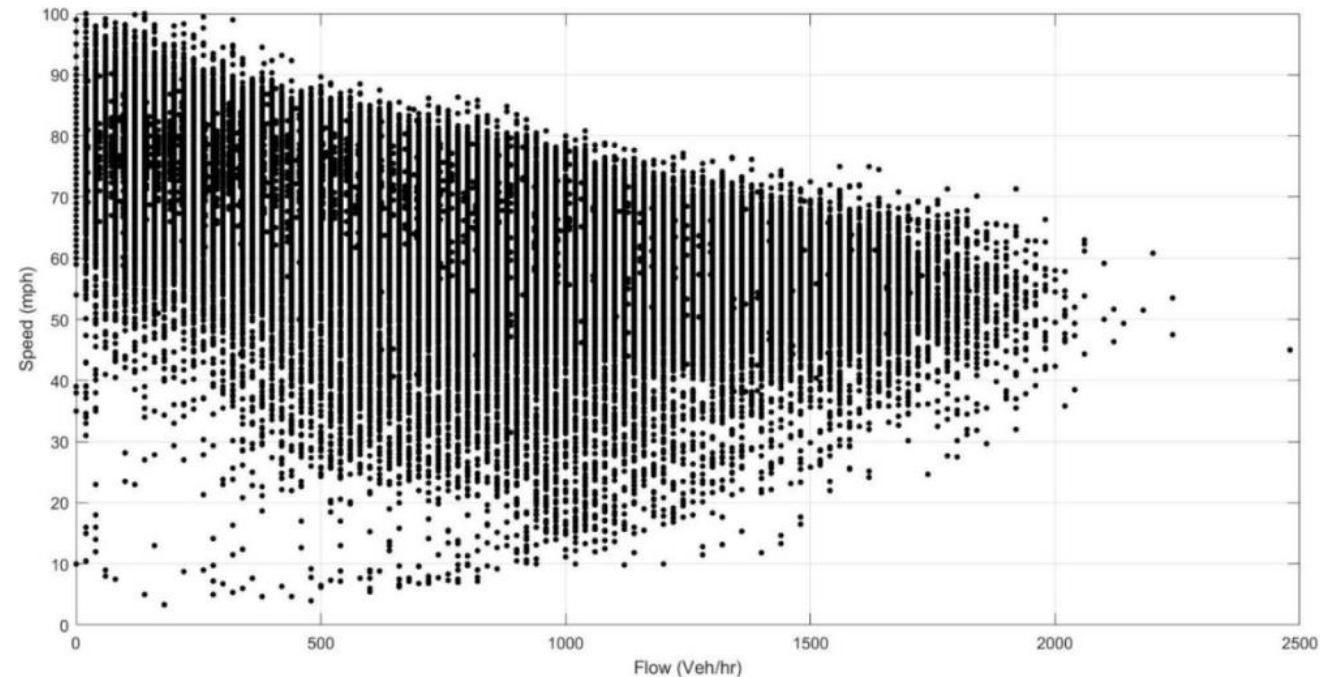

Figure 51: Flow-Speed Plot for I-35E Southbound

Table 65 shows the scores for the various locations. The overall weighted score for northbound and southbound was 0.99 and 0.90 , respectively. Again, these were weighed by direction, and the final score for I-35E was 0.95 .

Table 65: Scoring Index for I-35E

\begin{tabular}{|l|r|r|l|c|c|}
\hline \multicolumn{2}{|c|}{ Northbound } & \multicolumn{3}{c|}{ Southbound } \\
\hline \multicolumn{1}{|c|}{ Location } & $\begin{array}{c}\text { ML } \\
\text { Volume }\end{array}$ & Score & \multicolumn{1}{c|}{ Location } & $\begin{array}{c}\text { ML } \\
\text { Volume }\end{array}$ & Score \\
\hline Wheelock Avenue & $1,389,948$ & 0.98 & North of Goose Lake Road & 297,803 & 0.99 \\
\hline Roselawn Avenue & $1,164,595$ & 0.98 & CR E & 295,948 & 0.98 \\
\hline County Road East & 625,705 & 0.98 & I-694 East Junction & 316,316 & 0.96 \\
\hline North of Goose Lake Road & 570,547 & 1.00 & I-694 & 439,030 & 0.87 \\
\hline County Road H2 & 477,337 & 0.99 & Little Canada Road & 542,857 & 0.85 \\
\hline South of County Road J & 430,478 & 0.99 & T.H. 36 & 637,167 & 0.83 \\
\hline
\end{tabular}




\begin{tabular}{|l|l|l|l|l|l|}
\hline- & - & - & Wheelock Avenue & 761,186 & 0.92 \\
\hline
\end{tabular}

\section{Scoring Summary}

The final step in this research was to compare the performance measures from variably priced facilities with the same performance measures from dynamically priced facilities. Table 66 summarizes these results. The results show that both pricing mechanisms are working. This comes as no surprise because the tolled lanes should be working better than the toll-free lanes, and these numbers confirm it. However, there is no clearly dominate form of pricing because both dynamic and variably priced facilities scored in a similar range. With so few facilities being variably tolled, it is difficult to get enough of a sample to perform a comparison. Ironically, the scoring index for one of the variably priced MLs is the lowest score, while the other has the highest score. All the dynamically priced facilities have scores in between those. This new metric was designed specifically for this comparison, and unfortunately, the results show no clear winner. With additional facilities, a clearly dominate pricing method might become clear. This is recommended for future research. The researchers do believe that these performance measures work well in evaluating the toll's ability to regulate ML demand and keep the ML operating smoothly. 
Table 66: Performance Measures from All Facilities

\begin{tabular}{|c|c|c|c|c|c|c|c|c|}
\hline \multirow[b]{2}{*}{$\begin{array}{l}\text { Performance } \\
\text { Measure }\end{array}$} & \multicolumn{3}{|c|}{ Variable Pricing } & \multicolumn{5}{|c|}{ Dynamic Pricing } \\
\hline & $\begin{array}{c}\text { SR-91 } \\
\text { (Orange } \\
\text { County } \\
\text { Portion) } \\
\end{array}$ & $\begin{array}{c}\text { I-25 North Express } \\
\text { Lanes }\end{array}$ & Average & I-35W & I-394 & I-35E & MoPac & Average \\
\hline TTS & 0.45 & 2.56 & 1.51 & 1.44 & 2.74 & 1.03 & 1.68 & 1.72 \\
\hline $\begin{array}{l}\text { Variability } \\
\text { benefit }\end{array}$ & 1.53 & 2.26 & 1.90 & 2.08 & 1.87 & 2.26 & 1.14 & 1.84 \\
\hline $\begin{array}{l}\text { Planning time } \\
\text { index benefit }\end{array}$ & 0.11 & 0.56 & 0.34 & 0.34 & 0.44 & 0.36 & 0.51 & 0.41 \\
\hline $\begin{array}{l}\text { Ability of the } \\
\text { toll to impact } \\
\text { congestion }\end{array}$ & $\begin{array}{l}\text { Positive } \\
\text { values at all } \\
\text { prices. Very } \\
\text { small (0.04) } \\
\text { at maximum } \\
\text { price. }\end{array}$ & $\begin{array}{l}\text { Small } \\
\text { negative/positive } \\
\text { at higher prices. } \\
\text { Large positive at } \\
\text { lower prices. }\end{array}$ & & $\begin{array}{l}\text { Small } \\
\text { positive } \\
\text { numbers at } \\
\text { higher prices. }\end{array}$ & $\begin{array}{l}\text { Small } \\
\text { negative } \\
\text { numbers at } \\
\text { higher prices. }\end{array}$ & $\begin{array}{l}\text { Large } \\
\text { negative } \\
\text { numbers at } \\
\text { higher prices. }\end{array}$ & $\begin{array}{l}\text { Small positive at } \\
\text { lower prices. } \\
\text { Slightly larger } \\
\text { positive/negative } \\
\text { at highest prices. }\end{array}$ & - \\
\hline $\begin{array}{l}\text { Achieve } \\
45 \text { mph goal } \\
\text { (percent of } \\
\text { time) }\end{array}$ & No (82\%) & Yes (97.5\%) & Yes $(90 \%)$ & Yes $(97 \%)$ & Yes (99\%) & Yes $(100 \%)$ & No $(87.5 \%)$ & Yes (96\%) \\
\hline $\begin{array}{l}\text { Achieve } \\
\text { internal speed } \\
\text { goal (percent of } \\
\text { time) }\end{array}$ & Yes $(90 \%)$ & N/A & Yes $(90 \%)$ & Yes $(93.5 \%)$ & Yes $(91.5 \%)$ & Yes (99\%) & Yes (95\%) & Yes (95\%) \\
\hline Scoring index & 0.45 & 0.97 & 0.71 & 0.75 & 0.88 & 0.95 & 0.86 & 0.86 \\
\hline
\end{tabular}




\section{Conclusion}

This research examined traffic data from two variably priced MLs (SR-91 and I-25) and four dynamically priced MLs (I-35W, I-394, I-35E, and MoPac). In theory, dynamic pricing should be more responsive to short-term fluctuations in traffic and be better able to maintain a high level of flow on the MLs. The downside is that dynamic pricing requires more data to set the price, and that requires additional sensors. Dynamic pricing is also a more difficult concept for the public and elected officials to understand and try.

The six MLs were examined based on seven metrics:

1. TTS: the average travel time saved by users of the MLS.

2. Variability benefit: defined as the standard deviation of travel times on the GPLs divided by the standard deviation of travel times on the MLs. The larger this ratio, the more reliable the MLs are compared to the GPLs.

3. Planning time index benefit: measures the reliability of the lanes. It is the difference between the planning time index of the GPLs minus the planning time index of the MLs. The planning time index is the ratio of the 95th percentile travel time divided by the free-flow travel time. Thus, it is how much longer (in percent) it takes to travel that route on a congested day versus uncongested travel.

4. Ability of the toll to impact congestion: examines the elasticity of demand on the MLs.

5. Speed threshold: the average travel speed of vehicles was found, and the percentage of the time that the average speed exceeded a given threshold was determined.

6. Speed graphs: a graphical display of performance of several of these metrics. The graph simply has a single point for the speed on both the GPLs and MLs for each time interval.

7. Scoring index: a new metric that simply gives the $E L$ a score from -3 to +3 based on the speed and flow on the MLs and GPLs. The larger positive numbers indicate that the MLS are operating at a high level with flow near or exceeding capacity while speeds are also high, while GPLs are congested. This indicates the toll is functioning well. Negative scores indicate the MLs are functioning poorly.

Based on these metrics, both the variably priced and dynamically priced lanes were functioning well. There were too few lanes and too little difference in their scores to definitively say one type of pricing was clearly better than the other. However, the dynamically priced lanes appear to have a slight edge in several metrics. The average of the metrics was calculated for both types of priced facilities. The dynamically priced lanes appear to have an edge in most of the metrics. The metrics of travel time savings, planning time index benefit, speed threshold, and scoring index were better for the dynamically priced facilities. Variability benefit was slightly better for the variably priced facilities. However, the magnitude of traffic data was non-uniform for both the facilities (ranging from four months for I-25 to two years for MnPass). Future research could add MLs to this analysis, and that may provide evidence for a clearly dominant pricing mechanism. Future research could also consider the person throughput or vehicle occupancy, instead of the vehicle throughput. The performance metrics could be weighted by 
the number of travelers and not just the number of vehicles and the results compared for both pricing types.

Therefore, the main contribution for this research is a set of metrics that can be used to analyze the ability of price to control congestion on MLs. These seven metrics include both the perspective of the traveler (TTS and variability) and the ML operator (throughput, toll ability to regulate flow, and achievement of speed objective). The scoring index was created as part of this research and provides a unique measure for each $M L$ based on the capacity of that ML and how well traffic flows on that lane compared to adjacent GPLs. 


\section{References}

91 Express Lanes (2019). RCTC 91 Express Lanes Toll. https://www.91expresslanes.com/wpcontent/uploads/2019/03/TollPolicy RCTC.pdf. Accessed Dec. 17, 2020.

Burris, M., and Brady, J. (2018). Unrevealed Preferences: Unexpected Traveler Response to Pricing on Managed Lanes. Transportation Research Record: Journal of the Transportation Research Board, 2672(5), 23-32.

California Department of Transportation (n.d.). I-15 Express Lanes. https://dot.ca.gov/caltransnear-me/district-11/current-projects/i-15-express-lanes. Accessed Dec. 17, 2020.

Cambridge Systematics, Inc. (2014). Express Lanes Reliability Measures.

Chung, C. (2013). A Review and Advance of High-Occupancy Toll Lanes' Toll Schemes. Journal of Eastern Asia Society for Transportation Studies, Vol. 10, 240-259

Colorado Department of Transportation (2020). I-25N Seg 2 (US36 to 120th Ave). : https://www.codot.gov/programs/expresslanes/copy of toll-rates/toll-rates-effectivejuly-20-2018-for-i-25-north-us-36-to-120th-seg-2.pdf. Accessed Sept. 20, 2020.

Fleckenstein, M., Schmit, M., and Khani, A. (2018). I-405 Traffic Data and Corridor Performance Analysis.

Ginn, D., Pryor, D., and Meyers, D. (2018). Arizona Perspectives on Priced Managed Lanes and Toll Roads (2014-2015).

Goodin, G., Burris, M., and Geiselbrecht, T. (2013). Application of a Performance Management Framework for Priced Lanes.

HNTB (2017). District Express Lanes Annual Report.

Hourdos, J. (2015). MnPASS Modeling and Pricing Algorithm Enhancement. Minnesota Department of Transportation, Research Services and Library.

I-77 Mobility Partners, LLC (n.d.). 177 Express Lanes Homepage. https://www.i77express.com/pricing/how-pricing-is-determined/. Accessed Dec. 17, 2020.

Janson, M., and Levinson, D. (2014). HOT or Not. Research in Transportation Economics, 44, 2132.

Kittelson and Associates, Inc. (2013). Southbound I-680 Express Lane Performance Evaluation: An After Study. 
Laval, J., Yin, Y., Lou, Y., and Cho, H. (2012). Comparative Analysis of Dynamic Pricing Strategies for Managed Lanes (2012-089S).

MoPac Express Lane Fact Sheet (2019).

Mobilityauthority.com,.https://www.mobilityauthority.com/upload/files/Fact\%20Sheet s/Toll_Pay_MopacEL_09_09_19.pdf. Accessed Feb. 11, 2021.

Minnesota Department of Transportation (n.d.). MnPASS. http://mnpass.org/. Accessed Dec. 17, 2020].

North Carolina Department of Transportation (2018). I-77 Express Lanes Project Performance Audit. https://www.auditor.nc.gov/EPSWeb/reports/performance/PER-2018-4200.pdf. Accessed Dec. 17, 2020.

Orange County Transportation Authority (OCTA) (n.d.). Homepage. https://www.octa.net/91Express-Lanes/Toll-Schedules. Accessed Sept. 20, 2020.

Orange County Transportation Authority (OCTA) (2020). On the Move. https://blog.octa.net/now-open\%2C-91-project-will-improve-travel-to-riversidecounty/. Accessed Sept. 20, 2020.

Perez, B., Fuhs, C., Gants, C., Giordano, R., and Ungemah, D. (2012). Priced Managed Lane Guide 2012.

Perez, B., Giordano, R., and Stamm, H. (2011). Evaluation and Performance Measurement of Congestion Pricing Projects. Transportation Research Board.

Poe, C., and MacGregor, M. (2008). Design and Operation of the I-30 Tom Landry Managed Lane Value Pricing Project in Dallas, Texas. Texas Transportation Institute. http://www.keepitmovingdallas.com/sites/default/files/hearing\%20schematics/I30WTR B2008Poster251\%205.pdf. Accessed Oct. 22, 2020.

Schultz, G., Mineer, S., Hamblin, C., Halliday, D., Groberg, C., and Burris, M. (2015). I-15 Express Lanes Study Phase II: Recommendations.

Utah Department of Transportation (2020). Keeping Utah Moving. https://www.udot.utah.gov/connect/docs/express-lanes-toll-rate-algorithm/. Accessed Sept. 20, 2020.

Washington State Legislature (n.d.). RCW 47.56.880: Interstate 405 and State Route Number 167 Corridors-Tolls Authorized-Eligible Toll Facility-Toll Rate Schedule-Capacity Improvements-Performance. Measures-Violation.

https://app.leg.wa.gov/rcw/default.aspx?cite=47.56.880. Accessed Dec. 17, 2020. 
Wilbur Smith Associates (2010). Chicago Regional Congestion Pricing Study.

Ye, M. (2017). Dynamic Pricing for Managed Lanes: Synthesis of Current Best Practices and Framework for Integration with Connected and Automated Vehicles. University of Virginia.

Yin, Y., and Lou, Y. (2009). Dynamic Tolling Strategies for Managed Lanes. Journal of Transportation Engineering, 135(2), 45-52.

Yin, Y., Washburn, S., Wu, D., Kulshrestha, A., Modi, V., Michalaka, D., and Lu, J. (2012). Managed Lane Operations-Adjusted Time of Day Pricing vs. Near-Real Time Dynamic Pricing Volume I: Dynamic Pricing and Operations of Managed Lanes. Final Report to the Florida Department of Transportation 


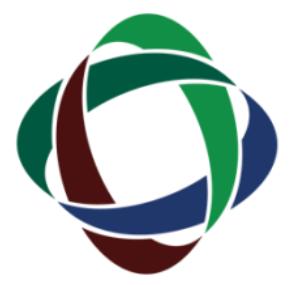

\section{N I C R}

NATIONAL INSTITUTE FOR CONGESTION REDUCTION

The National Institute for Congestion Reduction (NICR) will emerge as a national leader in providing multimodal congestion reduction strategies through real-world deployments that leverage advances in technology, big data science and innovative transportation options to optimize the efficiency and reliability of the transportation system for all users. Our efficient and effective delivery of an integrated research, education, workforce development and technology transfer program will be a model for the nation.

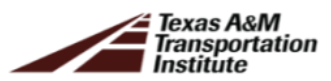

